\title{
ANÁLISE DA ESTRUTURA GENÉTICA DAS POPULAÇÕES DE MILHO ( Zea mays L.) BR-105 E BR-106 E RESPECTIVOS SINTÉTICOS IG-3 E IG-4 POR MEIO DE MICROSSATÉLITES
}

\section{Luciana Rossini Pinto}

Engenheiro Agrônomo

Orientadora: Profa. Dra. MARIA LÚCIA CARNEIRO VIERA

Tese apresentada à Escola Superior de Agricultura "Luiz de Queiroz" / Universidade de São Paulo, para obtenção do título de Doutor em Agronomia, Área de Concentração: Genética e Melhoramento de Plantas.

\section{PIRACICABA}

Estado de São Paulo - Brasil

Maio - 2001 


\section{ERRATA}

\section{Página Parágrafo}

onde se lê

$\begin{array}{cl}2^{0} & \text { via seleção recorrente } \\ 3^{0} & \text { híbrido interpopulacional } \\ 4^{0} & \text { ciclos subsequientes } \\ 1^{0} & \text { heterozigosidade } \\ 2^{0} \text { (eq 4) } & \boldsymbol{N} \\ 1^{0} \text { (eq 6) } & \boldsymbol{F t}-\mathbf{1} \\ 2^{0} & \text { revelados } \\ 3^{0} & \text { codantes } \\ 3^{0} & \text { etídio } \\ \text { Figura } 4 & \text { sec } \\ 1^{0} & \text { número } \\ 3^{0} & \text { sobre } \\ 1^{0} & \boldsymbol{H} \\ 1^{0} & D_{S T} \\ 3^{0} & \text { Bnlg } 155 \\ 1^{0} & \text { variáveis } \\ 4^{0} & \text { expressivos } \\ 2^{0} & \text { foram encontrados } \\ 4^{0} & \text { Nas populações.... } \\ & \\ \text { Tabela } 19 & (0,084 \text { a } 0,138) \\ & (0,142 \text { a } 0,256)\end{array}$

109

1
1
1
6

13

15

21

31

39

40

48

55

56

57

65

66

67

74

74

.

\section{leia-se}

via seleção recorrente (Souza Júnior, 1997).

híbrido interpopulacional (Souza Júnior, 1997).

ciclos subseqüentes (Souza Júnior, 1997).

heterozigosidade esperada

$\mathrm{Ne}$

$F_{(t-1)}$

obtidos

codificadoras

etídeo

segundos

proporção

sob

Ho

$D_{S T}=$

Bnlg 155 à concentração de $1 \mathrm{mM}$ componentes elevados foi encontrado

Nas populações BR-105 e BR-106 e nos

sintéticos IG-3 e IG-4, respectivamente, 3,6\%, $8,6 \%, 6,9 \%$ e $7,3 \%$....

$(0,092$ a 0,160$)$

$(0,047$ a 0,089$)$ 


\author{
Pinto, Luciana Rossini \\ Análise da estrutura genética das populações de milho (Zea mays L.) BR-105 e BR-106 \\ e respectivos sintéticos IG-3 e IG-4 por meio de microssatélites / Luciana Rossini Pinto. - - \\ Piracicaba, 2001. \\ 142 p. : il. \\ Tese (doutorado) - Escola Superior de Agricultura Luiz de Queiroz, 2001. \\ Bibliografia. \\ 1. Divergência genética 2. Genética de população 3. Milho hibrido 4. Seleção \\ recorrente I. Título
}


"Cada um que passa em nossa vida, passa sozinho, porque cada pessoa é única para nós e nenhuma substitui a outra.

Cada um que passa em nossa vida, passa sozinho, mas não vai sozinho e nem nos deixa só,

leva um pouco de nós mesmos e deixa um pouco de si. Há os que levam muito, mas não há os que não levam nada.

Isso é a mais bela prova de que cada um é importante e ninguém aparece em nossa vida por acaso." 


\section{AGRADECIMENTOS}

À Profa. Dra. Maria Lúcia Carneiro Vieira pela orientação e atenção dispensadas durante estes anos, os quais contribuíram para o meu desenvolvimento profissional.

Ao Prof. Dr. Cláudio Lopes de Souza Júnior pela proposta da presente pesquisa e sugestões.

À Profa. Anete Pereira de Souza (UNICAMP/CEBMEG) pelo incentivo e treinamento.

Aos professores do Departamento de Genética da ESALQ/USP, em especial ao Prof. Dr. Roland Vencovsky, pelos ensinamentos.

Ao colega Sérgio Tadeu Sibov (UNICAMP) pela paciência e tempo dispensado durante meu treinamento com os microssatélites.

A Alexandre M. Sebbenn e Alexandre S. Coelho pelas valiosas contribuições, e ao amigo Américo J. dos Reis pelo auxílio da elaboração dos gráficos.

Aos amigos Carlos Alberto, Elizabete, Monalisa, Mariza, Vera, Ricardo, Maria Teresa, Ilene, Adriano, Michel, Adriana, Maria, Heiko, Luciana, Marlene, Rainério, Inês e Maria Aldete pelo convívio ao longo destes anos.

A Matheus e Gustavo pela atenção e cooperação constantes.

Aos meus colegas do Programa de Pós-Graduação em Agronomia (Genética e Melhoramento de Plantas).

Ao Conselho Nacional Científico e Tecnológico (CNPq) pela concessão da bolsa de estudos.

Aos funcionários do Departamento de Genética (ESALQ), em especial a Antônio Jocelino Desidério.

Às bibliotecárias Silvana Oliveira, Eliana Sabino e Silvia pelo auxílio na organização das referências bibliográficas, a Léia pelos serviços burocráticos e ao Berdan pela encadernação da tese.

Aos meus pais, Aramis e Cristina, e minha irmã Ana, sempre presentes em todos os momentos de minha vida, e a quem devo minha eterna gratidão, e ao Ricardo pela companhia e paciência constantes. 


\section{SUMÁRIO}

Página

LISTA DE FIGURAS ................................................................................ viii

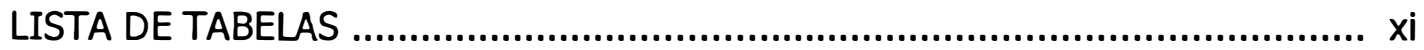

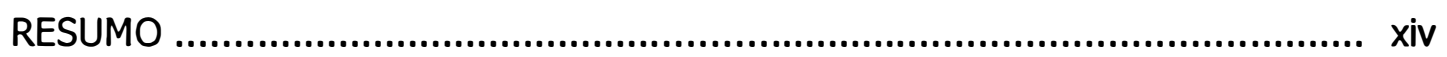

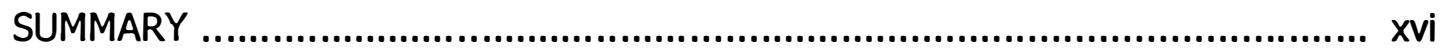

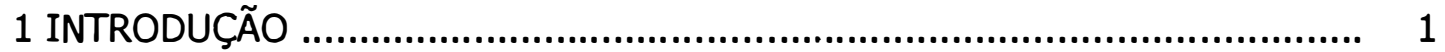

2 REVISSÃO DE LITERATURA …......................................................... 4

2.1 Estrutura genética de populações de plantas............................................. 4

2.2 Deriva genética ............................................................................ 12

2.3 Seleção recorrente recíproca ............................................................. 18

2.4 Descrição das populações BR-105, BR-106 e seus sintéticos IG3 e IG4 23

2.5 Marcadores microssatélites e variabilidade em milho ................................ 28

3 MATERIAL E MÉTODOS .................................................................... 35

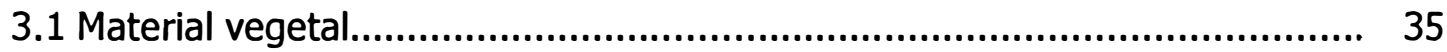

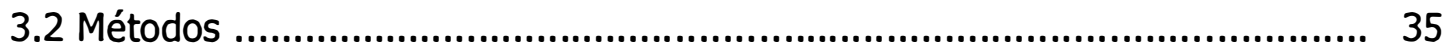

3.2.1 Análise por marcadores microssatélites (simple sequence repeats- SSR) 35

3.2.1.1 Coleta do material para extração do DNA .......................................... 35

3.2.1.2 Extração do DNA genômico ............................................................ 36

3.2.1.3 Quantificação do DNA ............................................................... 37

3.2.1.4 Amplificação do DNA genômico (SSR- PCR) ................................... 38

3.2.1.5 Separação dos produtos de amplificação ........................................... 39

3.2.2 Análise dos dados ..................................................................... 45

3.2.2.1 Freqüências alélicas ................................................................... 46

3.2.2.2 Índices de diversidade ............................................................ 47

a Porcentagem de locos polimórficos $(P)$............................................... 47 


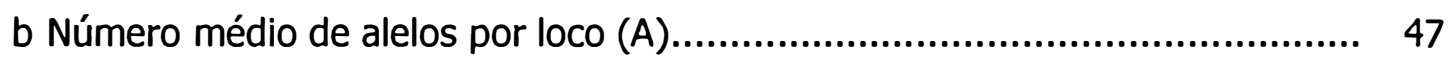

c Número efetivo de alelos (ne) ............................................................. 47

d Heterozigosidade observada (Ho) ......................................................... 48

e Diversidade gênica (heterozigosidade esperada - He) .................................. 49

f Conteúdo de polimorfismo (PIC)......................................................... 50

3.2.2.3 Índice de fixação de Wright $(\hat{f})$................................................ 51

3.2.2.4 Diversidade gênica esperada sob ação da deriva genética ................... 51

3.2.2.5 Tamanho efetivo populacional $(\hat{N} e)$............................................ 52

3.2.2.6 Determinação da significância das diferenças nas freqüências alélicas entre populações .............................................................................. 53

3.2.2.7 Aderência às proporções do equilíbrio de Hardy-Weinberg .................. 54

3.2.2.8 Análise da estrutura genética das populações (partição da diversidade pelo método de $\mathrm{Nei}, 1973)$........................................................................ 55

3.2.2.9 Diferenciação genética entre populações $\left(R_{S T}\right)$ para polimorfismos gerados por marcadores microssatélites ................................................... 57

3.2.2.10 Distância genética $(\sigma \mu)^{2}$ para polimorfismos detectados por marcadores microssatélites ..................................................................... $\quad 59$

3.2.2.11 Distância genética de Nei ......................................................... 60

3.2.3.12 Análise de coordenadas principais ....................................................63 63

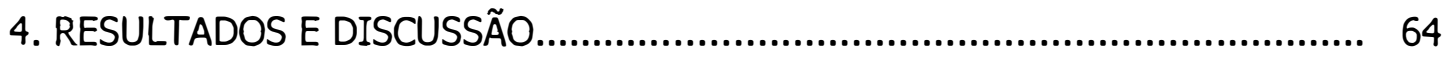

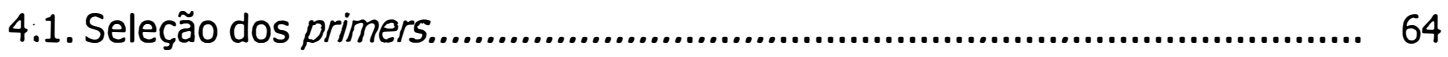

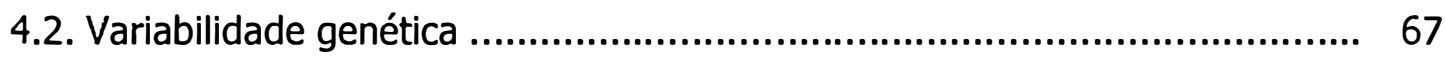

4.2.a Freqüências alélicas ................................................................... $\quad 74$

4.2.b Número médio de alelos por loco, porcentagem de locos polimórficos e número efetivo de alelos 
4.2.c Heterozigosidade observada ( $H o$ ), esperada $(\hat{H} e)$ e aderência às proporções de Hady-Weinberg.................................................................... 91

4.3 Diversidade gênica (heterozigosidade esperada) sob a ação da deriva

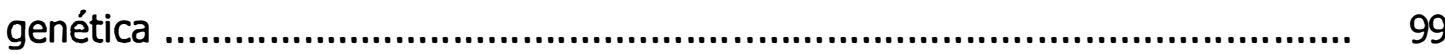

4.4 Partição da diversidade .................................................................. 108

4.5 Distância genética e análise de coordenadas principais........................... 111

4.6 Considerações Finais ..................................................................... 120

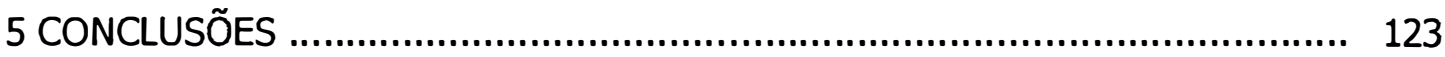

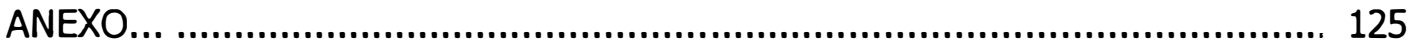

REFERÊNCIAS BIBLIOGRÁFICAS ........................................................ 129 


\section{LISTA DE FIGURAS}

Página

1 População BR-105 (A) mostrando grãos alaranjados duros do tipo flint e população $B R-106$ (B) com grãos amarelos dentados 26

2 Esquema de obtenção das duas variedades sintéticas denominadas IG-3 e IG-4, derivadas das populações BR-105 e BR-106, respectivamente.

3 Representação do padrão de bandas observado para marcadores SSR, considerando três alelos: $(\mathrm{AT})_{10},(\mathrm{AT})_{14},(\mathrm{AT})_{20}$. Indivíduos homozigóticos: $(1,2,4)$ apresentam ambos alelos com o mesmo númeo de repetições, enquanto os heterozigóticos apresentam alelos com número diferente de repetições (3,5 e 6$)$

4 Relação dos programas de amplificação para locos de microssatélites com redução da temperatura de anelamento de $1^{\circ} \mathrm{C}$ a cada dois ciclos durante a etapa inicial (touchdown). Todos programas contêm uma etapa de desnaturação inicial a $94^{\circ} \mathrm{C}$ por 3 minutos e de extenção final de $72^{\circ} \mathrm{C}$ por 3 minutos.

5 Reação de PCR com o primer Bnlg 155, com diferentes concentrações de magnésio $(1,0 ; 2,0$ e 3,0 mM) e demais variáveis da reação constantes.... 
Página

6 Polimorfismos detectados utilizando cinco marcadores microssatélites em populações de milho em géis de agarose metaphora 3\%. A) MAGE05 (BR-105), B) Bnlg 131 (BR-105), C) MTTGBO2 (BR-106), D) Bnlg 155 (IG-3), e) Bnlg 109 (IG-4).

7 Padrões de amplificação para locos de microssatélites: primer Bnlg 197 na população BR-105 (A) e no sintéticos IG-3 (B); primer Bnlg 669 na população BR-106 (C) e no sintético IG-4 (D)..................................... 70

8 Distribuição das freqüências alélicas na população BR-105 e sintético IG-3 (A) e na população BR-106 e respectivo sintético IG-4 (B).

9 Distribuição das heterozigosidades observada (Ho) e esperada (He) ao longo dos locos de microssatélites para as populações e os sintéticos.

10 Dendrograma das populações BR-105 e BR-106 e sintéticos IG-3 e IG-4 com base em 30 locos de microssatélites. $\mathrm{O}$ agrupamento foi realizado segundo o método UPGMA, considerando a matriz de distância genética de Nei

11 Dendrograma das populações BR-105 e BR-106 e sintéticos IG-3 e IG-4 com base em 30 locos de microssatélites. O agrupamento foi realizado segundo o método UPGMA, considerando a matriz de distância genética de $(\delta \mu)^{2}$

12 Associações entre as populações BR-105, BR-106 e os sintéticos IG-3 e IG-4 obtida pela análise de coordenadas principais (PCO). Distância de Nei (1978). 
13 Associações entre as populações BR-105, BR-106 e os sintéticos IG-3 e IG-4 obtida pela análise de coordenadas principais (PCO). Distância de $(\delta \mu)^{2}$ Goodstein et al.(1995).

14 Associações entre populações e sintéticos com base na leitura dos Genótipos individuais em 30 locos microssatélites. BR-106 (verde), IG-4 (rosa), BR-105 (vermelho) e IG-3 (azul). 


\section{LISTA DE TABELAS}

Página

1 Loco (cromossomo), seqüência dos primers (foward/reverse) com os seus respectivos tamanhos e temperaturas de anelamento para 94 SSRs...........

2 Locos de microssatélites, cromossomo (Bin), condições de amplificação (Programa), tempo de anelamento (s) e concentração de magnésio (mM) utilizados na reação de PCR

3 Motivo, número de alelos, tamanho do alelos (pb) e conteúdo de polimorfismo (PIC), referente a 30 locos de microssatélites

4 Comparação dos fragmentos $(\mathrm{pb})$ de microssatélites obtidos nas populações e sintéticos com os relatados para linhagens elites.

5 Locos, alelos (pb), freqúências alélicas ( $\hat{p} u$ ), intervalo de confiança a 95\% de probabilidade (IC 95\%), tamanho da amostra (n) referente a população BR-105 e o sintéticoIG-3 para 30 locos de microssatélites

6 Locos, alelos (pb), freqúências alélicas ( $\hat{p} u$ ), intervalo de confiança a 95\% de probabilidade (IC 95\%), tamanho da amostra (n) referente a população BR-106 e o sintéticoIG-4 para 30 locos de microssatélites

7 Alelos exclusivos e freqüência com que ocorrem nas populações e nos sintéticos. 
8 Alelos exclusivos e freqüência com que ocorrem nas populações originais e respectivos sintéticos

9 Diferenciação das freqüências alélicas por loco entre as populações BR-105 e BR-106 e entre os sintéticos IG-3 e IG-4. $\chi^{2}$ para grupos 87 com graus de liberdade $(\mathrm{gl})$ e desvio padrão.

10 Diferenciação das freqüências alélicas por loco entre as populações e entre os sintéticos. $\chi^{2}$ para grupos com graus de liberdade (gl) e desvio padrão.

11 Variabilidade genética em 30 locos de microssatélites presentes nas populações BR-105 e BR-106 e nos sintéticos IG-3 e IG-4

12 Heterozigosidade observadas $(H o)$, esperadas $(H e)$ e índice de fixação de Wright $(\hat{f})$ para 30 locos de microssatélites

13 Aderência às proporções de Hardy-Weinberg para as populações BR-105 BR-106 em 30 locos de microssatélites pelo teste exato

14 Aderência às proporções de Hardy-Weinberg para os sintéticos IG-3 e IG-4,em 30 locos de microssatélites pelo teste exato

15 Diversidade gênica observada no ciclo 0 (BR-105) e no ciclo 1 (IG-3) e diversidade gênica esperada sob deriva genética $\left(D_{t}\right)$ após um ciclo ( $t$ ) de seleção recorrente recíproca, considerando $N e=4,57$, e intervalos de confiança a $95 \%$ de probabilidade para 30 locos de microssatélites. 
16 Diversidade gênica observada no ciclo $O$ (BR-106) e no ciclo 1 (IG-4) e diversidade gênica esperada sob deriva genética $\left(D_{t}\right)$ após um ciclo ( $t$ ) de seleção recorrente recíproca, considerando $N e=5,71$, e intervalos de confiança a $95 \%$ de probabilidade para 30 locos de microssatélites.

17 Estimativas do tamanho efetivo populacional $(\hat{N} e)$ e intervalo de confiança a $95 \%$ para os sintéticos IG-3 e IG-4

18 Valores médios de diversidade nas populações BR105 e BR106 $\left(C_{0}\right)$ e nos sintéticos IG3 $\left(C_{1}\right)$ com base em 30 locos de microssatélites.... 108

19 Valores médios de diversidade nas populações originais $\left(C_{0}\right)$ e respectivos sintéticos $\left(C_{1}\right)$ com base em 30 locos de microssatélites... 109

20 Identidade gênica (I) acima da diagonal, e distância genética ( $D=-\ln D$ ) abaixo da diagonal, para populações BR-105, BR-106 e os sintéticos IG-3 e IG-4 com base em 30 locos de microssatélites.

21 Distância genética $(\delta \mu)^{2}$ de Goodstein et al. (1995), para as populações e os sintéticos, com base em 30 locos de microssatélites 


\section{ANÁLISE DA ESTRUTURA GENÉTICA DAS POPULAÇÕES DE MILHO (Zea mays L.) BR-105, BR-106 E RESPECTIVOS SINTÉTICOS IG-3 E IG-4 POR MEIO DE MICROSSATÉLITES}

Autor: LUCIANA ROSSINI PINTO

Orientador: Profa. Dra. MARIA LÚCIA CARNEIRO VIEIRA

\section{RESUMO}

Microssatélites foram utilizados para avaliar a estrutura genética das populações de milho BR-105, BR-106 e respectivos sintéticos IG-3 e IG-4 obtidos após um ciclo de seleção recorrente recíproca de elevada intensidade. Foram utilizados 30 locos de microssatélites, os quais, revelaram um total de 125 alelos distribuídos entre as populações e os sintéticos. Uma redução no número de alelos foi observada nos sintéticos IG-3 (23\%) e IG-4 (17\%). 0 teste de diferenciação das freqüências alélicas em relação a: $B R-105 \times B R-106, I G-3 \times I G-4$, $B R-105 \times I G-3$ e $B R-106 \times I G-4$ foi significativo $(P<0,05)$ para a maioria dos locos. Um alto número de alelos exclusivos foi identificado entre as populações (23 alelos) e entre os sintéticos (30 alelos) dos quais, a maior parte com freqüências baixas $(<0,01)$.

Metade dos locos mostrou aderência às proporções de equilíbrio de Hardy-Weinberg ( $53 \%$ na BR-105 e 57\% na BR-106). Nos sintéticos, às proporções dos locos sob equilíbrio de Hardy-Weinberg foram $93 \%$ e $70 \%$ em IG-3 e IG-4, respectivamente. Conseqüentemente, o índice de fixação de Wright médio $(\hat{\bar{f}})$ apresentou valores mais baixos $(\hat{f}<0,05)$ nos sintéticos em relação aos encontrados para as populações originais $(\hat{\bar{f}}>0,05)$. 
A diversidade gênica total foi similar nas populações, ambas com valores altos. Nos sintéticos, a diversidade gênica total não foi significativamente diferente da esperada teoricamente sob o modelo de deriva genética, indicando que as perdas de variabilidade genética podem ser atribuídas aos efeitos da deriva genética provocados pelo tamanho efetivo populacional reduzido.

Os tamanhos efetivos populacionais estimados para ambos sintéticos com base nos 30 locos de microssatélites mostraram valores próximos aos teoricamente esperados. 0 índice de diferenciação genética $\hat{G}_{S T}$ aumentou cerca de $77 \%$ das populações $\left(\hat{G}_{S T}=11,00 \%\right)$ para os sintéticos $\left(\hat{G}_{S T}=19,50\right)$. Os valores $\hat{R}_{S T}$ estimados foram semelhantes aos obtidos pelo $\hat{G}_{S T}$ nas análises da partição da diversidade. A distância genética de Nei foi de 18,6\% entre as populações BR-105 e BR-106 e de 24,1\% entre os sintéticos IG-3 e IG-4. A distância $(\delta \mu)^{2}$ foi superior à distância de Nei: $26,7 \%$ entre BR-105 e BR-106, e 36,1\% entre IG-3 e IG-4. O nível de diversidade gênica total encontrado nos sintéticos, suporta a sua utilização em um novo ciclo de seleção recorrente recíproca. 


\title{
GENETIC STRUCTURE OF MAIZE (Zea mays L.) POPULATIONS BR-105 AND BR-106 AND THEIR SYNTHETICS IG-3 AND IG-4 BY MICROSATELLITE MARKERS
}

\author{
Author: LUCIANA ROSSINI PINTO \\ Adviser: Profa. Dra. MARIA LÚCIA CARNEIRO VIEIRA
}

\section{SUMMARY}

Microsatellites were used to evaluate the genetic structure of the maize populations BR-105, BR-106 and their synthetics IG-3 and IG-4, obtained after one cycle of reciprocal recurrent selection with high intensities over the original populations. Thirty microsatellite loci were examined. A total of 125 alleles were identified, and distributed among the populations and their synthetics. Reductions in the number of alleles were observed in the synthetics IG-3 (23\%) and IG-4 (17\%). The population differentiation tests concerning the allele frequencies in relation to $B R-105 \times B R-106$, $I G-3 \times I G-4, B R-105 \times I G-3$ and $B R-106 \times I G-4$ were significant for most of the loci $(P<0.05)$. A high number of private alleles were identified between the populations (23 alleles) and between the synthetics (30 alleles), most of them present at low frequencies $(<0.010)$.

Half of the population loci showed Hardy-Weinberg proportions (53\% in BR-105 and $57 \%$ in BR-106). Concerning the synthetics, the proportions of loci under HardyWeinberg equilibrium were $93 \%$ and $70 \%$ in IG-3 and in IG-4, respectively. As a 
consequence, the mean fixation index estimation $(\hat{\bar{f}})$ was lower $(\hat{\bar{f}}<0.05)$ in the synthetics with respect to the original populations $(\hat{\bar{f}}>0.05)$.

The total gene diversity was similar in the populations and both presented high values. In the synthetics, the total gene diversity was not different from the theoretical expectations under the genetic drift model, so the loss of genetic variability can be attributed to the effects of random genetic drift caused by the effective population size.

The effective population size estimated from 30 microsatellite loci for both synthetics were very similar to the predicted. The differentiation index $\left(\hat{G}_{S T}\right)$ increased $77 \%$ from the original populations ( $\hat{G} s T=11 \%$ ) to their synthetics ( $\hat{G}_{s T}=19,5 \%$ ). The $\hat{R}_{S T}$ values were very similar to those obtained by $\hat{G}_{S T}$ in the partition of genetic analysis. The value of Nei's genetic distance was $18,6 \%$ between BR-105 and BR-106, and $24,1 \%$ between IG-3 and IG-4. The distance $(\delta \mu)^{2}$ was higher than Nei's: $26,7 \%$ between BR-105 and BR-106 and 36\% between IG-3 and IG-4. The total gene diversity assessed support their use in a new cycle of reciprocal recurrent selection. 


\section{INTRODUÇÃO}

Os programas de melhoramento de milho, em sua grande maioria, voltados para a produção de híbridos, são amplamente difundidos nos países de agricultura desenvolvida.

A utilização de populações melhoradas maximiza a obtenção de híbridos superiores e de linhagens produtivas, as quais reduzem o custo da semente híbrida. A escolha da população a ser melhorada está associada à variabilidade genética disponivel para os caracteres a serem selecionados. Populações que apresentam potencial genético podem ser melhoradas via seleção recorrente.

Os métodos de seleção recorrente utilizam um processo cíclico de melhoramento para aumentar, gradualmente, a freqüência de alelos favoráveis na população. Duas categorias de seleção recorrente são utilizadas no melhoramento de populações: a seleção recorrente intrapopulacional e a seleção recorrente interpopulacional ou recíproca. A seleção recorrente intrapopulacional têm como objetivo o melhoramento per se das populações, enquanto a seleção recorrente interpopulacional, a performance do cruzamento entre duas populações, isto é, do híbrido interpopulacional.

A manutenção da variabilidade genética das populações é muito importante nos programas de seleção recorrente, principalmente, a longo prazo, pois a variabilidade deve se manter em níveis satisfatórios para que as populações sejam utilizadas em ciclos subseqüentes. Neste contexto, o conhecimento da estrutura genética de populações pode vir a fornecer informações importantes a respeito do grau e da distribuição da variabilidade genética, tanto de populações com potencial para o melhoramento quanto para aquelas que passaram por um processo seletivo. 
Nas investigações sobre a estrutura genética de populações, marcadores moleculares representam uma importante ferramenta, pois fornecem uma idéia mais precisa da diversidade gênica. Esses marcadores têm permitido a estimativa de parâmetros populacionais como freqüências gênicas e genotípicas, grau de endogamia, tamanho efetivo populacional, taxa de cruzamento, entre outros (Carlini, 1998). As análises com marcadores moleculares podem também vir a complementar o melhoramento de plantas sob vários aspectos, como por exemplo, para fornecer medidas de diversidade gênica confiáveis que possam ser aplicadas para determinar as relações entre linhagens e cultivares, na escolha de genitores, para estimar alterações na diversidade gênica ao longo do tempo e avaliar o potencial do germoplasma para exploração da variabilidade genética (Lamkey \& Lee, 1993).

Os microssatélites representam regiões não codificadoras do DNA que consistem de pequenos motivos (de 1 a 6 nucleotídeos) repetidos lado a lado. Estes marcadores são de natureza codominante o que torna possível, para um determinado loco, a distinção entre indivíduos homozigóticos e heterozigóticos. A grande vantagem da utilização de marcadores microssatélites parece estar associada ao fato de, na maioria dos casos, representarem um único loco o qual é freqüentemente multialélico. Além disso, são altamente informativos e a sua robustez tem permitido o intercâmbio de dados entre laboratórios (Saghai-Maroof et al., 1994 ; Morgante \& Oliveri, 1993).

Devido ao milho se constituir em uma das culturas de maior destaque existe, atualmente, uma gama enorme de oligonucleotídeos (disponíveis e de fácil acesso) que permitem a amplificação das regiões de microssatélites, tornando possivel uma amostragem ampla do genoma. Como são marcadores codominantes permitem estudos genéticos, principalmente, ao nível de populações, a exemplo da proposta do presente trabalho que visa estimar:

a) a variabilidade genética das populações BR-105 e BR-106;

b) os níveis de variabilidade genética disponíveis nos sintéticos IG-3 e IG-4, originados após um ciclo de seleção recorrente recíproca nas populações BR-105 e BR-106, respectivamente; 
c) a divergência genética entre as populações BR-105 e BR-106 e entre os sintéticos IG-3 e IG-4;

d) e, verificar o comportamento das freqüências alélicas ao longo de um ciclo de seleção recorrente recíproca. 


\section{REVISÃO DE LITERATURA}

\subsection{Estrutura genética de populações de plantas}

A estrutura genética se refere à distribuição heterogênea (não aleatória) dos alelos e genótipos no espaço e no tempo resultante da ação de forças evolutivas tais como mutação, migração, seleção e deriva genética que atuam dentro do contexto de cada espécie e população (Hamrick, 1982).

O número médio de alelos por loco, a proporção de locos polimórficos (sob os critérios de $95 \%$ e 99\%), a heterozigosidade observada e esperada têm sido os parâmetros genéticos mais utilizados em vários estudos para quantificar a variabilidade genética encontrada em diversas fontes de germoplasma de milho (Llauradó et al., 1993; Sanou et al., 1997; Senior et al., 1998; Rebourg et al., 1999).

A estimativa da freqüência de um alelo particular em uma população, chamada de freqüência gênica ou alélica, é considerada fundamental nos estudos evolutivos, pois a mudança genética de uma população pode ser avaliada pela mudança nas suas freqüências gênicas (Nei, 1987).

De acordo com Hartl \& Clark (1989), para comparar diferentes genes e diferentes populações é necessário ter em mãos alguma medida quantitativa adequada da variação genética. Tal medida pode ser quantificada utilizando o conceito de freqüência alélica. A freqüência de um determinado alelo em um grupo de indivíduos diplóides é a proporção dos alelos de um loco que são do tipo prescrito. Em síntese, a freqüência de qualquer alelo prescrito em uma amostra é igual a duas vezes o número de indivíduos homozigóticos para o alelo (cada homozigoto carrega duas cópias do alelo) mais o número de indivíduos 
heterozigóticos para aquele alelo (cada heterozigoto carrega apenas uma cópia) dividido por duas vezes o número de indivíduos na amostra, em virtude de cada indivíduo carregar dois alelos em um loco.

Segundo este mesmo autor, a freqüência alélica em uma amostra de indivíduos de uma população é uma estimativa da verdadeira freqüência alélica da população como um todo, sendo que tal estimativa será próxima à freqüência real se a amostra for suficientemente grande e representativa. Por esta razão, estimativas da freqüência alélica devem ser baseadas em amostras compostas por 100 ou mais indivíduos.

A idéia de frequêencia alélica suporta o conceito de polimorfismo. Um loco é considerado polimórfico quando a freqüência do alelo mais comum é menor do que 0,95 (sob o critério de $95 \%$ ) ou 0,99 (sob o critério de $99 \%$ ). A quantidade de polimorfismo, expressa pelo número de locos polimórficos $(P)$, é utilizada em termos de proporção média de locos polimórficos por população, ou seja, é o número de locos polimórficos dividido pelo número total de locos da amostra (Torggler et al., 1995).

O número de locos polimórficos é considerado um guia grosseiro para avaliar o nível de variação genética em uma amostra. A percentagem de locos polimórficos é dependente do tamanho da amostra e das variações nas metodologias (técnicas eletroforéticas) empregadas. Além disso, o ponto de truncamento na definição de polimorfismo é, em uma primeira análise, arbitrário (Brown \& Weir,1983; Doebley et al., 1985). Entretanto, para Hartl \& Clark (1989) o corte a 0,95 usado na definição de polimorfismo, apesar de arbitrário, serve para focar a atenção naqueles genes com variação alélica comum.

O número de alelos observados por loco aumenta em função do tamanho da amostra. Desta forma, com grandes amostras tem-se maior chance de detectar alelos muito raros (Torggler et al., 1995).

O número de alelos presentes em uma amostra, isto é, o número de alelos por loco, determina a sua riqueza alélica. Quanto à distribuição das freqüências alélicas, uma amostra cujos alelos são igualmente freqüentes é mais diversa do que uma amostra que contém um alelo predominante e os demais 
raros. Segundo Brown \& Weir (1983), embora as freqüências alélicas constituam os parâmetros básicos da genética de populações, por si só, não são índices de diversidade genética. $O$ que preenche este papel é uma série de transformações, inicialmente ao nível de um único loco e depois combinada sobre locos, para produzir medidas resumidas de diversidade.

O conhecimento da freqüência dos heterozigotos apresenta importância na medida em que cada heterozigoto carrega diferentes alelos os quais representam a existência de variação genética na população. A variação nas populações pode ser caracterizada pela heterozigosidade ou pela diversidade gênica, sendo que a diversidade gênica é uma medida mais apropriada para populações endogâmicas em que a variação resulta da presença contínua de diferentes homozigotos (Weir, 1996).

A heterozigosidade média ou diversidade gênica não depende da arbitrariedade intrínsica à definição de polimorfismo e, portanto, pode ser definida em termos de freqüência gênica (Nei,1987).

Em uma população sob panmixia, a homozigosidade e a heterozigosidade são estimadas, respectivamente, através das expressões: $g=p i^{2}$ e $1-g$, em que $p i$ refere-se à freqüência do i-ésimo alelo na população. Neste caso, assume-se que não há dominância e que todos os heterozigotos são identificáveis, tal como ocorre nas variações isoenzimáticas (Nei \& Roychoudhury, 1974) e demais marcadores codominantes, como o RFLP e os microssatélites.

Nei (1987) ressalta que a heterozigosidade média não equivale à proporção média de heterozigotos quando as freqüências genotípicas desviam das proporções do equilíbrio de Hardy-Weinberg. Entretanto, se for considerada a probabilidade de dois alelos tomados ao acaso de uma população serem diferentes, esta probabilidade será equivalente à heterozigosidade em uma população diplóide de cruzamentos ao acaso, e pode ser definida em termos de freqüência gênica da mesma forma que a heterozigosidade. Esta quantidade pode ser chamada de diversidade gênica e ser usada para qualquer organismo (quer seja haplóide, diplóide ou poliplóide), podendo ser empregada em qualquer 
sistema reprodutivo (quer seja cruzamento aleatório, autofecundação ou propagação vegetativa). Neste caso, a diversidade gênica é uma simples medida da variabilidade genética.

Segundo Nei \& Roychoudhury (1974), a variabilidade genética de uma população é usualmente medida pela heterozigosidade média por loco, enquanto as diferenças gênicas entre duas populações podem ser estimadas pela distância genética.

De acordo com o princípio de Hardy-Weinberg, em uma população de tamanho infinito, praticando cruzamento ao acaso, as freqüências gênicas e genotípicas permanecem constantes de geração a geração na ausência de migração, mutação, seleção e deriva genética. Este princípio permite o cálculo teórico da freqüência de um determinado genótipo, independente do número de alelos existentes. Hartl \& Clark (1989) apontam o princípio deste equilíbrio como um modelo adequado que proporciona um quadro estatístico da organização da variação genética nas populações.

Segundo Weir (1996), a aderência dos dados às proporções do equilíbrio de Hardy-Weinberg, em última análise, mostra que não há associação entre alelos dentro dos indivíduos (independência entre os alelos); sendo assim, as freqüências genotípicas na população tornam-se o produto da freqüência dos alelos.

As análises conduzidas para detectar variações significativas do equilíbrio de Hardy-Weinberg são baseadas em testes de aderência (goodness-of-fit), os quais comparam os resultados observados com os teoricamente esperados pelo princípio, sendo o qui-quadrado $\left(\chi^{2}\right)$ a estatística mais utilizada (Pasteur et al., 1988).

A aderência das populações às proporções do equilíbrio de HardyWeinberg pode ser estimada utilizando-se das estatísticas $F$ (índices de fixação de Wright). Neste caso, valores de $F$ iguais a zero indicam que os genótipos da população se encontram em equilíbrio, enquanto valores de $F$ maiores que zero apontam excesso de homozigotos e valores menores do que zero, excesso de heterozigotos (Sebbenn, 1997). 
O coeficiente de endogamia ( $F$ ) expressa a probabilidade de dois alelos de qualquer loco serem idênticos por ascendência num indivíduo (Falconer \& Mackay, 1996). Este coeficiente pode expressar também a endogamia média de todos os indivíduos de uma população, numa dada geração.

De acordo com Metter \& Gregg (1973), o grau de endogamia medido pelo coeficiente $\mathrm{F}$ de Wright, expressa a quantidade de heterozigotia dissipada. Assim, considerando a expressão geral de Wright, as proporções dos genótipos $A A$ : Aa : aa, no ponto de equilíbrio, são dadas por:

$$
p^{2}+F p q: 2 p q-F 2 p q: q^{2} F p q
$$

Para um certo grau de endogamia, a proporção de heterozigotos será reduzida à $F 2 p q$, da qual, metade será adicionada a cada uma das classes de homozigotos. Desta forma, em uma população sem endogamia o coeficiente $F$ será nulo e neste caso os valores de Wright reduzem-se às proporções de HardyWeinberg.

Posteriormente, o coeficiente de endogamia $(F)$ de Wright (1951) foi estendido para quantificar a diferenciação genética de populações segundo níveis hierárquicos de endogamia (Alfenas, 1998).

Segundo Gonzáles-Candelas \& Palacios (1995), o método introduzido por Wright descreve a estrutura genética da população de organismos diplóides em termos de três estatísticas $F$ ou correlações alélicas.

Basicamente, as estatísticas $F$ de Wright ou medidas correspondentes de Cockerham quantificam o grau de parentesco entre vários pares de alelos. Estas estatísticas, mais precisamente, os parâmetros $F_{S T}, F_{T T}$ e $F_{I S}$ oferecem uma forma conveniente de se resumir a estrutura populacional (Weir \& Cockerham, 1984). Assim sendo, segundo a notação de Cockerham, temos que:

$F$ - representa a correlação de genes (alelos) dentro de indivíduos no conjunto das populações;

$\theta$ - representa a correlação de genes (alelos) de diferentes indivíduos na mesma população; 
$f$ - representa a correlação de genes (alelos) dentro de indivíduos dentro da população.

Esses parâmetros apresentam a seguinte relação (Weir \& Cockerham, 1984):

$$
\begin{gathered}
f=\frac{(F-\theta)}{1-\theta} \\
\text { ou } \\
1-F_{I T}=\left(1-F_{I S}\right)\left(1-F_{S T}\right)
\end{gathered}
$$

e são relacionados com as estatísticas $F$ de Wright da seguinte forma,

$$
\begin{aligned}
& F=F_{I T} \\
& \theta=F_{S T} \\
& f=F_{I S}
\end{aligned}
$$

De acordo com Wright (1965), na discriminação da estrutura de populações o conceito de endogamia como correlação na união de gametas deve ser preferido em relação à probabilidade de autozigose. O coeficiente de endogamia tomado como correlação pode assumir valores negativos $(-1 \mathrm{a}+1)$ ao passo que como probabilidade assume valores sempre positivos, entre 0 e 1.

Como metodologia no estudo da estrutura genética de populações, as estatísticas $F$ de Wright têm um caráter mais restrito, pois assumem que todos os desvios de panmixia são exclusivamente devidos aos efeitos da deriva genética e do sistema reprodutivo, excluindo os efeitos de mutação e seleção.

Nesse sentido, Nei (1973) propôs um método pelo qual a diversidade gênica (heterozigosidade) de uma população subdividida é analisada em seus componentes, ou seja, diversidade gênica dentro e entre subpopulações. A diversidade gênica de Nei (1973) é aplicável à qualquer população sem restrição ao número de alelos por loco, ao padrão de forças evolutivas como mutação, seleção e migração, como também ao sistema reprodutivo da espécie. 
Nei (1973) demonstrou que a variação na freqüência gênica em uma população subdividida pode ser avaliada diretamente em termos de heterozigosidade ou diversidade gênica. A diversidade gênica na população total ( $\left.H_{T}\right)$ é partida em componentes que se somam, considerando a diversidade gênica dentro $(H s)$ e entre as subpopulações ( $D s T$ ). Assim $H T=H s+D s t$. A magnitude absoluta da diferenciação gênica entre subpopulações mensurada pelo Dst é obtida pela diferença entre a heterozigosidade referente à população total $\left(H_{T}\right)$ e a heterozigosidade média dentro das subpopulações $(H s)$, isto é, $D s T=H_{T}-H s$, enquanto a diferenciação gênica relativa à população total (GST) é dada pela razão entre $D s t$ e $H T\left(G s T=D s T / H_{T}\right)$. Esta medida $(G s T)$ equivale à estatística $F_{S T}$ de Wright.

A distância genética entre duas populações fornece uma estimativa relativa do tempo decorrido desde que as populações existiam como uma única e coesiva unidade. Estimativas pequenas de distâncias podem ser uma indicação de subestruturação populacional, isto é, subpopulações nas quais existem cruzamentos aleatórios mas entre as quais há uma reduzida quantidade de fluxo gênico. Também podem ocorrer em populações completamente isoladas as quais foram recentemente separadas. Quando duas populações estão geneticamente isoladas, os processos de mutação e deriva genética levam à diferenciação nas freqüências alélicas nos locos seletivamente neutros. As diferenças nas freqüências alélicas tendem a aumentar com o aumento no tempo de separação entre as populações até cada população tornar-se fixada para alelos distintos (Murray, 1996).

Vários métodos têm sido desenvolvidos para estimar a distância genética com base nas freqüências alélicas. A medida mais comumente utilizada de distância foi desenvolvida por Nei (1972). A distância genética de Nei (1972) pressupõe uma medida de identidade gênica $(I)$ a qual expressa a probabilidade de que dado alelo em um loco, tomado ao acaso, em duas populações, seja idêntico em relação à probabilidade de que dois alelos do mesmo loco, tomados também ao acaso, em cada população, sejam também idênticos (Alfenas, 1998). 
Desta forma, em termos algébricos, a distância de Nei (1972) é dada pelo cologaritmo neperiano da identidade gênica $(D=-\ln I)$ sendo $I$ estimado pela expressão:

$$
I=\frac{J x y}{\sqrt{J x J y}}=
$$

na qual, $J_{x y}$ é a probabilidade de que dois alelos tomados nas populações $\mathrm{x}$ e y sejam idênticos ( $\sum x_{i} y_{i}$ medida para todos os locos) e $J_{x}$ e $J_{y}$ são as probabilidades de que dois alelos tomados ao acaso dentro de cada uma das populações ( $\mathrm{x}$ e y) sejam idênticos (sendo $\sum x_{i}^{2}$ e $\sum y_{i}^{2}$ para cada loco).

Goodman (1997) ressalta que as medidas de diferenciação genética estabelecidas, $F_{S T}$ de Wright, Gst de Nei e $\theta$ de Weir e Cockerham, bem como a distância genética de Nei têm como base os modelos de mutação de alelos infinitos (infinite allele model- IAM) ou dos $k$ alelos ( $k$ allele models - KAM) pelos quais os eventos de mutação podem gerar novos alelos que não existem previamente na população (IAM) ou saltam para um novo estado alélico " $k$ " (KAM). Tais modelos são adequados, por exemplo, para as variações aloenzimáticas, porém não são apropriados para os polimorfismos gerados por marcadores microssatélites, nos quais a maioria das mutações envolvem a adição ou subtração de um número pequeno da unidade de repetição (motivo) que compõe o microssatélite. Este processo de mutação é conhecido como modelo de mutação stepwise (Stepwise mutation model - SMM) sendo consistente com a distribuição dos alelos em um loco de microssatélite (Goldstein et al., 1995 ; Murray 1996).

Nesse sentido, Slatkin (1995) desenvolveu uma medida de diferenciação genética semelhante ao $F_{S T}$ que incorpora a história de mutação contida nos alelos sob SMM. Em linhas gerais, esta medida $R s T$ equivale à fração da variância total no tamanho do alelo (em termos do número de unidades de repetições) que se encontra entre populações.

Em termos de distância genética, a diferença no número de repetições entre os alelos de locos de microssatélites traz informação a respeito do tempo 
decorrido desde o compartilhamento de um alelo ancestral comum. Esta informação é desconsiderada pela distância genética baseada no modelo dos alelos infinitos (IAM). Desta forma, Goldstein et al. (1995) estabeleceu uma medida de distância genética, na qual $(\sigma \mu)^{2}$ equivale à diferença entre o número médio de repetições encontrado nos alelos nas populações A e B, ou seja, $(\sigma \mu)^{2}$ $=\mu_{A}-\mu_{B}$ (Murray, 1996). Tanto Rst como $(\sigma \mu)^{2}$ parecem fornecer medidas mais acuradas dos parâmetros genéticos populacionais baseados em dados de microssatélites (Goodman, 1997).

\subsection{Deriva genética}

Os gametas que transmitem os genes para a geração seguinte carregam uma amostra dos genes da geração genitora; se esta amostra não for suficientemente grande as freqüências gênicas estarão sujeitas a sofrer modificações entre uma geração e a seguinte. Esta mudança na freqüência gênica característica do processo dispersivo e resultante da amostragem se dá ao acaso podendo ser predita em magnitude em termos da variância da mudança, isto é, da freqüência alélica, porém a sua direção é imprevisível. Esse processo de mudança aleatória na freqüência gênica é denominado deriva genética e pode ser entendido como uma flutuação aleatória na freqüência alélica levando eventualmente à fixação ou à perda do alelo. A deriva genética ocorre em qualquer população finita sendo mais rápida nas populações de tamanho pequeno (Futuyama, 1992; Falconer \& Mackey, 1996).

A diferenciação entre populações (subpopulações) derivadas de uma mesma população (população base) é uma das conseqüências do processo dispersivo. Desta forma, a população como um todo, isto é, o conjunto de todas as subpopulações apresenta uma deficiência de heterozigotos apesar de cruzamentos aleatórios ocorrerem dentro de cada subpopulação. Este efeito de endogamia devido à subdivisão da população pode ser representado pelo índice de fixação $F_{S T}$, o qual mensura a probabilidade de identidade por descendência 
dos alelos em uma subpopulação em relação à população total, tomada como população base ou ancestral. Apesar de ocorrerem cruzamentos ao acaso dentro de cada subpopulação, devido aos gametas se combinarem de forma aleatória, quaisquer dois alelos na subpopulação podem ser idênticos por descendência devido ao tamanho limitado da população (Hartl \& Clark,1989).

$O$ efeito da amostragem continuada ao longo de gerações sucessivas faz com que cada subpopulação flutue irregularmente em freqüência gênica e as subpopulações se dispersem, tornando-se progressivamente diferenciadas. A medida que o processo dispersivo ocorre, a variância da freqüência gênica entre as subpopulações aumenta, e em qualquer geração $t$, a variância da freqüência gênica $\left(\sigma_{q}^{2}\right)$ entre as subpopulações é:

$$
\sigma_{q}^{2}=p_{0} q_{0}\left[1-\left(1-\frac{1}{2 N}\right)^{t}\right]
$$

sendo $p_{0} q_{0}$ as freqüências iniciais dos alelos $p$ e $q$ e $N$ o tamanho da população.

No processo dispersivo existem duas fases: a fase inicial em que as freqüências se distanciam do valor inicial, a qual conduz a uma segunda fase, estacionária, que ocorre quando as freqüências estão espalhadas uniformemente sobre os limites de zero $(p=0)$ e um $(p=1)$ e todas as freqüências alélicas, exceto os dois limites, são igualmente prováveis (Falconer \& Mackay, 1996). O alelo mais comum no início do processo dispersivo têm a maior chance de se fixar. Assim, assumindo-se que não exista desequilíbrio de ligação com um alelo em outro loco afetado por seleção, a probabilidade de que um alelo seletivamente neutro seja fixado é precisamente igual à sua freqüência inicial $p$ (Futuyama, 1992).

O estreitamento da passagem de genes de uma população original para outra por intermédio de uma geração reduzida (efeito de afunilamento) têm efeito sobre as gerações subseqüentes (Beiguelman, 1994). O afunilamento de populações ocorre freqüentemente na natureza quando grupos pequenos de 
emigrantes de uma população estabelecida dão início a uma nova. A deriva genética que acompanha esse processo é conhecida como efeito fundador e a variabilidade desta população torna-se estreitamente dependente da amostra de alelos trazida por seus fundadores. Este efeito fundador leva a diferenças significativas entre as freqüências alélicas na população original e na população recém formada (Alfenas, 1998; Hartl \& Clark, 1989).

Além da diferenciação entre populações, a deriva genética leva à perda de variação genética dentro das populações, ou seja, à uniformidade genética a longo prazo e ao aumento geral na freqüência de genótipos homozigóticos às custas dos heterozigóticos contribuindo para a depressão atribuída à endogamia, a qual é mais pronunciada quanto mais elevado for o grau de dominância do caráter. A redução dos heterozigotos ocorre devido à proporção de heterozigotos ser menor em freqüências alélicas extremas do que nas freqüências alélicas intermediárias.

A mudança na heterozigosidade devida à deriva genética pode ser expressa pela equação:

$$
H_{t}=H_{0}\left(1-\frac{1}{2 N_{e}}\right)^{t}
$$

em que $H_{t}$ representa a heterozigosidade após $t$ gerações, $H_{0}$ a heterozigosidade inicial e $N_{e}$ o tamanho efetivo populacional. Sob deriva genética, a heterozigosidade decresce em uma taxa geométrica, uma vez que é multiplicada pela constante $\left(1-\frac{1}{2 N_{e}}\right)$ a cada geração. A heterozigosidade declina mais rapidamente quanto menor o tamanho da população. Entretanto, a taxa de declínio da heterozigosidade parece ser maior do que é esperado teoricamente (Hartl \& Clark, 1989).

A redução do tamanho efetivo da população contribui para o cruzamento de indivíduos aparentados dentro da população o que, obviamente, proporciona o 
aparecimento da endogamia. Em uma dada geração $t$, o coeficiente de endogamia $\left(F_{t}\right)$ de uma população pode ser expresso por:

$$
F_{t}=\left(\frac{1}{2 N_{e}}\right)+\left[1-\left(\frac{1}{2 N_{e}}\right)\right] F_{t}-1
$$

sendo portanto composto por um incremento $1 / 2 N_{e}$ atribuível à nova endogamia e uma parte restante atribuível à endogamia pré-existente, representada pelo coeficiente de endogamia da geração anterior. Para expressar o coeficiente de endogamia é necessário um ponto de referência sem o qual o conceito não faz sentido. Este ponto de referência é a população base, na qual os alelos nos homozigotos são considerados não idênticos por descendência $(F=0)$ e com a qual a população em estudo será comparada (Falconer \& Mackay, 1996).

O processo dispersivo foi descrito considerando uma população idealizada cujo tamanho populacional é infinito e os cruzamentos são aleatórios não ocorrendo mutação, seleção e migração. Populações reais são pouco prováveis de ocorrer sob as condições da população idealizada, sendo que 0 número de indivíduos que se cruzam não descreve, na maioria das situações, de forma apropriada, os efeitos da endogamia e da deriva da freqüência gênica. Neste sentido, o conceito de tamanho efetivo $\left(N_{e}\right)$ foi introduzido para superar este problema, sendo definido como o número de indivíduos que pode dar origem à variância da freqüência alélica ou à taxa de endogamia se estes se acasalassem à maneira da população idealizada (Caballero, 1994). O tamanho efetivo corresponde ao número de indivíduos que contribuem efetivamente com genes para a geração seguinte. $O$ tamanho efetivo de uma população, em geral, difere do seu número real de indivíduos e, na maioria dos casos, é sempre menor (Hartl \& Clark, 1989). Em programas de seleção recorrente o tamanho efetivo se aproxima do número de linhagens selecionadas em cada ciclo e pode ser 
calculado pela média harmônica das linhagens selecionadas ao longo de todos os ciclos de seleção (Labate et al., 1997a).

Desta forma, ao longo de um período de $t$ gerações, têm-se que:

$$
\frac{1}{N_{e}}=\frac{1}{t}\left[\frac{1}{N_{1}}+\frac{1}{N_{2}}+\ldots . .+\frac{1}{N_{t}}\right]
$$

sendo a média harmônica dominada pelos termos $\left(N_{i}\right)$ de menor valor.

Nos programas de melhoramento, 0 uso de tamanho efetivo populacional inadequado leva à perda de variabilidade genética em virtude da fixação de alelos em resposta à deriva genética. A fixação dos alelos pode ser tanto a favor dos alelos favoráveis como para os desfavoráveis e se não houver mutação ou introdução de germoplasma na população não será gerada nova variabilidade nos locos fixados (Guzman \& Lamkey, 2000).

Tanto a deriva genética quanto a seleção tendem a provocar alterações na variabilidade genética. As freqüências alélicas se diferenciam entre e dentro de populações por deriva genética e/ou por seleção. A seleção proporciona mudanças nas freqüências alélicas em virtude da reprodução diferencial de genótipos. A probabilidade de perda de um alelo favorável durante a seleção recorrente devido à deriva genética, depende da vantagem seletiva do alelo $(s)$, da freqüência alélica inicial ( $\left.p_{o}\right)$ e do tamanho efetivo populacional $(\mathrm{Ne}$ ). Esta probabilidade é ligeiramente reduzida para alelos favoráveis ( $s>0)$, a não ser que estes alelos apresentem um efeito gênico pronunciado. Conseqüentemente, a chance de que muitos-alelos raros favoráveis possam ser perdidos durante os ciclos iniciais de seleção recorrente são consideráveis (Messmer et al., 1991).

Em uma população finita, dois processos principais atuam para alterar a média da população ao longo dos ciclos de seleção recorrente: a seleção atuando para aumentar a média e a depressão por endogamia devida à deriva genética, atuando para o decréscimo da média. Desta forma, o sucesso de qualquer processo seletivo depende do balanço entre estas duas forças principais que afetam as freqüências alélicas de uma população. A resposta à seleção ocorre 
pelo aumento na freqüência de alelos favoráveis, enquanto a oscilação genética, devido ao tamanho efetivo populacional reduzido, pode aumentar a resposta à seleção se atuar na direção da mesma ou limitar a resposta se atuar no sentido oposto, o que é mais provável durante os primeiros ciclos de seleção, nos quais, as freqüências dos alelos favoráveis, em geral, são mais baixas (Rezende, 1997).

As alterações nas médias dos caracteres devido à deriva genética dependem não apenas do grau de dominância do caráter em questão como do tamanho efetivo populacional. Os componentes da variância genética também são afetados pela deriva genética. Quanto menor o tamanho efetivo, maior a redução das magnitudes dos componentes da variância genética, sendo mais acentuados para a variância genética dominante do que para a variância genética aditiva (Souza Júnior, 1995).

Moreira (1999) avaliando os efeitos da deriva genética em duas gerações de amostragens de tamanho reduzido ( $N_{e}=5$ ) nas populações de milho BR-105 e BR-106 observou comportamentos diferentes quanto aos efeitos da deriva genética sobre as médias dos caracteres (produção de grãos, altura da planta e espiga, posição relativa da espiga na planta e prolificidade) nestas populações, os quais foram atribuídos às diferenças em suas estruturas genéticas. A BR-105 apresentou maiores amplitudes de variação para o caráter produção de grãos nas duas gerações de amostragens em relação à população BR-106. Ao avaliar os efeitos da deriva genética em caracteres quantitativos nestas populações foram observadas diferenciação entre as subpopulações e redução da variabilidade genética, inferindo-se que as populações estudadas sofreram os efeitos da deriva genética devido ao tamanho reduzido da amostra em função das alterações das freqüências alélicas. 


\subsection{Seleção recorrente recíproca}

A meta principal dos melhoristas de milho é desenvolver populações e linhagens endogâmicas que podem ser cruzadas para formar híbridos superiores.

O desenvolvimento de híbridos é conduzido pelo processo de endogamia e hibridação no qual linhagens endogâmicas, obtidas por autofecundações sucessivas, são utilizadas em cruzamentos para gerar híbridos. Este procedimento permite extrair e fixar os melhores genótipos de uma população ou de um híbrido interpopulacional além de permitir a sua reprodução indefinidamente. Entretanto, como este processo não se caracteriza como um método de melhoramento contínuo, a probabilidade de obter híbridos superiores aos já obtidos em uma segunda amostragem de uma população torna-se extremamente baixa. Desta forma, o emprego de populações melhoradas pelos processos de seleção recorrente contribui para a futura extração de linhagens e híbridos mais produtivos já que existe uma maior concentração de alelos favoráveis na população (Souza Júnior, 1988).

Em linhas gerais, o termo seleção recorrente abrange os métodos de seleção que são conduzidos de forma cíclica. A seleção recorrente visa, independente do caráter sob seleção, aumentar a freqüência dos alelos favoráveis e manter a variabilidade genética para permitir a continuidade do processo em ciclos futuros, sendo este último, o fator que difere fundamentalmente a seleção recorrente de outros esquemas de seleção cíclica (Hallauer et al., 1988; Souza Júnior, 1997).

Como um todo, o processo de seleção recorrente pode ser visto como um ciclo que envolve basicamente: a obtenção de progênies da população a ser melhorada, avaliação destas progênies em experimentos com repetições, e a seleção e recombinação das progênies superiores para formar uma população, dando continuidade a um novo ciclo seletivo (Hallauer et al., 1988).

A seleção recorrente pode ser empregada para melhorar o comportamento per se de uma população (seleção recorrente intrapopulacional) ou o cruzamento de duas populações (seleção recorrente interpopulacional ou 
recíproca). A seleção recorrente recíproca visa, ḋ priori, o melhoramento simultâneo de duas populações no desenvolvimento de linhagens com alta capacidade de combinação para a produção de híbridos, ou seja, visa melhorar a heterose do cruzamento de duas populações sendo que o melhoramento das populações per se não é considerado.

Na seleção recorrente interpopulacional genótipos de duas populações são avaliados em cruzamentos recíprocos sendo que cada população é utilizada como testadora da outra. As populações melhoradas são geradas pela recombinação dos genótipos de cada população que apresentam a melhor capacidade de combinação com a população recíproca. Portanto, apesar da seleção ser praticada com base no comportamento dos cruzamentos, a recombinação é feita dentro de cada população mantendo suas identidades. Desta forma, para cada genótipo são utilizados dois tipos de progênies, respectivamente, interpopulacionais para as unidades de seleção e intrapopulacionais para as unidades de recombinação (Souza Júnior, 1997).

Segundo este autor, na seleção recorrente recíproca o melhoramento per se das populações não ocorre de maneira eqüitativa. Em geral, apenas uma das populações apresenta taxas adequadas de melhoramento sendo que a outra apresenta taxas muitos menores ou mesmo negativas, o que diminui o seu comportamento per se em relação à população original. Em populações divergentes, uma das populações apresenta, em média, a freqüência dos alelos favoráveis superior à população recíproca. A população com menor freqüência de alelos favoráveis torna-se então, uma excelente testadora da população de maior freqüência de alelos favoráveis, porém, esta última, torna-se uma péssima testadora para a população de menor concentração de alelos favoráveis.

O sucesso da seleção recorrente recíproca parece estar associado ao aumento das freqüências dos alelos complementares selecionados em cada população. A recombinação das progênies selecionadas dentro de cada população, ou seja, a manutenção de dois pool gênicos separados permite com que alelos diferentes sejam fixados em cada população. Para estes locos, os híbridos interpopulacionais estarão em heterozigose (Labate et al., 1997b). 
A manifestação da heterose depende, à priori, da presença de locos em heterozigose. A expressão da heterose considera os efeitos conjuntos de todos os locos que diferem no cruzamento de duas linhagens ou populações e inclui os efeitos atribuídos à dominância, os quais são devidos aos locos heterozigóticos.

Lamkey \& Edwards (1997) ressaltam que a heterose é função do quadrado da diferença na freqüência alélica entre duas populações e, portanto, é específica a um cruzamento particular e dependente da dominância direcional. Entretanto, a ausência de heterose não exclui a presença de dominância em locos individuais devido aos efeitos de cancelamento entre locos. Conforme Eyherabide \& Hallauer (1991) é esperado que o melhoramento no nível da heterose, manifestada por um cruzamento interpopulacional, esteja associado com um futuro aumento no nível de heterose, manifestado pelos cruzamentos entre linhagens selecionadas.

A seleção recorrente recíproca capitaliza os dois tipos de ação gênica, isto é, tanto os efeitos aditivos, como os de dominância, conseqüentemente, tanto a capacidade geral de combinação como a capacidade específica (CEC). A capacidade geral de combinação (CGC) é interpretada como indicativo de genes que apresentam efeitos aditivos, enquanto a capacidade específica, de genes com efeitos epistáticos e de dominância (Hallauer \& Miranda Filho, 1988). O efeito de capacidade específica de combinação manifestada no cruzamento de dois materiais é baixo se estes apresentam pouca divergência genética, isto é, freqüências alélicas baixas ou altas nos mesmos locos (Pinto, 2000).

As alterações nas freqüências alélicas em locos marcadores podem fornecer informações úteis a respeito de regiões específicas do genoma que estão sendo favorecidas pela seleção (Frascaroli \& Landi, 1998). Mudanças genéticas em populações de milho sob seleção foram inicialmente investigadas via marcadores isoenzimáticos.

Brown \& Allard (1971) utilizaram nove locos de isoenzimas para monitorar os efeitos de dois ciclos de seleção recorrente recíproca em populações de milho de grupos heteróticos distintos (flint e dent). As mudanças observadas nas freqüências alélicas foram atribuídas à deriva genética associada ao tamanho 
restrito da população na fase de seleção. Segundo esses autores, o tamanho restrito da população foi suficiente para gerar associações esporádicas entre pares de locos (desequilíbrio gamético). o comportamento dos polimorfismos isoenzimáticos indicaram que a deriva genética foi o fator principal para determinar a estrutura das populações.

Stuber \& Moll (1972) monitoraram as freqüências alélicas de locos revelados para o sistema peroxidase e fosfatase ácida durante nove ciclos de um programa de seleção para a produção de grãos. A freqüência do alelo de maior mobilidade mostrou correlação positiva com a produção $(r=0.91)$ nos primeiros seis ciclos de seleção.

Heredia-Díaz et al. (1996) observaram mudanças significativas nas freqüências alélicas em 8 locos de RFLP, ao longo de seis ciclos de seleção recorrente para resistência ao acamamento, sendo quem as alterações nas freqüências alélicas foram maiores do que as esperadas sob a ação da deriva genética.

Em programas de seleção recorrente recíproca a longo prazo, altas intensidades de seleção podem provocar reduções na variabilidade genética das populações selecionadas, limitando o número de ciclos futuros de seleção.

Labate et al. (1997a) utilizando 82 locos de RFLP avaliaram a variabilidade genética nas populações de milho BSSS (Iowa Still Stalk Synthetic) e BSCB1 (Iowa Corn Borer Synthetic N $N_{1}$ ) antes da seleção recorrente recíproca (ciclo zero, $C_{0}$ ) e no $12^{\circ}$ ciclo $\left(C_{12}\right)$ bem como nas linhagens genitoras $(P)$, utilizadas para compor estas populações. Nenhum genitor individual teve uma contribuição genética excessiva em ambos os ciclos ( $C_{0}$ e $\left.C_{12}\right)$ nas respectivas populações. As populações genitoras BSSS e BSCB1 mostraram-se similares geneticamente (distância genética de Nei equivalente a 0,07) e após 12 ciclos de seleção divergiram substancialmente (distância genética de Nei equivalente a 0,66), o que evidencia que a distância genética entre as duas populações BSSS e BSCB1 no $12^{\circ}$ ciclo aumentou cerca de dez vezes em relação aos genitores. Dentro de ambas, o nível de polimorfismo decresceu em $30 \%$ considerando os genitores $(P)$ e as populações no $12^{\circ}$ ciclo. $O$ número de alelos por loco decresceu 
de quatro para menos que três. As populações do $12^{\circ}$ ciclo foram geradas pelo intercruzamento de 20 linhagens $S_{1}$ selecionadas.

Posteriormente, Labate et al. (1999) relataram que as mudanças nas freqüências alélicas dessas populações observadas na maioria dos locos entre $C_{0}$ e $\mathrm{C}_{12}$ foram muito acentuadas para serem atribuídas somente à deriva genética. As mudanças foram interpretadas como uma evidência positiva de seleção direcional ou carona genética (genetic hitchhiking). A hipótese de deriva genética foi rejeitada para 11 e 17 locos, respectivamente, nas populações BSSS (R) e BSCB1 (R). Tais locos "não neutros" foram encontrados em todos os cromossomos, dispersos pelo genoma, e mostraram um padrão de mudanças genéticas complementares entre as duas populações.

Embora intensidades de seleção elevadas propiciem o surgimento da deriva genética devida ao tamanho efetivo reduzido das populações selecionadas, altas intensidades de seleção aumentam a freqüência de alelos favoráveis a taxas elevadas por ciclo, aumentando a probabilidade de seleção de linhagens elites (Rezende \& Souza Júnior, 2000).

Estes autores avaliaram os efeitos da seleção e deriva genética nas populações BR-105 e BR-106 sob um ciclo de seleção recorrente recíproca de alta intensidade (2,0 e 2,5\%, respectivamente), utilizando linhagens $S_{3}$ desenvolvidas pelo método genealógico. A produção aumentou $16,7 \%$ para o cruzamento interpopulacional, $14,7 \%$ para a população BR-105 e decresceu $10,1 \%$ para a população BR-106. O processo de melhoramento do híbrido interpopulacional ocorreu sem que houvesse perda da distribuição normal e presença de assimetrias na distribuição dos dados, indicando que o efeito conjunto da seleção e da deriva genética não afetou significativamente os padrões de variação das progênies interpopulacionais, garantindo a integridade da variabilidade genética necessária para a realização de futuros ciclos de seleção. Rezende \& Souza Júnior, (2000) utilizaram o modelo proposto por Smith (1983) para separar os efeitos da depressão por endogamia atribuídos à deriva genética dos efeitos referentes ao aumento na freqüência de alelos favoráveis via seleção. Tal modelo estima, entre outros, os parâmetros $A O I$ e $D O I$, os quais correspondem aos 
efeitos aditivos e de dominância respectivamente na i-ésima população original, e o parâmetro $D Q I$, referente à perda de heterozigotos devido à deriva genética na i-ésima população, quando o tamanho efetivo populacional é menor que 20 . Os efeitos da deriva genética ( $D Q I$ e $D Q I$ ) foram negativos e significativos para todos os caracteres, em ambas populações, exceto para a prolificidade na população BR-106. Para a produção, $D Q I$ foi - 0,30 Mg/ha para a BR-105 e 0,85 Mg/ha para BR-106. Conseqüentemente, os efeitos da deriva genética na população BR-106 foram mais pronunciados do que na BR-105. A BR-105 é menos sensivel à depressão por endogamia do que a BR-106. A magnitude das alterações observadas na heterose do híbrido interpopulacional e na depressão por endogamia das populações foi atribuída às modificações nas freqüências dos alelos de efeito dominante nas populações per se e no híbrido interpopulacional, e principalmente aos efeitos da oscilação genética.

\subsection{Descrição das populações BR-105, BR-106 e seus sintéticos IG-3 e} IG-4

De acordo com Souza Júnior et al. (1993) a população BR-105 se caracteriza por apresentar porte baixo, ciclo precoce, grãos alaranjados duros e baixa depressão por endogamia. Esta população, inicialmente chamada de Suwan, foi obtida na Tailândia por seleção entre progênies $S_{1}$. No Brasil, foi introduzida em 1976, sendo que já foi submetida a cinco ciclos de seleção com irmãos germanos realizados no Centro Nacional de Pesquisa de Milho e Sorgo (Embrapa). A população BR-106 apresenta porte baixo, ciclo precoce e grãos amarelados dentados, segregando em baixa freqüência para grãos brancos (Figura 1). Esta população foi obtida pelo intercruzamento das variedades tardias de porte alto Centralmex, Composto Dentado e Maya com a BR-108 (Tuxpenõ-1), de ciclo precoce e porte baixo. Após duas gerações de recombinação, seguiramse três ciclos de seleção para redução da altura da planta e espiga. 
As populações BR-105 e BR-106 per se são muito produtivas e apresentam elevada capacidade geral de combinação (Naspolini Filho et al., 1981), sendo que o híbrido intervarietal é muito produtivo, apresentando heterose elevada tanto em relação à média dos pais quanto em relação ao pai superior, o que vem a sugerir a ocorrência de divergência genética entre essas populações.

IG-3 e IG-4 são variedades sintéticas derivadas, respectivamente, das populações BR-105 e BR-106 (Figura 2). Para a sua obtenção, 400 linhagens $S_{3}$ de cada população foram submetidas à seleção para capacidade de combinação, utilizando como testadores as populações recíprocas. Esta seleção foi feita com base na avaliação do caráter produção de grãos, entre outros. As 40 linhagens superiores de cada população foram avaliadas quanto ao seu comportamento per se e 8 linhagens elite da população BR-105 e 10 linhagens elite da população BR106 foram selecionadas quanto à uniformidade. As oito linhagens elite da população BR-105 foram intercruzadas gerando o sintético IG-3, e as dez linhagens elite da população BR-106, também por intercruzamento, geraram o sintético IG-4 (Rezende, 1997).

As linhagens foram inicialmente intercruzadas em um sistema dialélico e, a seguir, o material foi recombinado por três gerações. Espera-se que os sintéticos obtidos após um ciclo de seleção recorrente estejam próximos do equilíbrio de ligação e em equilíbrio de Hardy-Weinberg. A intensidade de seleção aplicada para a formação dos sintéticos IG-3 e IG-4 foi de 2,0 e 2,5\% respectivamente. Os tamanhos efetivos populacionais correspondem a 4,57 e 5,71 conferindo coeficientes de endogamia $(F)$ de 10,94 e $8,75 \%$, respectivamente (Rezende, 1997). Desta forma, nota-se que as 8 e 10 linhagens elites derivadas das populações BR-105 e BR-106, respectivamente, constituem os gametas presentes nos sintéticos IG-3 e IG-4.

A divergência genética das linhagens elite oriundas da população BR105 e BR-106 foram avaliadas com marcadores RAPD por Lanza et al. (1997). Valores das correlações entre o comportamento de híbridos simples e a divergência genética das linhagens genitoras foram estabelecidos. Os 32 primers 
avaliados nas 18 linhagens produziram um total de 325 bandas consistentes das quais $262(80,6 \%)$ foram polimórficas. A análise de agrupamento dividiu as linhagens em três grupos distintos (GI, GII e GIII). O grupo I incluiu três linhagens da BR-106 e uma da BR-105, o grupo II incluiu sete linhagens da BR105 e uma da BR-106, e seis linhagens da BR-106 foram incluídas no grupo III. A distância genética média entre as linhagens dentro dos grupos foi de $0,73,0,52 \mathrm{e}$ 0,46 , respectivamente para GI, GII e GIII.

Segundo os autores, os resultados do agrupamento obtido pelos marcadores RAPDs não concordaram com a divisão previamente estabelecida com dados genealógicos (Naspolini Filho et al., 1981), na qual apenas dois grupos foram observados. A diferença entre os resultados obtidos com dados de marcadores RAPD e genealógico foi atribuída à grande variabilidade das populações tropicais de milho, as quais podem ser alocadas em mais de um grupo heterótico. Tais grupos não são distinguidos quando utiliza-se somente dados fenotípicos. A heterose para a produção de grãos foi mais positivamente correlacionada $(r=0,63)$ com a distância genética das combinações das linhagens entre os grupos GI e GIII.

Pinto (2000) trabalhando com as mesmas linhagens observou para o caracter "produção de grãos" que os grupos heteróticos formados a partir das estimativas da capacidade especifica de combinação (CEC) foram similares aqueles obtidos por marcadores RFLP, sendo portanto úteis para alocar as linhagens nos grupos heteróticos. As distâncias genéticas obtidas via RFLP mostraram que os grupos nos quais os hibridos apresentaram as menores produtividades médias foram também os menos divergentes. Os dados gerados com os marcadores RFLP separaram as linhagens provenientes das populações BR-105 e BR-106 em dois grupos e, posteriormente, separaram as linhagens em grupos heteróticos dentro de cada população. Além disso, foi observado que dentro das populações existe variabilidade suficiente para a formação de grupos heteróticos. 

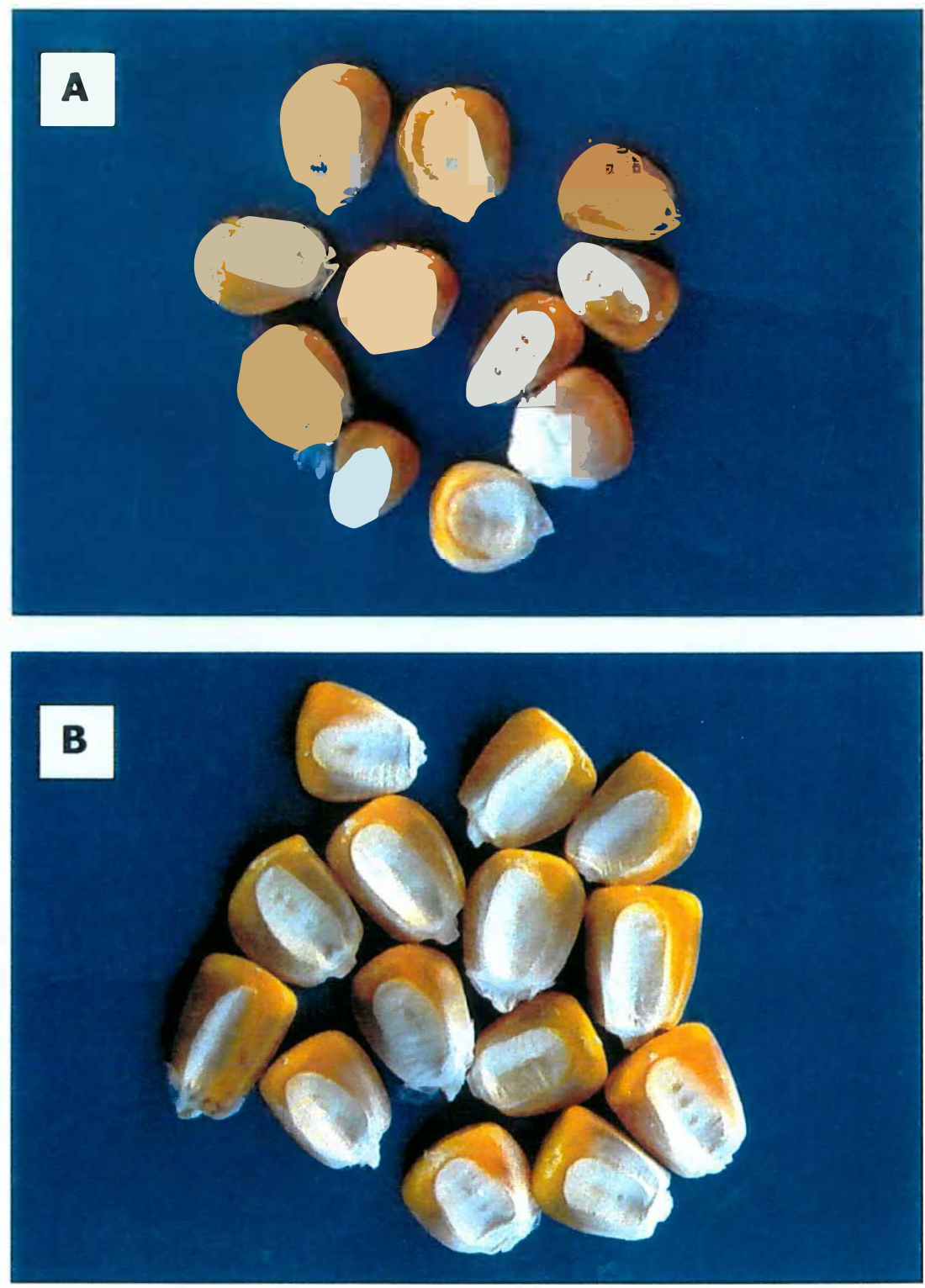

Figura 1- População BR-105 (A) mostrando grãos alaranjados duros do tipo flint, população BR-106 (B) com grãos amarelos dentados. 
Populações:

\section{BR-105}

\{

Testadores:

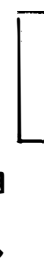

BR-106

$b$

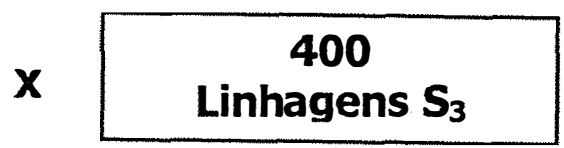

Seleção para capacidade de combinação

\}
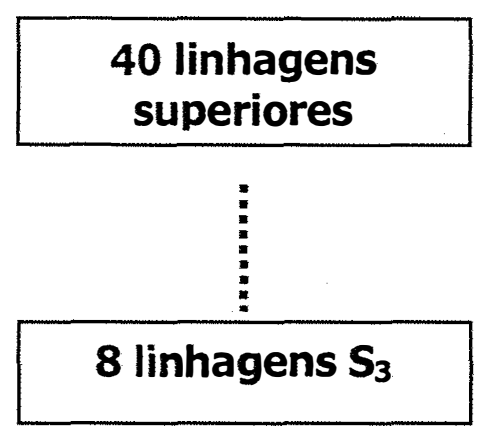

\}

INTERCRUZAMENTO

\{

Sintéticos:
\}

40 linhagens superiores

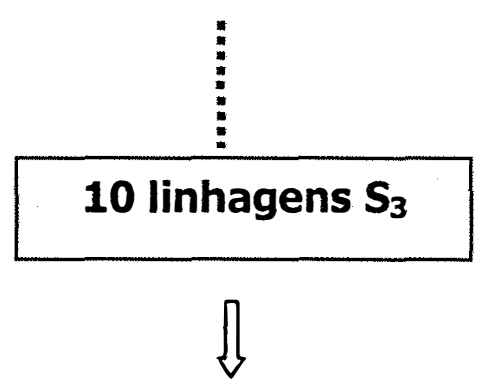

INTERCRUZAMENTO

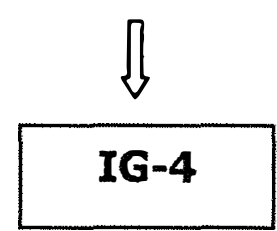

Figura 2- Esquema de obtenção das duas variedades sintéticas denominadas IG-3 e IG-4, derivadas das populações BR-105 e BR-106, respectivamente. 


\subsection{Marcadores microssatélites e a variabilidade em milho}

Uma fração significativa dos genomas da maioria dos eucariotos é constituída por sequências de DNA repetitivo. Esta classe de DNA inclui: o DNA satélite (DNA altamente repetitivo), as sequências de minissatélites e microssatélites (DNA moderadamente repetitivo) e os elementos transponiveis (DNA moderadamente repetitivo, móvel, de sequências dispersas) (Charlesworth et al., 1994).

Segundo SIA et al. (1997) a definição de microssatélite (simple sequence repeats - SSRs) é de certo modo arbitrária quanto ao número de pbs que compõe a unidade de repetição (motivo), sendo definida como uma região na qual 1 a 10 pbs são repetidos lado a lado (em tandem) cerca de oito ou mais vezes.

Os microssatélites representam regiões instáveis do genoma, que estão sob alterações mutacionais, geralmente adições ou deleções de um número integral de repetições a taxas muito maiores do que as observadas nas sequências de DNA não repetitivo. Valores duas a três vezes maior em magnitude em relação aos valores conhecidos para aloenzimas têm sido apontados (Jarne \& Lagoda, 1996). A instabilidade dos microssatélites resulta em locos polimórficos que são extremamente úteis, principalmente, em estudos de mapeamento. Tal polimorfismo aparece quando os alelos diferem quanto ao número de repetições em tandem no segmento amplificado (Figura 3).

O polimorfismo dos marcadores microssatélites é revelado pela PCR reação em cadeia da polimerase, através da amplificação do DNA genômico total utilizando dois primers únicos compostos de sequências curtas de nucleotídeos que flanqueiam e, portanto, definem o loco de microssatélite. Os produtos da amplificação obtidos de diferentes indivíduos podem ser separados em géis de agarose ou poliacrilamida. O valor dos microssatélites como marcadores é atribuído à sua natureza multialélica, herança codominante, facilidade de deteç̧ão pela PCR, abundância relativa, cobertura extensiva do genoma e 
necessidade de quantidades pequenas de DNA para dar início às reações (Powell et al., 1996).

De acordo com Jarne \& Lagoda (1996), os microssatélites podem ser classificados em três famílias, respectivamente, de repetições puras, compostas e interrompidas. Nas repetições puras, os locos de microssatélites são formados por um único tipo de motivo repetido (CACACACACACACACACACA); nas repetições compostas mais de um tipo de motivo compõe o microssatélite e nas repetições interrompidas os motivos são intercalados por nucleotídeos que não fazem parte da unidade de repetição (CACATTCACACATTCATTCA).

Os tipos mais comuns de microssatélites são formados por motivos contendo dois, três e quatro nucleotídeos. Os locos compostos por repetições de dinucleotídeos são os mais utilizados (Wang et al., 1998; Casacuberta et al., 2000). Entretanto, a amplificação de repetições de dinucleotídeos têm se mostrado vulnerável à formação das chamadas bandas stutter (Smith \& Devey, 1994).

Este tipo de produto gerado pela amplificação de locos de microssatélites e também referido como banda sombra, ou produto do deslize da DNA polimerase, difere em tamanho do alelo principal por um número a mais ou a menos de repetições. Porém, no caso dos locos de repetições dinucleotídicas a banda stutter predominante é, em geral, duas bases menor que a banda referente ao alelo principal. Este padrão de multibanda dificulta a interpretação dos locos de repetições dinucleotídicas, principalmente quando dois alelos de um indivíduo apresentam um tamanho próximo.

Em geral, a amplificação de locos com repetições tetranucleotídicas fornece uma interpretação mais fácil devido à observação de apenas uma banda stutter com quatro bases a menos e de intensidade menor (10\%) em relação à banda principal. Alelos de maior comprimento têm demonstrado um alto percentual de bandas stutter, comparado a alelos de menor comprimento (Walsh et al., 1996). 


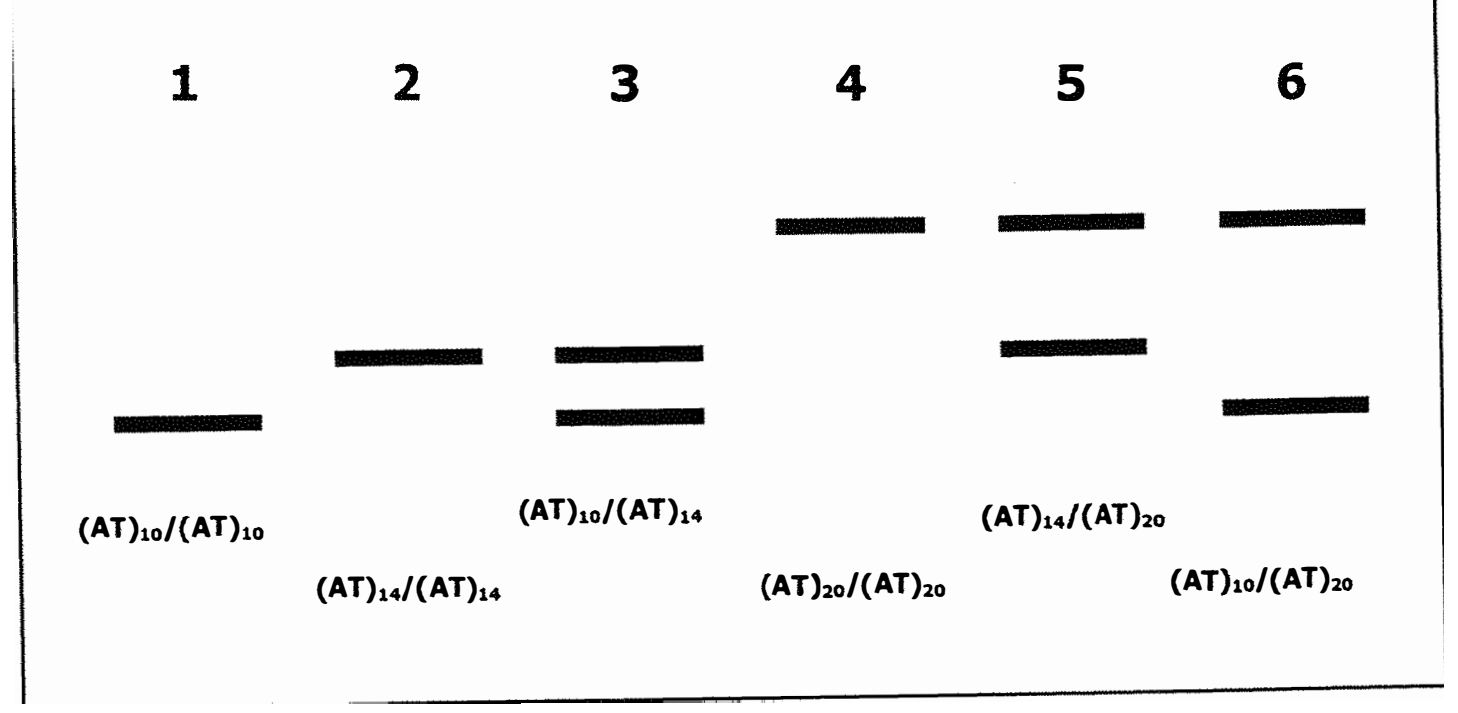

Figura 3 - Representação do padrão de bandas observado para Marcadores SSR, considerando três alelos: $(A T)_{10},(A T)_{14},(A T)_{20}$. Indivíduos homozigóticos: $(1,2,4)$ apresentam ambos alelos com o mesmo número de repetições, enquanto os heterozigóticos apresentam alelos com número diferente de repetições $(3,5$ e 6$)$. 
Segundo esses autores, DNA polimerases com alta capacidade de síntese podem reduzir significativamente 0 aparecimento de bandas stutter durante a amplificação de repetições dinucleotídicas.

De acordo com Lagercrantz et al. (1993), os microssatélites (SSR) são cerca de cinco vezes menos abundantes nos genomas vegetais em relação ao de mamíferos. Buscas realizadas em bancos de dados revelaram certas características atribuíveis aos SSR de plantas que os distingue dos SSR de humanos. Considerando apenas repetições de comprimento de 20 pb ou mais, AT/TA têm sido apontado como o dinucleotídeo mais comum, seguido de $A A / T T$ e GA/CT. O motivo GT/CA significativamente menos abundante nas plantas é o mais freqüente em humanos. Em relação à densidade dos SSRs, estima-se nas plantas a presença de um microssatélite maior que $20 \mathrm{pb}$ a cada $29 \mathrm{~Kb}$ em relação a cada $6 \mathrm{~Kb}$ em humanos. Em média, nas monocotiledôneas, é esperado um microssatélite a cada $64,6 \mathrm{~Kb}$ enquanto nas dicotiledôneas um microssatélite a cada $21,2 \mathrm{~Kb}$. Para Zea mays estima-se a presença de um microssatélite a cada $58,6 \mathrm{~Kb}$ (Wang et al., 1994).

Wang et al. (1994) analisando repetições de microssatélites (mononucleotídicas e tetranucleotídicas) nos bancos de dados de sequências de DNA (Genebank e EMBL) de diversas espécies vegetais indicaram que as repetições mono, di e tetranucleotídicas estão localizadas em regiões não codantes. Exceto as repetições de trinucleotídeos contendo G-C foram freqüentêmente localizadas em regiões codantes em contraste às sequências $(A A T)_{n}$ e $(T T A)_{n}$ observadas em regiões não codantes. $A$ instabilidade das repetições trinucleotídicas está relacionada com certas doenças em humanos (Sia et al., 1997; Thomson \& Esposito, 1999).

A abundância dos microssatélites em milho foi revelada inicialmente por Chin et al. (1996) pela avaliação de 576 sequências disponíveis nos bancos de dados Genebank e EMBL. Deste total, foram identificados 200 microssatélites em potencial, sendo as repetições (AG/CT) $n$, $(C C T / G G A)_{n}$ e $(C C G / G G C)_{n}$ as mais freqüentes. A grande maioria dos microssatélites foi encontrada em CDNAs, nos sítios de seqüências expressas (ESTs) e em genes conhecidos, incluindo íntrons e 
sequências flanqueadoras $5^{\prime}$ e $3^{\prime}$, o que reflete a ocorrência de repetições em genes do milho ou adjacentes a estes. As repetições de trinucleotídeos foram encontradas, em sua maioria, em seqüências codantes, dos 89 trinucleotídeos identificados, $66 \%$ encontraram-se nestas sequências.

Em virtude da "informatividade" de um loco marcador estar associada ao número de alelos capazes de ser identificados, o valor de um marcador na deteç̧ão do polimorfismo, isto é, o conteúdo de informação de polimorfismo (PIC) têm sido estimado pela diversidade gênica ou heterozigosidade. Valores de PIC fornecem uma estimativa do poder discriminatório de um marcador considerando não apenas o número de alelos em um loco como também as freqüências relativas dos alelos na população. Desta forma, locos marcadores com um maior número de alelos e cujas freqüências são semelhantes apresentarão os maiores valores de PIC (Senior et al., 1998).

Em um levantamento para avaliar os níveis de variabilidade alélica detectada com microssatélites em seis culturas de maior relevância, Powell et al. (1996) relataram em soja de 11 a 26 alelos por loco (PIC 0,71 a 0,95), arroz de 5 a 11 alelos por loco (PIC 0,64 a 0,90), cevada de 3 a 37 alelos (PIC 0,46 a 0,93), trigo de 2 a 7 alelos por loco (PIC 0,29 a 0,79), milho de 2 a 12 alelos por loco (PIC 0,40 a 0,89) e em tomate a presença de cerca de 1 a 5 alelos por loco.

Considerando o número de alelos detectados via marcadores microssatélites, deve-se ressaltar que a natureza do gel utilizado para a separação dos alelos exerce influência sobre o número de alelos detectados. Géis de poliacrilamida desnaturante permitem a separação de fragmentos que diferem em apenas 1 pb (Loridon et al., 1996) enquanto géis de agarose apresentam um limite de resolução acima de 4 pb (Senior et al., 1996). O aumento de resolução dos géis de poliacrilamida em relação aos de agarose leva à detecção de um número maior de alelos por loco, o que se constitui de extrema importância para locos de microssatélites de repetições dinucleotídicas em que os produtos da amplificação estão na faixa de 130 a 200 pb, e seqüências diferindo por 2 pbs não podem ser distinguidas nos géis de agarose (Senior et al., 1998). 
Em cana-de-açúcar, o número de alelos detectados por loco em géis de poliacrilamida, em cinco genótipos, variaram de 3 a 12 com uma média de 8 alelos por loco, valores de PIC entre 0,48 e 0,80 com média de 0,72 (Cordeiro et al., 2000). Senior \& Heun (1993) avaliaram seis locos de microssatélites (seis pares de primers) em oito linhagens de milho utilizando géis de agarose metaphor a $3 \%$ e detectaram cerca de 3,5 alelos/loco.

Chin et al. (1996) trabalharam com 200 locos de microssatélites em nove linhagens de milho provenientes de diversas genealogias. Destes 200 locos, 69 foram polimórficos e revelaram cerca 2 a 4 alelos em géis de agarose metaphor.

Noventa e quatro linhagens elite de milho representativas da diversidade genética entre linhas derivadas de raças do cinturão de milho dentado foram avaliadas, utilizando-se 70 locos de microssatélites. Estes locos permitiram a identificação em géis de agarose de 365 alelos. Em média, foram detectados cinco alelos por loco com uma variação de 2 a 33 alelos. Valores de PIC variaram de 0,17 a 0,92 com um valor médio de 0,59 sendo os valores mais elevados (PIC $=0,67)$ encontrados para os locos de microssatélites constituídos de repetições dinucleotídicas (Senior et al., 1998).

A principal razão do crescente sucesso dos microssatélites como ferramenta em estudos de genética deve-se ao fato deste marcador proporcionar uma alta incidência de polimorfismos detectáveis em relação a outras técnicas como RFLPs e RAPDs. Pejic et al. (1998) realizaram um estudo comparativo entre os marcadores do tipo RAPD, RFLP e SSRs em um grupo de 33 linhagens de milho para avaliar sua informatividade e aplicabilidade em análises de diversidade genética. O conteúdo informativo avaliado pela heterozigosidade esperada e o número médio de alelos foi maior para os marcadores microssatélites. Devido ao fato dos microssatélites representarem regiões não codantes do DNA (não funcionais), à priori, não estão sujeitos a fortes pressões seletivas. Portanto, espera-se que a presença ou ausência de um marcador particular não venha influenciar a sobrevivência do indivíduo (Heath et al., 1993).

No Brasil, há vários laboratórios trabalhando com os marcadores microssatélites de plantas com objetivos diversos; este trabalho resulta da 
integração entre o Centro de Biologia Molecular e Engenharia Genética UNICAMP e o Laboratório de Biologia Celular e Molecular de Plantas da ESALQ/USP. 


\section{MATERIAL E MÉTODOS}

\subsection{Material vegetal}

Foram utilizadas as populações de milho BR-105 e BR-106 e os respectivos sintéticos IG-3 e IG-4 obtidos após um ciclo de seleção recorrente recíproca, conforme descrito (ítem 2.4). Estes materiais são procedentes do programa de melhoramento de milho do Departamento de Genética da Escola Superior de Agricultura Luiz de Queiroz, e foram cedidos pelo Prof. Dr. Cláudio Lopes de Souza Júnior para a investigação da sua estrutura genética. Para cada uma das quatro populações foram utilizados 96 indivíduos.

\subsection{Métodos}

3.2.1 Análise por Marcadores Microssastélites (Simple Sequence Repeats - SSR)

\subsubsection{Coleta do material para extração do DNA}

O DNA foi extraído de folhas coletadas de plantas cultivadas em casa de vegetação 35 dias após a germinação. Cerca de três a quatro folhas foram coletadas de cada planta e, após a retirada da nervura principal, estas foram colocadas em um saco feito de tela devidamente etiquetado. O material foi colocado em caixas de isopor refrigeradas com gelo e, em seguida, submetido à 
liofilização durante três dias. Após a liofilização, foi moído em um moinho mecânico (Ciclotec-1093 Sample Mill, Tecator) colocado em tubos de plástico e armazenado à temperatura de $-20^{\circ} \mathrm{C}$ até a extração.

\subsubsection{Extração do DNA genômico}

A extração do DNA foi conduzida conforme a metodologia descrita por Saghai-Maroof et al. (1984).

Trezentas miligramas de tecido foliar liofilizado e moído foram colocados em um tubo Falcon de $15 \mathrm{~mL}$. Em seguida, foram adicionados $9 \mathrm{~mL}$ de tampão CTAB (100mM Tris-HCl pH 7,5; $700 \mathrm{mM} \mathrm{NaCl} ; 50 \mathrm{mM}$ EDTA pH 8,0; 1\% CTAB; $140 \mathrm{mM}$ de $\beta$-mercaptoetanol) recém preparado à temperatura de $65^{\circ} \mathrm{C}$. Os tubos foram incubados a $65^{\circ} \mathrm{C}$ por $1 \mathrm{~h} 30 \mathrm{~min}$., sendo homogeneizados por inversão lenta de cinco em cinco min. Após este período, os tubos foram deixados em repouso à temperatura ambiente por 10 min. e, em seguida, foram adicionados $4,5 \mathrm{~mL}$ de uma solução clorofórmio-álcool isoamílico (24:1), misturando-se por inversão lenta durante $10 \mathrm{~min}$. Os tubos foram centrifugados a $2800 \mathrm{rpm}$ por $10 \mathrm{~min}$. à temperatura ambiente e a fase aquosa (superior) foi transferida para um novo tubo. Novamente, foram adicionados $4,5 \mathrm{~mL}$ da solução clorofórmio-álcool isoamílico (24:1), misturando-se por inversão lenta durante 10 min., com posterior centrifugação a $2800 \mathrm{rpm}$ por $10 \mathrm{~min}$. A fase aquosa foi transferida para um novo tubo, utilizando ponteiras com as pontas cortadas e adicionou-se $50 \mu \mathrm{L}$ de RNase a $10 \mathrm{mg} / \mu \mathrm{L}$ permanecendo durante $2 \mathrm{~h}$ à temperatura ambiente.

A cada tubo foram adicionados $6 \mathrm{~mL}$ de isopropanol, misturando-se lentamente por inversão durante $1 \mathrm{~min}$. A seguir, os tubos foram centrifugados (2800 rpm por $10 \mathrm{~min}$., temperatura ambiente), o sobrenadante foi descartado e 0 precipitado foi lavado com $2 \mathrm{~mL}$ da solução Wash 1 (76\% de etanol absoluto, 2,5M $\mathrm{NaOAC}$ ) por $20 \mathrm{~min}$. Novamente, os tubos foram centrifugados (2800 rpm por 10 min. à temperatura ambiente), o sobrenadante foi descartado e $2 \mathrm{~mL}$ da solução

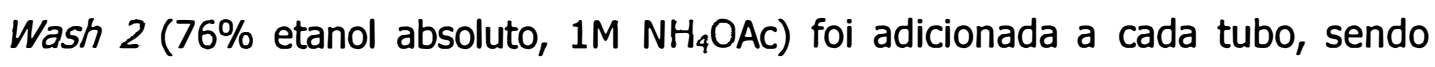


descartada logo em seguida. O pellet foi deixado à temperatura ambiente para secar e, posteriormente, resuspenso em $2 \mathrm{~mL}$ de tampão TE (10mM Tris- $\mathrm{HCl} \mathrm{pH}$ 8,0;1,0mM EDTA pH 8,0) overnight.

Foram adicionados $2 \mathrm{~mL}$ de fenol equilibrado com agitação lenta durante um min. Os tubos foram centrifugados (2.800 rpm por $10 \mathrm{~min}$., à temperatura ambiente) com posterior transferência da fase aquosa (com ponteiras cortadas) para novo tubo. Em seguida, foram adicionados $2 \mathrm{~mL}$ de uma solução clorofórmioálcool isoamílico (24:1), com inversões lentas por 1 min. e nova centrifugação (2.800 rpm por $10 \mathrm{~min}$.) foi efetuada. A fase aquosa foi transferida para novo tubo (utilizando ponteiras cortadas) e $5 \mathrm{~mL}$ de etanol absoluto acrescido de $100 \mu \mathrm{l}$ de $\mathrm{NaCl} 5 \mathrm{M}$ foram adicionados aos tubos, invertendo-os levemente durante 1 min.. Os tubos foram centrifugados ( $2.800 \mathrm{rpm}$ por $10 \mathrm{~min}$., temperatura ambiente), o sobrenadante foi descartado, e o precipitado foi lavado com $2 \mathrm{~mL}$ da solução Wash 1 por 20 min. Após nova centrifugação, o sobrenadante foi descartado e $2 \mathrm{~mL}$ da solução Wash 2 foram adicionados e descartados em seguida. $O$ pellet permaneceu por uma hora à temperatura ambiente para secar, e posteriormente foi resuspenso overnight em $500 \mu \mathrm{L}$ de tampão TE.

\subsubsection{Quantificação do DNA}

O DNA de cada indivíduo foi quantificado em gel de agarose $0,8 \%$ (Gibco BRL) corado com brometo de etídio $(10 \mathrm{mg} / \mathrm{mL}$ ) e posteriormente visualizado sob luz ultra violeta e fotodocumentado (Gel doc - Bio Rad). Inicialmente, as amostras foram diluídas 100 vezes ( $5 \mu \mathrm{L}$ do DNA da solução estoque em $495 \mu \mathrm{L}$ de tampão TE) sendo aplicados no gel, $5 \mu \mathrm{L}$ e $10 \mu \mathrm{L}$ da diluição para cada indivíduo. A intensidade da banda referente às duas diluições foi comparada com um padrão de DNA do fago $\lambda$, de quantidades conhecidas $(20,40$, 60 e $80 \mathrm{ng}$ ). A quantidade de DNA ( $\mathrm{ng} / \mu \mathrm{L}$ ) presente na solução estoque foi então estimada para cada indivíduo. 
Com base nos valores previamente quantificados procedeu-se a nova requantificação. Foram aplicados ao gel $4 \mu \mathrm{L}$ de uma amostra à uma concentração pré-estabelecida de $10 \mathrm{ng} / \mu \mathrm{L}$ de DNA a qual foi novamente comparada com o padrão a 20, 40 e 60ng. De posse dos valores estimados foi feita uma diluição de trabalho a $10 \mathrm{ng} / \mu \mathrm{L}$ para cada um dos 384 indivíduos.

\subsubsection{Amplificação do DNA genômico (SSR - PCR)}

As reações de amplificação foram conduzidas conforme descrito por Senior \& Heun (1993) em um volume final de $20 \mu \mathrm{L}$ contendo $40 \mathrm{ng}$ de DNA molde;

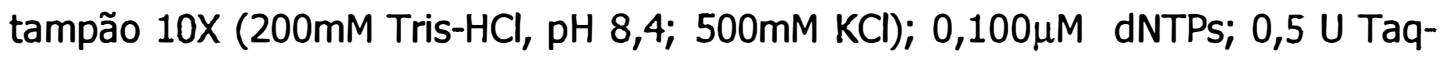
DNA polimerase; $2,0 \mathrm{mM}$ de $\mathrm{MgCl}_{2} ; 0,2 \mu \mathrm{M}$ de primers foward/reverse. A amplificação foi conduzida em termociclador PTC-100 (MJ Research, USA) utilizando programas touchdown desenvolvidos por Ogliari et al. (2000) com modificações (Figura 4).

Seguindo o procedimento de Ogliari et al. (2000), inicialmente todos os locos de microssatélites foram amplificados no programa 1 (MSAT1) considerado como básico, independente das temperaturas de anelamento estimadas para os respectivos pares de primers (foward/reverse).

Os locos que não amplificaram bem, foram submetidos aos demais programas cuja escolha teve como base a temperatura de anelamento "específica" para cada par de primers. Considerou-se as equações:

$$
\begin{gathered}
T_{a(1)}=4(G+C)+2(A+T)-5^{\circ} C \\
T_{a(2)}=81,5+16,6\left\{\log \left[K^{+}\right]+0,4(\% G+C)-(675 / n)\right\}
\end{gathered}
$$


A eq.(8) desenvolvida para primers de até 20pb e a eq.(9) para primers maiores de 20pb (Tabela 1). A eq.(9) leva em consideração a concentração de potássio presente no tampão da reação, a porcentagem de $G+C$ e o comprimento do primer ( $n$ ) (Alkami, 1999).

Tempos de anelamento de 30 e 40 segundos foram utilizados para determinados pares de primers no sentido de reduzir a presença de anelamentos inespecíficos, principalmente naqueles programas de amplificação que utilizam temperaturas de anelamento mais baixas. Ajustes na concentração de magnésio $(1,0 ; 2,0$ e $3,0 \mathrm{mM})$ foram empregados considerando as demais variáveis da PCR constantes.

\subsubsection{Separação dos produtos de amplificação}

Os produtos da amplificação foram separados em géis de agarose a $3 \%$ ( $50 \%$ agarose metaphor FMC-Bio products e $50 \%$ agarose Gibco), sob voltagem constante de 100 em tampão TBE (0,09M Tris; 0,09M ácido bórico; 2 mM EDTA). Foram utilizados marcadores de peso molecular de 50pb e de 100pb (Gibco-BRL). Posteriormente, foram corados com brometo de etídio, visualizados sob luz ultravioleta e fotodocumentados. 


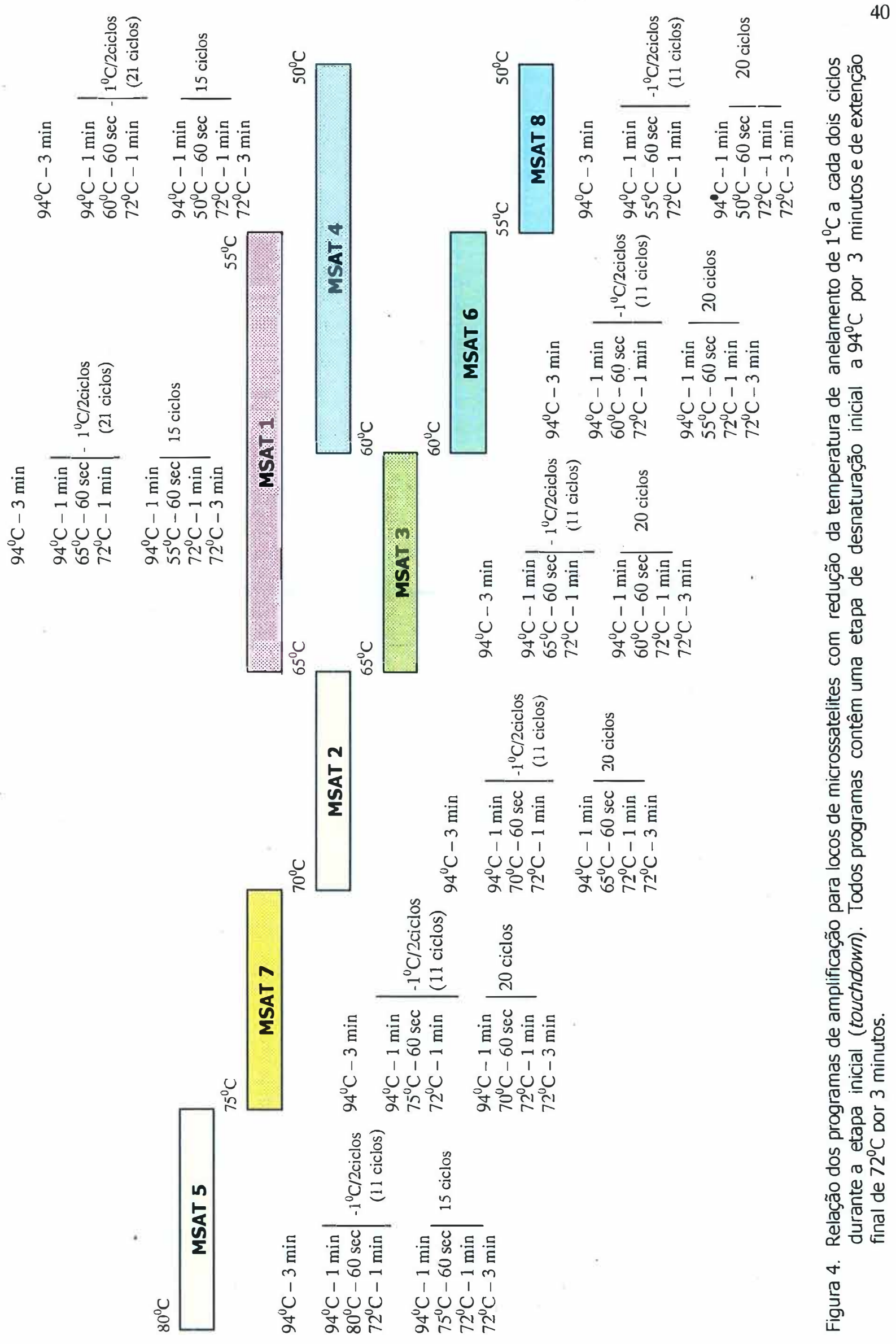


Tabela 1. Loco (cromossomo), seqüência dos primers (foward/reverse) com os seus respectivos tamanhos e temperaturas de anelamento para 94 SSRs.

\begin{tabular}{|c|c|c|c|c|}
\hline \multirow[t]{2}{*}{ Loco/Bin } & \multirow[t]{2}{*}{$\begin{array}{l}\text { Sequiência dos primers } \\
\text { Foward/reverse }\end{array}$} & \multirow[t]{2}{*}{$\begin{array}{l}\text { Tamanho } \\
\text { (bp) }\end{array}$} & \multicolumn{2}{|c|}{$\begin{array}{c}\text { Temperatura } \\
\text { anelamento } \\
\left({ }^{\circ} \mathrm{C}\right)\end{array}$} \\
\hline & & & $T_{\mathrm{a}}(1)$ & $T_{a}(2)$ \\
\hline Bnlg 149 & CAT CCT CCA AAA GCA CTA CGT & 21 & 57 & 47.46 \\
\hline 1.00 & CAG CTG TCC GAC ACT TAT TCT GTA & 24 & 65 & 50.65 \\
\hline Phi 056 & ACG CCC AGA TCT GTI CCT TCT C & 22 & 63 & 51.60 \\
\hline 1.01 & ATG GCG GCA GGC CGA TTG Tा & 20 & 59 & 50.77 \\
\hline Bnlg 109 & GCC AGC TGA TGT CTG ATG AAC AGC ACA & 27 & 77 & 56.18 \\
\hline 1.02 & GAT CGG GCC AGA TIT CTC AAG TCG TCA & 27 & 75 & 56.18 \\
\hline Bnlg 176 & AGT TCA CGT CCA GCT GAA TGA CAG & 24 & 67 & 52.30 \\
\hline 1.03 & CGC GCA TCG CAT GCT TAT CCT A & 22 & 63 & 51.38 \\
\hline Phi 001 & TGA CGG ACG TGG ATC GCT TCA C & 22 & 65 & 53.46 \\
\hline 1.03 & AGC AGG CAG CAG GTC AGC AGC G & 22 & 69 & 57.19 \\
\hline Phi 095 & CCG ATC GGC TTा ATC ACT GTT TAG C & 25 & 69 & 52.60 \\
\hline 1.03 & ATG CAC CAT TCT AGC ACT ATA GCA ACA & 27 & 77 & 53.61 \\
\hline Bnlg 504 & CGG CAG CTC CAG CAC CGG CAT & 21 & 67 & 57.06 \\
\hline 1.11 & AGT GTC CAC ATA CCG CCA CAC ACG TाT & 27 & 69 & 56.18 \\
\hline Phi 055 & GAG ATC GTG TGC CCG CAC C & 19 & 59 & 52.45 \\
\hline 1.09 & TTC СTC CTG CTC CTC AGA CGA & 21 & 61 & 51.20 \\
\hline Bnlg 100 & TGC ACG CAC GGG CAC TGA AC & 20 & 61 & 52.82 \\
\hline $1.09-1.10$ & TAA GAC ATC TAT GGC CAC CGG AG & 22 & 61 & 53.94 \\
\hline Phi 094 & AAA GAG GAG GAA CGC GAA GGA C & 22 & 63 & 51.60 \\
\hline 1.09 & TCA CAT CCT GGC GGT CAC CA & 20 & 59 & 50.77 \\
\hline Bnlg 131 & CTC TGC GCT ACC TIT CTG AGT C & 22 & 63 & 51.37 \\
\hline 1.11 & GCG GAA TCC TTG TGT TCT TG & 20 & 55 & 46.67 \\
\hline Phi 097 & TGC TTC ACA TTC AGT CAC CGT CAG & 24 & 67 & 52.29 \\
\hline 1.01 & CCA CGA CAG ATG ATT ACC GAC C & 22 & 63 & 51.60 \\
\hline MACE01F06 & CAG GTA CTA CGT GCC GTG & 18 & 53 & 47.47 \\
\hline 1.08 & CTA GAG ACA AAC GAG GCT AGG & 21 & 59 & 49.29 \\
\hline Bnlg 400 & AGC TGT GAC TGT GAA GGG AAA A & 22 & 59 & 47.87 \\
\hline 1.09 & CGT CAC ACC GCT GTT TCT TG & 23 & 57 & 48.72 \\
\hline Bnlg 125 & GGG ACA AAA GAA GAA GCA GAG & 21 & 57 & 45.35 \\
\hline 2.02 & GAA ATG GGA CAG AGA CAG ACA AT & 23 & 61 & 48.40 \\
\hline Bnlg 108 & GCA CTC ACG CGC ACA GGT CA & 20 & 61 & 52.82 \\
\hline 2.04 & CGC CTG CCA AGG TAC ATC AC & 20 & 59 & 50.77 \\
\hline Bnlg 180 & CTA GAG CCT TCG TCG CAG AG & 20 & 59 & 50.77 \\
\hline 2.05 & AAC GGC GGC GAG ATA AAA T & 19 & 51 & 43.66 \\
\hline Bnlg 121 & AGT TCT ACA GGC TTC TTG TCC AA & 23 & 61 & 48.20 \\
\hline 2.06 & CTA TAA AGA AGG TAA CTG GIT GCT C & 25 & 65 & 49.32 \\
\hline Bnlg 198 & GTT TGG TCT TGC TGA AAA ATA AAA & 24 & 57 & 43.68 \\
\hline 2.08 & GCT GGA GGC CTA CAT TAT TAT CTC & 24 & 65 & 50.65 \\
\hline Phi 127 & ATA TGC ATT GCC TGG AAC TGG AAG GA & 26 & 71 & 52.88 \\
\hline 2.08 & AAT TCA AAC ACG CCT CCC GAG TGT & 24 & 67 & 52.29 \\
\hline Bnlg 602 & CCC GAT AGC CAA GCT CTC GCC AA & 24 & 69 & 55.58 \\
\hline 3.04 & AGC TCG TGG ACC GAA CAA GCC CA & 24 & 69 & 55.58 \\
\hline Phi 029 & TTG TCT ПTC TTC CTC CAC AAG CAG CGA A & 28 & 77 & 54.85 \\
\hline 3.04 & ATT TCC AGT TGC CAC CGA CGA AGA ACT T & 28 & 75 & 54.66 \\
\hline
\end{tabular}


Tabela 1. Loco (cromossomo), seqüência dos primers (foward/reverse) com os seus respectivos tamanhos e temperaturas de anelamento para 94 SSRs.

\begin{tabular}{|c|c|c|c|c|}
\hline \multirow[t]{2}{*}{ Loco/Bin } & \multirow[t]{2}{*}{$\begin{array}{l}\text { Seqüência dos primers } \\
\text { Foward/reverse }\end{array}$} & \multirow[t]{2}{*}{$\begin{array}{l}\text { Tamanho } \\
\text { (bp) }\end{array}$} & \multicolumn{2}{|c|}{$\begin{array}{c}\text { Temperatura } \\
\text { anelamento } \\
\left({ }^{\circ} \mathrm{C}\right)\end{array}$} \\
\hline & & & $T_{a}(1)$ & $\mathrm{T}_{\mathrm{a}}(2)$ \\
\hline $\begin{array}{l}\text { Bnlg } 127 \\
9.03\end{array}$ & $\begin{array}{l}\text { CAT GTA TAC GAG AAG CAC CCT AT } \\
\text { ATC GTA ACT CAG CGG TTT GTG }\end{array}$ & $\begin{array}{l}23 \\
21\end{array}$ & $\begin{array}{l}61 \\
67\end{array}$ & $\begin{array}{l}46.61 \\
47.30\end{array}$ \\
\hline Bnlg 240 & TGC AGG TGT ATG GGC AGC TA & 20 & 57 & 48,17 \\
\hline 8.06 & AAG AAC AGA AGG CAT TGA TAC ATA A & 25 & 61 & 45,72 \\
\hline Phi 065 & AGG GAC AAA TAC GTG GAG ACA CAG & 24 & 67 & 52.29 \\
\hline 9.03 & CGA TCT GCA CAA AGT GGA GTA GTC & 24 & 67 & 52.59 \\
\hline Bnlg 490 & GCC CTA GCT TGC TAA TTA ACT AAC A & 25 & 65 & 49.32 \\
\hline 4.05 & ACT GTA AGG GCA GTG GAC CTA TA & 23 & 63 & 50.18 \\
\hline Bnlg 653 & CGC ATT GCC ATG GAT GAA GAA CTG G & 25 & 71 & 54.24 \\
\hline 5.04 & GCA AGC GCC TCA CAA GGT ATG CAC A & 25 & 73 & 55.88 \\
\hline Bnlg 640 & TGC GGA TCC AAC ACG GAC TGT CC & 23 & 69 & 55.53 \\
\hline 10.03 & GCA GGC TCT CCG CCC ACA CCT C & 22 & 71 & 59.06 \\
\hline Bnlg 565 & TAA GAA CGA CGA ACG GTA ACT G & 22 & 59 & 47.87 \\
\hline 5.02 & GCT CAC TGC ACG CCA ACA C & 19 & 57 & 50.29 \\
\hline Phi 006 & AGG CGG CGT GCT GAA CAC CT & 20 & 61 & 52.82 \\
\hline 4.11 & CGC TTC ATC TCC CGT GAC AAT G & 22 & 36 & 51.60 \\
\hline Phi 008 & CGG CTA CGG AGG CGG TG & 17 & 55 & 51.57 \\
\hline 5.03 & GAT GGG CCC ACA CAT CAG TC & 20 & 59 & 50.77 \\
\hline Phi 027 & CAC AGC ACG TTG CGG ATT TCT CT & 23 & 65 & 51.96 \\
\hline 9.03 & GCG TAC GTA CGA CGA AGA CAC & 21 & 61 & 51.20 \\
\hline Phi 034 & TAG CGA CAG GAT GGC CTC TTC T & 22 & 63 & 51.60 \\
\hline 7.02 & GGG GAG CAC GCC TTC GTT CT & 20 & 61 & 42.82 \\
\hline Phi 071 & GGA GTT CAT CAG CTA CCC CAT CT & 23 & 65 & 51.96 \\
\hline 10.04 & TTC TGC TTG TTG ATC TGC ACC CAC & 24 & 67 & 52.29 \\
\hline Phi 072 & ACC GTG CAT GAT TAA TIT CTC CAG CCT T & 28 & 75 & 53.38 \\
\hline 4.0 & GAC AGC GCG CAA ATG GAT TGA ACT & 24 & 67 & 52.29 \\
\hline Phi 073 & TTA CTC CTA TCC ACT GCG GCC TGG AC & 26 & 77 & 57.61 \\
\hline 3.05 & GCG GCA TCC CGT ACA GCT TCA GA & 23 & 69 & 55.53 \\
\hline PHI 074 & CCC AAT TGC AAC AAC AAT CCT TGG CA & 26 & 71 & 52.88 \\
\hline 4.04 & GTG GCT CAG TGA TGG CAG AAA CT & 23 & 65 & 51.96 \\
\hline Bnlg 381 & TCC CTC TTG AGT GIT TAT CAC AAA & 24 & 61 & 47.17 \\
\hline 2.03 & GTT TCC ATG GGC AGG TGT AT & 20 & 55 & 46.67 \\
\hline Bnig 434 & GTG CAA AGG GGA GAG AGG AA & 20 & 57 & 48.72 \\
\hline 7.03 & TCG CCG TTC TTC GCC TTA G & 19 & 55 & 48.13 \\
\hline Bnlg 439 & TTG ACA TCG CCA TCT TGG TGA CCA & 24 & 67 & 52.29 \\
\hline 1.03 & TCT TAA TGC GAT CGT ACG AAG TTG TGG AA & 29 & 77 & 53.61 \\
\hline Bnlg 469 & AGG GTG TAC AGG TCC AAG TCC AA & 23 & 65 & 51.96 \\
\hline 7.05 & AAT GTG GGT CGT CAG CCA TCA G & 22 & 63 & 51.60 \\
\hline Bnlg 292 & TGG TAG GAC CTT ACA ATG GGA & 21 & 57 & 47.46 \\
\hline 9.06 & CGG GAG TAC TGC TAC ACA CGA & 21 & 61 & 51.15 \\
\hline Bnilg 279 & GCA TGC GTA CCT TCA AGC TA & 20 & 55 & 46.67 \\
\hline 9.07 & TGT GTT CAT CGG CAA TIT TG & 20 & 51 & 42.57 \\
\hline Phi 084 & AGA AGG AAT CCG A TC CAT CCA AGC & 24 & 67 & 52.29 \\
\hline 10.04 & CAC CCG TAC TTG AGG AAA ACC C & 22 & 63 & 51.60 \\
\hline
\end{tabular}


Tabela 1. Loco (cromossomo), seqüência dos primers (foward/reverse) com os seus respectivos tamanhos e temperaturas de anelamento para 94 SSRs.

\begin{tabular}{|c|c|c|c|c|}
\hline \multirow[t]{2}{*}{ Loco/Bin } & \multirow[t]{2}{*}{$\begin{array}{l}\text { Seqüência dos primers } \\
\text { Foward/reverse }\end{array}$} & \multirow[t]{2}{*}{$\begin{array}{l}\text { Tamanho } \\
\text { (bp) }\end{array}$} & \multicolumn{2}{|c|}{$\begin{array}{c}\text { Temperatura } \\
\text { anelamento } \\
\left({ }^{\circ} \mathrm{C}\right)\end{array}$} \\
\hline & & & $T_{a}(1)$ & $T_{a}(2)$ \\
\hline $\begin{array}{l}\text { Bnlg } 137 \\
10.05\end{array}$ & $\begin{array}{l}\text { AGA CAA CTA CCC CCA CCC A } \\
\text { CCA GGT TAC CGT GAA ATG CT }\end{array}$ & $\begin{array}{l}19 \\
20\end{array}$ & $\begin{array}{l}55 \\
55\end{array}$ & $\begin{array}{l}48.17 \\
46.67\end{array}$ \\
\hline Bnlg 153 & TCC ACT GCT CCT CCA CTG C & 19 & 57 & 50.22 \\
\hline 10.06 & CAC TTC AAA CTG TCA AAT CTC CA & 23 & 59 & 46.56 \\
\hline Phi 017 & CGT TGG CGA CCA GGG TGC GTT GAA T & 25 & 77 & 59.16 \\
\hline 9.02 & TGC AAC AGC CAT TCG ATC ATC AAA C & 25 & 67 & 50.96 \\
\hline Phi 059 & AAG CTA ATT AAG GCG GGT CAT CCC & 24 & 67 & 52,29 \\
\hline 10.02 & TCC GTG TAC TCG GCG GAC TC & 20 & 61 & 53,72 \\
\hline МАСТО2В08 & GAT CCT ACC AAA ATC TTA TAG GC & 23 & 59 & 46.61 \\
\hline 9.01 & ACA GCT AGC CAA GAT CTG ATT & 21 & 55 & 45.35 \\
\hline МАСТ02B10 & AAA TAG TCC AGA AAA AAA TAG TGT G & 25 & 59 & 44.40 \\
\hline$?$ & ACC TCT TGT TTT CCA CAG TTC & 21 & 55 & 43.35 \\
\hline MACT02E01 & GAA GTC GAT CCA TCC ACC & 18 & 51 & 45.20 \\
\hline 6.06 & GGG GTA GTG GAG ATA ACT AGT G & 22 & 61 & 49.74 \\
\hline MAG1A03 & TGA TCA TCA TAA GCA CAC CG & 20 & 53 & 44.62 \\
\hline 3.06 & CCA ATG TGA AGC AAG AGA GAA & 21 & 55 & 45.35 \\
\hline MAGE05 & GTG CAA ACT AAT CCA AAG CAA & 21 & 53 & 43.40 \\
\hline 2.05 & ATG TAG GGA CAA AGG AAT AAA TCA & 24 & 59 & 45.46 \\
\hline MTTGB02 & TCA GTG CTT TCA TTG TAA CGA & 21 & 53 & 43.40 \\
\hline 4.06 & ATA AAC ATC TTG CCA GCA AA & 20 & 49 & 40.52 \\
\hline Phi 075 & GGA GGA GCT CAC CGG CGC ATA A & 22 & 67 & 55.33 \\
\hline 6.00 & AAAGGT TAC TGG ACA AAT ATG CGT AAC TCA & 30 & 77 & 52.45 \\
\hline PHI 077 & GAG AAG AGG ATC AGG TTC GTT CCA & 24 & 67 & 52.29 \\
\hline 6.01 & CGC GTT GTA CAT CTT GCC TGC TT & 23 & 65 & 51.96 \\
\hline Phi 081 & AAG GAA CTG GTG AGA GGG TCC $\pi$ & 23 & 65 & 51.96 \\
\hline 6.05 & AGC CCG ATG CTC GCC ATC TC & 20 & 61 & 52.82 \\
\hline Phi 083 & CAA ACA TCA GCC AGA GAC AAG GAC & 24 & 67 & 52.29 \\
\hline 2.04 & ATT CAT CGA CGC GTC ACA GTC TAC T & 25 & 69 & 52.60 \\
\hline Phi 092 & GTG GGG GAG CCT ACT ACA GG & 20 & 61 & 52.82 \\
\hline 4.08 & GAC GAG GCC ATC ATC ACG GT & 20 & 59 & 50.77 \\
\hline МАСЕООВ03 & TGT TCT CAA CAA CCA CCG & 18 & 49 & 42.92 \\
\hline 5.01 & CGT TTA GCG ATA TCA TIT TCC & 21 & 53 & 43.40 \\
\hline MACE01A03 & AGA AAA TGG TGA GGC AGG & 18 & 49 & 42.92 \\
\hline 5.04 & TAT GAA ATC TGC ATC TAG AAA TTG & 24 & 57 & 43.75 \\
\hline MACE01C01 & AGC AGG TAC CAC AAT GGA G. & 19 & 49 & 45.97 \\
\hline 8.08 & GTG TAC ATC AAG GTC CAG ATT T & 22 & 57 & 46.01 \\
\hline MACE01G01 & GAT GTC GTG TGA GTG ACC TG & 20 & 57 & 48.72 \\
\hline 7.03 & GTG TTG CTA TTG CAG TGA GAC & 21 & 57 & 47.30 \\
\hline Bnlg 589 & GGG TCG TाT AGG GAG GCACCT TTG GT & 25 & 77 & 57.74 \\
\hline 4.11 & GCG ACA GAC AGA CAG ACA AGC GCA TTG T & 28 & 81 & 57.95 \\
\hline Bnilg 143 & GCA CTG CCG GAG TGC CTT CT & 20 & 61 & 52.82 \\
\hline 5.01 & ATG CCG TGA TCT GTG ACA TCT AAC C & 25 & 59 & 52.60 \\
\hline Phi 113 & GCT CCA GGT CGG AGA TGT GA & 20 & 59 & 50.77 \\
\hline 5.03 & CAC AAC ACA TCC AGT GAC CAG AGT & 24 & 67 & 52.29 \\
\hline
\end{tabular}


Tabela 1. Loco (cromossomo), seqüência dos primers (foward/reverse) com os seus respectivos tamanhos e temperaturas de anelamento para 94 SSRs.

\begin{tabular}{|c|c|c|c|c|}
\hline \multirow[t]{2}{*}{ Loco/Bin } & \multirow[t]{2}{*}{$\begin{array}{l}\text { Seqüência dos primers } \\
\text { Foward/reverse }\end{array}$} & \multirow[t]{2}{*}{$\begin{array}{l}\text { Tamanho } \\
\text { (bp) }\end{array}$} & \multicolumn{2}{|c|}{$\begin{array}{l}\text { Temperatura } \\
\text { anelamento } \\
\left({ }^{\circ} \mathrm{C}\right)\end{array}$} \\
\hline & & & $T_{a}(1)$ & $T_{a}(2)$ \\
\hline $\begin{array}{l}\text { Bnlg } 150 \\
5.04\end{array}$ & $\begin{array}{l}\text { GAA AAA CCC CCT CCC CAT AT } \\
\text { AAT GGC CGA ACA CAA TTC AA }\end{array}$ & $\begin{array}{l}20 \\
20\end{array}$ & $\begin{array}{l}75 \\
67\end{array}$ & $\begin{array}{l}46.67 \\
42.57\end{array}$ \\
\hline Bnlg 278 & CAT GCA TCA ACG TAA CTC CCT & 21 & 57 & 4746 \\
\hline 5.05 & CAT GTC ACG CGT TCC ACT TG & 20 & 57 & 48.72 \\
\hline Phi 048 & GCA AAC CTT GCA TGA ACC CGA TTG T & 25 & 69 & 52.60 \\
\hline 5.07 & CAA GCG TCC AGC TCG ATG ATT TC & 23 & 65 & 51.96 \\
\hline Bnlg 386 & CAC CCT CCC TTT GCA GGT A & 19 & 55 & 48.17 \\
\hline 5.09 & TGG TTT ATC AGA TAA CGA TTC AGC & 24 & 61 & 46.98 \\
\hline Bnlg 161 & GCT TTC GTC ATA CAC ACA CAT TCA & 24 & 63 & 49.01 \\
\hline 6.0 & ATG GAG CAT GAG CTT GCA TAT TT & 23 & 59 & 46.56 \\
\hline Bnlg 238 & CTT ATT GCT TTC GTC ATA CAC ACA CAT TCA T & 31 & 69 & 52.60 \\
\hline 6.00 & GAG CAT GAG CTT GCA TAT TTC TTG TGG & 27 & 65 & 51.96 \\
\hline Bnlg 666 & AAA AGG CAA GTA GCT AGC ATG CAT TTG CAG & 30 & 81 & 53,42 \\
\hline 8.05 & GGC TCA CGT CCG TAT CCA AAC CAA CA & 26 & 75 & 55,49 \\
\hline Phi 063 & GGC GGC GGT GCT GGT AG & 17 & 55 & 51.56 \\
\hline 10.02 & CAG CTA GCC GCT AGA TAT ACG CT & 23 & 67 & 51.96 \\
\hline Bnlg 118 & CTT CCA GCC GCA ACC CTC & 18 & 55 & 49.75 \\
\hline 5.07 & CCA ACA ACG CGG ACG TGA & 18 & 53 & 47.47 \\
\hline Bnig 128 & CAC CTG GAG GGA CCC ATT CC & 20 & 61 & 52.82 \\
\hline 9.07 & AGG ACC ACA GGA TCC ATC ATC CT & 23 & 65 & 51.96 \\
\hline Bnlg 236 & CGC TIT GCA GTA CCA GTA CAC AC & 23 & 65 & 51.96 \\
\hline 10.06 & GAC GAC AAC TGC AGA GTA CCA GA & 23 & 65 & 51.96 \\
\hline Bnilg 244 & GAT GCT ACT ACT GGT CTA GTC CAG A & 25 & 67 & 52.60 \\
\hline 9.02 & СТС СТС САС TCA TCA GCC TTG A & 22 & 63 & 51.60 \\
\hline Bnlg 371 & CAA CGC GAA GCA GAG ATA AAA & 21 & 49 & 45.35 \\
\hline 2.06 & TCG TCG CAT GAC CAT AGT AGC & 21 & 59 & 49.25 \\
\hline Bnlg 667 & CGT GGA TGT AAG GGG GCG CGC T & 22 & 69 & 57.12 \\
\hline 4.05 & GGC CGC TGC TCA ACA CAG GCA G & 22 & 69 & 57.12 \\
\hline Bnig 197 & GCG AGA AGA AAG CGA GCA GA & 20 & 57 & 48.72 \\
\hline 3.07 & CGC CAA GAA GAA ACA CAT CAC A & 22 & 59 & 47.69 \\
\hline Phi 021 & TTC CAT TCT CGT GTT CTT GGA GTG GTC CA & 29 & 81 & 56.44 \\
\hline 4.03 & CTT GAT CAC CTT TCC TGC TGT CGC CA & 26 & 75 & 56.00 \\
\hline Bnlg 107 & GCA ACT AGA AGT AGA TGG CTT GTT ATG G & 28 & 75 & 53.44 \\
\hline 6.01 & CAA CAA CAA GTG GCT GGC TAG GGT GAA & 27 & 77 & 56.24 \\
\hline Bnlg 391 & CAG ATA TCA CAG CAT CAG AAG ATC A & 25 & 65 & 49.32 \\
\hline 6.01 & AAA ATG TAA GAA CTT GTT TGG GAT T & 25 & 59 & 44.40 \\
\hline Phi 078 & CAG CAC CAG ACT ACA TGA CGT GTA A & 25 & 69 & 52.60 \\
\hline 6.05 & GGG CCG CGA GTG ATG TGA GT & 20 & 61 & 52.82 \\
\hline Phi 070 & GCT GAG CGA TCA GIT CAT CCA G & 22 & 63 & 51.60 \\
\hline 6.07 & CCA TGG CAG GGT CTC TCA AG & 20 & 59 & 50.77 \\
\hline Bnlg 398 & CGT CGG CCA ACA GGG TAT C & 19 & 57 & 50.22 \\
\hline 7.02 & CTC GCA CGC GGT CTT CTT C & 19 & 57 & 50.22 \\
\hline
\end{tabular}


Tabela 1. Loco (cromossomo), seqüência dos primers (foward/reverse) com os seus respectivos tamanhos e temperaturas de anelamento para 94 SSRs.

\begin{tabular}{|c|c|c|c|c|}
\hline \multirow[t]{2}{*}{ Loco/Bin } & \multirow[t]{2}{*}{$\begin{array}{l}\text { Seqüência dos primers } \\
\text { Foward/reverse }\end{array}$} & \multirow[t]{2}{*}{$\begin{array}{c}\text { Tamanho } \\
\text { (bp) }\end{array}$} & \multicolumn{2}{|c|}{$\begin{array}{c}\text { Temperatura } \\
\text { anelamento } \\
\left({ }^{\circ} \mathrm{C}\right)\end{array}$} \\
\hline & & & $T_{a}(1)$ & $T_{a}(2)$ \\
\hline Bnlg 657 & TCT GAG GAT GCC CAA TCA TGC GC & 23 & 67 & 53.75 \\
\hline 7.02 & CGT TTC CGT TCG TCA CCA GCT CG & 23 & 67 & 55.53 \\
\hline Bnlg 572 & ACT GGA CTG TCC TCG TGC CTA & 21 & 61 & 51.20 \\
\hline 7.03 & CAA AAA AAG ATT CGT TCG GAG TAA & 24 & 59 & 45.46 \\
\hline Bnlg 155 & ACC GAG TAG CCG AGA CAC G & 19 & 57 & 50.22 \\
\hline 7.04 & AGA GTC CTG GAG CCA CAT GAG & 21 & 61 & 51.15 \\
\hline Phi 116 & GCA TAC GGC CAT GGA TGG GA & 20 & 59 & 50.77 \\
\hline 7.06 & TCC CTG CCG GGA CTC CTG & 18 & 55 & 52.03 \\
\hline Bnlg 669 & GCA CGC ACC AGC AGT CGG CAG T & 22 & 69 & 57.12 \\
\hline 8.03 & CGG CCT AGT GGG CAT GGA GCC T & 22 & 69 & 57.12 \\
\hline Phi 119 & AGG TGA GGA GAG GAA AGG TTG T & 22 & 61 & 49.74 \\
\hline 8.04 & GCC ACT CCG CAT CCG AGC & 18 & 57 & 51.94 \\
\hline Bnlg 430 & CT ACT GAG CAT CTT CCT TCT TCT CC & 25 & 69 & 47.46 \\
\hline 9.03 & TCC GGT GAT GCT CCA GCG AC & 20 & 61 & 52.82 \\
\hline Phi 115 & CTA GTG GGC GAA CAA CTG GTA AG & 23 & 65 & 51.96 \\
\hline 8.03 & AAA GAG ACC GTG TCA GGA TTG CC & 23 & 65 & 51.96 \\
\hline Phi 014 & AGA TGA CCA GGG CCG TCA ACG AC & 23 & 69 & 55.53 \\
\hline 8.04 & CCA GCT TCA CCA GCT TGC TCT TCG TG & 26 & 77 & 57.61 \\
\hline Phi 015 & GCA ACG TAC CGT ACC TTT CCG A & 22 & 63 & 51.60 \\
\hline 8.08 & ACG CTG CAT TCA ATT ACC GGG AAG & 24 & 67 & 52.29 \\
\hline
\end{tabular}

\subsubsection{Análise dos dados}

A genotipagem dos indivíduos em termos de "genes" e seus respectivos alelos foi feita pela interpretação dos padrões de bandas obtidos nos géis. Cada loco foi definido por um par de primers (foward/reverse), havendo no máximo duas bandas por indivíduo. A presença de duas bandas indica que 0 genótipo é heterozigótico enquanto a presença de uma banda, homozigótico. 


\subsubsection{Freqüências alélicas}

O cálculo da freqüência alélica foi feito pela contagem direta dos diferentes genótipos presentes na amostra, segundo a expressão:

$$
\hat{p}_{u}=\mathrm{P}_{u u}+\frac{1}{2} \sum_{u \neq \nu} \mathrm{P}_{u v}
$$

na qual:

$\hat{p}_{u}$ - freqüência do alelo $u$ na população

$\mathrm{P}_{u u}$ - freqüência genotípica dos homozigotos para o alelo $u$

$\mathrm{P}_{u v}$ - freqüência genotípica para os heterozigotos sendo o alelo $u$ diferente de $v$.

A variância da freqüência alélica foi dada pela expressão:

$$
\operatorname{var}\left(\hat{p}_{u}\right)=\frac{1}{2 n} \hat{p}_{u}\left(1-\hat{p}_{u}\right)
$$

na qual $n$ corresponde ao tamanho da amostra. A partir da variância da freqüência alélica foi construído o intervalo de confiança que fornece uma idéia a respeito da amplitude de valores no qual a freqüência da população $\left(\hat{p}_{u}\right)$ se encontra.

Considerando um tamanho amostral razoavelmente amplo $(n \geq 30)$ existe $95 \%$ de chance que o intervalo:

$$
\hat{p}_{u} \pm 1,96 \sqrt{\operatorname{vâr}\left(\hat{p}_{u}\right)} \quad \text { inclua a freqüência } \hat{p}_{u} \text { (Weir, 1996). }
$$




\subsubsection{2 Índices de diversidade}

Os índices de diversidade genética foram obtidos usando o programa computacional BIOSYS-1, desenvolvido por Swofford \& Selander (1991).

\section{a) Porcentagem de locos polimórficos ( $P$ )}

A porcentagem de locos polimórficos foi calculada utilizando como critério a freqüência do alelo mais comum, isto é, se menor que 100, 99 ou 95\%.

\section{b) Número médio de alelos por loco (A)}

O número médio de alelos por loco foi obtido pela relação entre o número total de alelos e o número total de locos.

\section{c) Número efetivo de alelos (ne)}

O número efetivo de alelos ( $n e$ ) é uma medida complementar ao número médio de alelos por loco utilizada na descrição de materiais (populações).

O número efetivo de alelos foi calculado pela expressão:

$$
n e=\frac{1}{\sum \hat{p} u^{2}}
$$

na qual $\hat{p} u$ é a freqüência do alelo $u$.

Por utilizar em sua expressão a freqüência gênica (o que não acontece com o número médio de alelos) os alelos raros são tomados em consideração, portanto, quanto maior o ne maior será a diversidade do material. 


\section{d) Heterozigosidade observada ( $\mathrm{Ho}$ )}

A heterozigosidade observada representa o número de genótipos heterozigóticos presentes na amostra (contagem direta) podendo ser referida para um único loco ou como uma média referente a vários locos.

Para um único loco $(l)$, a heterozigosidade observada foi obtida pela expressão:

$$
H_{l}=\sum_{u} \sum_{v \neq u} \frac{n_{u v}}{n}
$$

na qual:

$n_{l u v}$ - número observado de heterozigotos no loco $(l)$ para os alelos $u$ e $v$ sendo $u \neq v$

$n$ - número total de indivíduos avaliados para o loco $(l)$

Para $m$ locos, a heterozigosidade média observada $\left(\bar{H}_{0}\right)$ foi obtida somando-se os valores de heterozigosidade referente a cada loco e dividindo este valor pelo número total de locos (monomórficos e polimórficos), conforme a expressão:

$$
\bar{H}_{0}=\frac{1}{m} \sum_{l=1}^{m} H l
$$

A variância amostral para um único loco foi dada por:

$$
\operatorname{var}\left(\hat{H}_{l}\right)=\frac{1}{n} \hat{H}_{l}\left(1-\hat{H}_{l}\right)
$$


A variância para a heterozigosidade média observada foi obtida pela soma dos valores individuais das variâncias de cada loco dividida pelo número total de locos $(m)$.

\section{e) Diversidade gênica (heterozigosidade esperada -He)}

Em populações panmíticas os valores de heterozigosidade são próximos aos de diversidade sendo tomados como sinônimos e definidos em função das freqüências gênicas (Weir, 1996). A heterozigosidade esperada ( $\mathrm{He}$ ) ou Diversidade gênica $(D)$ é a probabilidade que dois alelos tomados ao acaso, em um dado loco, em uma população, sejam diferentes (Nei, 1987).

A estimativa não tendenciosa da diversidade para um loco foi obtida pela expressão:

$$
\hat{D}_{l}=\frac{2 n\left(1-\sum \hat{p}_{u}{ }^{2}\right)}{2 n-1}
$$

na qual:

$n$ - número de indivíduos avaliados para o loco $l$

$\hat{p}_{u}$ - freqüência do alelo u

A diversidade gênica total foi dada pela expressão :

$$
\hat{D}=\sum_{l=1}^{m} \frac{\hat{D}_{l}}{m}
$$

na qual $\hat{D}_{l}$ é a diversidade gênica para o loco $l$ e $m$ é o número de locos avaliados. 
Sendo a variância estimada por:

$$
\operatorname{Var}(\hat{D})=\frac{\operatorname{Var}\left(\hat{D}_{l}\right)}{m}
$$

na qual:

$$
\operatorname{var}\left(\hat{D}_{l}\right)=\frac{1}{n} \hat{D}_{l}\left(1-\hat{D}_{l}\right)
$$

As variâncias das estatísticas de diversidade foram calculadas para a obtenção do desvio padrão dos parâmetros estimados. Nas expressões das variâncias assumiu-se que os locos são estatisticamente independentes, com os alelos em equilíbrio de ligação.

\section{f) Conteúdo de informação de polimorfismo (PIC)}

O conteúdo de informação de polimorfismo fornece uma estimativa do poder discriminatório de um marcador, e é sinônimo do termo diversidade gênica descrita por WEIR (1996), sendo calculado pela mesma expressão:

$$
P I C=1-\sum \hat{p}_{u}^{2}
$$

Valores de PIC variam de zero (monomorfismo) a 1 (altamente discriminativo, com muitos alelos em freqüências eqüitativas). 


\subsubsection{3 Índice de fixação de Wright $(\hat{f})$}

$O$ índice de fixação de Wright $(\hat{f})$ foi estimado para quantificar o excesso ou deficiência de heterozigotos tanto nas populações como nos sintéticos pela expressão:

$$
\hat{f}=1-\frac{H o}{H e}
$$

na qual $\mathrm{Ho}$ e $\mathrm{He}$ referem-se as heterozigosidades observadas e esperadas, respectivamente. $O$ intervalo de confiança a 95\% de probabilidade para o índice de fixação $(\hat{f})$ foi estimado por bootstrap com 10.000 reamostragens pelo programa GDA - Genetic Data Analysis - (Lewis \& Zaykin, 2001).

\subsubsection{Diversidade gênica esperada sob a ação da deriva genética}

A redução da variabilidade medida pela diversidade gênica foi comparada com as expectativas teóricas sob a ação da deriva genética assumindo que a variabilidade genética observada é seletivamente neutra (Labate, 1997a). Desta forma, os valores de diversidade obtidos nos sintéticos IG-3 e IG-4, após um ciclo de seleção recorrente, foram comparados com os valores teóricos esperados sob deriva genética, segundo a expressão:

$$
\hat{D}_{t}=D_{o}\left[1-\left(\frac{1}{2 N e}\right)\right]^{t}
$$


na qual:
$\hat{D}_{t}$ - diversidade no tempo $t$
$D_{0}$ - diversidade no tempo zero
$\mathrm{Ne}$ - tamanho efetivo populacional
$t \quad$ - tempo medido em gerações

Foram utilizados os tamanhos efetivos de 4,57 e 5,71 referentes aos sintéticos IG-3 e IG-4, respectivamente.

\subsubsection{Tamanho efetivo populacional}

O tamanho efetivo populacional ( $\hat{N} e$ ) foi estimado utilizando o método descrito por Waples (1989), desenvolvido para populações que sofreram mudanças nas freqüências alélicas entre dois eventos de amostragem:

$$
\hat{N} e=\frac{t}{2\left(\hat{\bar{F}} c-\frac{1}{2 S_{e}}-\frac{1}{2 S_{\iota}}\right)}
$$

na qual:

$t$ - tempo entre dois eventos de amostragem

So e $S_{t}$ - tamanho da amostra respectivamente nos dois eventos de amostragem.

$\hat{\bar{F}} c$ - variância média padronizada na freqüência alélica ponderada sobre locos (Nei \& Tajima, 1981). 
Para cada loco é expressa por:

$$
\hat{\bar{F}} c=\frac{\sum_{u=1}^{k}\left(p_{u}-p_{u}^{\prime}\right)^{2}}{\sum_{u=1}^{k} \frac{\left(p_{u}+p_{u}^{\prime}\right)}{\left(2-p_{u} p_{u}^{\prime}\right)}}
$$

sendo $\hat{p}_{u}$ e $\hat{p}_{u}^{\prime}$ as freqüências dos alelos $u$ nos dois eventos de amostragem e $k$, o número de alelos no loco.

O intervalo de confiança a $95 \%$ de probabilidade foi calculado com base no número $u$ de alelos independentes:

$$
I C 95 \% \text { para } \hat{N} e=\left[\frac{n \hat{N} e}{X_{0.05, n}^{2}}, \frac{n \hat{N} e}{X^{2} 0.995, n}\right]
$$

\subsubsection{Determinação da significância das diferenças nas freqüências alélicas entre populações}

Para verificar se a distribuição das freqüências dos alelos é idêntica nas quatro populações foi aplicado um teste exato utilizando o programa TFPGA (Tools for Population Genetic Analyses) desenvolvido por Miller (1997). O TFPGA emprega um procedimento de reamostragem numérica (Cadeias de Markov e Monte (arlo) o qual fornece uma excelente aproximação da probabilidade exata das diferenças observadas nas freqüências alélicas. Este procedimento analisa cada loco, em um conjunto de dados, para determinar se existem diferenças nas freqüências alélicas. Além disso, emprega um teste global (Teste Combinado de Fisher) sobre os locos para determinar a sua significância geral (Miller, 1997). Na 
condução desta análise foram empregadas 10 baterias de testes com 2000 permutações cada e 1000 passos de desmemorização.

As diferenças nas freqüências alélicas foram verificadas nos seguintes grupos: BR-105 e BR-106; BR-105 e IG-3; BR-106 e IG-4; IG-3 e IG-4.

\subsubsection{Aderência às proporções do equilíbrio de Hardy-Weinberg}

Para verificar a aderência de cada loco às proporções do equilíbrio de Hardy-Weinberg foi utilizado o teste exato, ou seja, a probabilidade exata de significância da amostra em aderência ao equilíbrio fornecida pelo programa TFPGA (item 3.2.2.6). $O$ teste exato é preferido nos casos em que o tamanho da amostra é pequeno ou as freqüências alélicas são baixas ou nulas. Na presença de locos com 10 ou mais alelos, mesmo considerando amostras de tamanho expressivo, o número de genótipos torna-se tão grande que algumas freqüências genotípicas são nulas tornando necessário o uso de testes exatos (Guo \& Thompson, 1992). Nestes casos, torna-se aconselhável a utilização de procedimentos de randomização os quais fornecem uma aproximação da probabilidade exata verdadeira. O procedimento de Monte Carlo envolve a construção, ao acaso, de múltiplos conjuntos de dados, utilizando as mesmas freqüências alélicas contidas no conjunto de dados original sob análise. A probabilidade condicional de cada conjunto de dados construídos aleatoriamente é comparada à probabilidade condicional da amostra observada. A significância do conjunto original de dados é então encontrada, determinando a proporção dos conjuntos de dados aleatórios que apresentam probabilidades condicionais menores ou iguais à probabilidade condicional do conjunto de dados original. Para este propósito o método de Monte Carlo emprega um procedimento de baterias de rotinas de randomização que permitem o cálculo do erro padrão dos valores da probabilidade estimada (Miller, 1997). 
Para o teste de aderência às proporções de Hardy-Weinberg foi utilizado o teste exato pelo método de Monte Carlo, utilizando-se 25 baterias de análises, cada uma com 2.000 permutações, totalizando 50.000 permutações.

\subsubsection{Análise da estrutura genética das populações (partição da diversidade pelo Método de Nei, 1973)}

Em virtude da metodologia desenvolvida por Nei (1973) não apresentar restrições quanto ao padrão de forças evolutivas como mutação, seleção e migração e, considerando que as populações estudadas passaram por um processo de seleção, a análise da estrutura genética das populações foi abordada através da partição da diversidade genética segundo o modelo proposto por Nei (1973) através da expressão:

$$
\hat{H} T=\hat{H} s+\hat{D}_{s T}
$$

na qual:

$\hat{H}$ - heterozigosidade esperada sobre equilíbrio de Hardy Weinberg ou diversidade gênica na população total.

$\hat{H}_{s}$ - heterozigosidade esperada sobre equilíbrio de Hardy Weinberg ou diversidade gênica dentro das populações (subpopulações)

$\hat{D} s T$ - diversidade gênica atribuível à diferenciação entre populações (subpopulações).

Dadas $s$ populações (subpopulações), $n$ indivíduos amostrados ao acaso da i-ésima população e $k$ alelos, a heterozigosidade foi estimada por: 


$$
H=\frac{1-\sum_{i}^{s} \sum_{u}^{k} P_{i u u}}{s}
$$

na qual:

$P_{i u u}$ - equivale à freqüência observada do genótipo $A u A u$ na i-ésima população.

A diversidade gênica dentro das populações foi estimada pela expressão:

$$
\hat{H} s=\frac{\tilde{n}}{\tilde{n}-1}\left(1-\sum_{u}^{k} \bar{p}_{u}^{2}-\frac{\hat{H} o}{2 \tilde{n}}\right)
$$

A diversidade gênica na população total é dada por:

$$
\hat{H}_{T}=1-\frac{\sum_{u}^{k} \bar{p}_{u}^{2}+\hat{H}_{s}}{\tilde{n} s}-\frac{\hat{H}_{0}}{2 \tilde{n} s}
$$

sendo:

$$
\begin{aligned}
& \bar{p}_{u}^{2}=\frac{\left(\sum_{i}^{s} \sum_{u}^{k} p_{i u}^{2}\right)}{s} \\
& \bar{p}_{u}^{2}=\frac{\left(\sum_{i}^{s} p_{i u}\right)^{2}}{s}
\end{aligned}
$$

na qual:

$p_{i u}$ - freqüência do alelo $u$ na amostra da i-ésima subpopulação

$\tilde{n}$ - média harmônica de $n_{i}$ 
Assim sendo, a partição da diversidade pode ser resumida da seguinte maneira:

\begin{tabular}{lc}
\hline \multicolumn{2}{c}{ PARTIÇÃO DA DIVERSIDADE } \\
\hline ENTRE POPULAÇÕES & $\hat{D}_{s T}\left(\hat{H}_{T}-\hat{H}_{s}\right)$ \\
DENTRO DE POPULAÇÕES & $\hat{H} s$ \\
TOTAL & $\hat{H} T$ \\
\hline
\end{tabular}

A diferenciação entre as populações foi estimada pelo $\hat{G}_{S T}$, o qual é obtido pela seguinte relação:

$$
\hat{G} s T=\frac{\hat{D}_{s T}}{\hat{H}_{T}}
$$

A diversidade total foi definida para o conjunto das populações no mesmo ciclo de seleção, ou seja, para as populações BR-105 e BR-106, no ciclo inicial $\left(C_{0}\right)$ e para os sintéticos IG-3 e IG-4, após um ciclo de seleção $\left(C_{1}\right)$. Para tanto, foi utilizado o programa FSTAT (Goudet, 1995).

\subsubsection{Diferenciação genética entre populações $\left(\hat{R}_{s T}\right)$ para polimorfismos gerados por marcadores microssatélites}

A estatística $R s T$ é adequada para estimar os níveis de diferenciação genética a partir de dados de microssatélites. Para a sua estimativa, foi utilizado um pacote RSTCALC desenvolvido por Goodman (1997) que consiste de dois programas: (Rst Standardize) e o (Rst Calc). O programa Rst Standardize executa um procedimento de padronização nos arquivos de dados genotipados para locos de microssatélites. Este procedimento consiste em expressar os alelos 
em termos de desvio padrão da média global, ao invés do número de repetições (motivo). Isto é necessário pois ao calcular as variâncias apropriadas para cada loco e ao tirar a média destas variâncias sobre vários locos, se o conjunto de dados contiver um loco com variâncias que diferem amplamente, locos com variâncias menores terão uma menor contribuição para o valor final de $R S T$, mesmo quando estes locos apresentam um alto nível de diferenciação. Cada alelo de cada loco foi padronizado pela seguinte expressão:

$$
\hat{Y} s=\frac{(\hat{Y}-G \hat{M})}{\hat{s}}
$$

na qual:

$\hat{Y}_{S} \quad$ - valor padronizado para o alelo $Y$

$G \hat{M}$ - tamanho médio do alelo em unidades de repetições para o loco $l$ sobre o conjunto de dados.

$\hat{s}$ - desvio padrão do tamanho do alelo (unidades de repetição) para o loco $l$ sobre conjunto de dados.

O RsT CALC têm como base o cálculo do $\hat{R} s T$ pela expressão desenvolvida por Slatkin (1995):

$$
\hat{R}_{S T}=\frac{(\hat{S}-\hat{S} w)}{\hat{S}}
$$


na qual:

$\hat{S}$ - duas vezes a variância estimada para o tamanho do alelo ao longo das populações.

$\hat{S} w$ - duas vezes a variância estimada para o tamanho do alelo dentro de cada população.

Entretanto, esta expressão assume que as populações têm o mesmo tamanho e que todos os locos apresentam variâncias equivalentes, sendo que a aplicação direta desta expressão pode levar a resultados tendenciosos. Nesse sentido o programa utiliza a expressão:

$$
R \hat{h} o=\frac{\hat{S} b}{(\hat{S} b+\hat{S} w)}
$$

na qual $\hat{S} b$ é o componente da variância entre populações. Neste caso $R \hat{h} o$ equivale a. $\hat{R}_{s T}$.

O intervalo de confiança a $95 \%$ para a estimativa de $\hat{R}_{s T}$ foi fornecido por bootstrap.

3.2.2.10 Distância genética para polimorfismos gerados com marcadores microssatélites $(\hat{\delta} \mu)^{2}$

O cálculo da distância $(\hat{\delta} \mu)^{2}$ para os dados de microssatélites foi feita utilizando o programa $R_{s T}$ CALC (Goodman , 1997), conforme a expressão: 


$$
(\hat{\delta} \mu)^{2}=\left(\hat{\mu}_{A}-\hat{\mu}_{B}\right)^{2}
$$

na qual:

$\hat{\mu}_{A}$ e $\hat{\mu}_{B}$ - são os tamanhos médios dos alelos, respectivamente nas populações A e B.

Os tamanhos médios dos alelos nas populações $A$ e $B\left(\hat{\mu}_{A}\right.$ e $\left.\hat{\mu}_{B}\right)$ são obtidos inicialmente calculando o tamanho médio do alelo em cada loco de cada população. Em seguida, é tirada uma média sobre todos os locos da diferença ao quadrado no tamanho médio do alelo (Goodman, 1997).

\subsubsection{Distância genética de Nei}

A distância genética de $\mathrm{Nei}$ (1972) pressupõe uma medida de identidade gênica ( $I$ ) expressa pela probabilidade que um dado alelo, em um loco tomado ao acaso, em duas populações diferentes, seja idêntico em relação à probabilidade de que dois alelos do mesmo loco, tomados também ao acaso, em cada população, sejam idênticos (Alfenas, 1998). Dado um loco com $n$ alelos com

freqüência $\hat{x}_{i}$ e $\hat{y}_{i}$, respectivamente, nas populações $a$ e $b$ (Labate et al., 1997a) têm-se:

População $a$

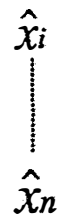

População $b$




Para $r$ indivíduos e $m$ locos, a identidade gênica ( $I$ ) é dada por:

$$
\hat{I}=\frac{\hat{G}_{a b}}{\sqrt{\left(\hat{G}_{a} \hat{G}_{b}\right)}}
$$

Sendo:

$\hat{G}_{a b}$ - probabilidade de que dois alelos ( $\hat{x}_{i}$ e $\hat{y}_{i}$ ) tomados ao acaso nas populações $a$ e $b$ sejam idênticos.

$\hat{G}_{a}$ - probabilidade de que dois alelos ( $\hat{x}_{i}$ e $\hat{y}_{i}$ ) tomados ao acaso dentro da população a sejam idênticos.

$\hat{G}_{b}$ - probabilidade de que dois alelos ( $\hat{x}_{i}$ e $\hat{y}_{i}$ ) tomados ao acaso dentro da população $b$ sejam idênticos.

Tais probabilidades são dadas pelas expressões:

$$
\begin{gathered}
\hat{G}_{a}=\frac{1}{m} \frac{\sum_{l=1}^{m}\left[\left(2 r \sum \hat{x}_{i}{ }^{2}\right)-1\right]}{2 r-1} \\
\hat{G}_{b}=\frac{1}{m} \cdot \frac{\sum_{l=1}^{m}\left[\left(2 r \sum \hat{y}_{i}{ }^{2}\right)-1\right]}{2 r-1}
\end{gathered}
$$


A distância genética não tendenciosa (Nei, 1978) foi estimada pela expressão:

$$
\hat{D}_{i s t}=-\ln (\hat{I})
$$

sendo $-\ln (\hat{I})$ o cologaritmo neperiano de $\hat{I}$.

As relações entre as populações BR-105, BR-106, IG-3 e IG-4 foram visualizadas em um dendrograma construído pelo método da média aritmética não ponderada (UPGMA, Unweighted Pair-Group Method with Arithmetic Means) utilizando o programa NTSYS (Numerical Taxonomy and Multivariate Analysis System) versão 1.7, desenvolvido por Rohlf (1992). O programa NTSYS também foi utilizado para calcular 0 coeficiente de correlação cofenética (valores cofenéticos) o qual, em linhas gerais, informa o grau de concordância entre o dendrograma obtido e a matriz de distância original (estabelecendo uma correlação entre as distâncias reais com as distâncias do dendrograma). A consistência do dendrograma foi avaliada através de bootstrap com 10.000 reamostragens, utilizando o programa BOOD (Avaliação de dendrogramas baseados em estimativas de distâncias/similaridades genéticas através do procedimento de bootstrap) desenvolvido por Alexandre S. G. Coelho, do Departamento de Genética Vegetal, da Universidade Federal de Goiás ${ }^{1}$.

1. Coelho, A . S. G. (UFGO) Comunicação pessoal, 2000. 


\subsubsection{Análise de coordenadas principais}

A análise de coordenadas principais é um método de ordenação desenvolvido a partir dos métodos de componentes principais (PCA). Assim como a análise de agrupamento, a análise de componentes principais têm como finalidade reduzir a dimensão espacial dos dados, transformando um conjunto original de variáveis provenientes de um espaço multidimensional em outro conjunto equivalente porém, limitado ao espaço bi ou tridimensional (Alfenas, 1998). Vem a complementar a análise de agrupamento dos dados a partir da matriz de distância original. A análise de coordenadas principais foi realizada pelo programa NTSYS (Rholf, 1992). 


\section{RESULTADOS E DISCUSSÃO}

A variabilidade genética das populações BR-105, BR-106 e respectivos sintéticos IG-3 e IG-4 foi estudada via marcadores de microssatélites em pelo menos uma região (bin) de cada um dos 10 cromossomos do milho. Os polimorfismos detectados permitiram traçar um esboço da estrutura genética destas populações, antes e após passarem por um ciclo de seleção recorrente recíproca, com altas intensidades de seleção. A análise da distribuição da diversidade gênica foi conduzida pelo método proposto por Nei (1973), o qual é o menos restritivo em suas presuposições. A diferenciação genética entre as populações e os sintéticos também foi investigada considerando-se o modelo de mutação SMM, delineado para microssatélites (Godstein, et al. 1995).

\subsection{Seleção dos primers}

Em virtude dos primers utilizados na amplificação dos locos de microssatélites variarem tanto no tamanho quanto na composição de nucleotídeos, fez-se necessário, em alguns casos, a otimização das condições de amplificação.

A utilização de um programa de amplificação básico (MSAT 1) independente das temperaturas de anelamento específicas para cada par de primers, simplifica a etapa de seleção dos primers. Entretanto, pequenos ajustes nas condições de amplificação contribuem para melhorar a qualidade das amplificações e conseqüentemente das genotipagens. 
Inicialmente, todos os pares de primers foram submetidos ao programa básico (MSAT 1), o qual foi eficiente na amplificação de $57 \%$ dos locos. Os pares de primers que não amplificaram satisfatoriamente foram submetidos aos demais programas de amplificação, cuja escolha foi auxiliada pela temperatura "específica" para cada par, definida pelas equações descritas no ítem 3.2.1.4. A temperatura "específica" para cada par de primers obtida pelas duas expressões não foi eficiente para apontar o melhor programa de amplificação.

Resultado semelhante foi obtido por Ogliari et al. (2000) na otimização da reação utilizando primers de microssatélites em milho onde a eq.(8) foi utilizada como um ponto de partida na escolha do programa de amplificação mais adequado. Apesar das inúmeras equações e softwares disponíveis para cálculo, a determinação da temperatura de anelamento ótima é, na prática, um processo que envolve certo grau de empirismo, mesmo porque, o resultado da amplificação não depende exclusivamente da temperatura de anelamento mas, também, da própria condição da reação da PCR.

Após definido o programa de amplificação mais adequado, os ajustes na concentração de magnésio mostraram-se efetivos, em melhorar a qualidade das amplificações para determinados pares de primers, como por exemplo, Bnlg 155 (Figura 5).

Para os programas de amplificação com temperaturas mais baixas foram empregados tempos de anelamento mais curtos (30 e 40s). Tempos de anelamento de 30 a 45 s são freqüentemente utilizados nas reações de PCR. Hillis et al. (1996) ressaltam que tempos mais curtos (30 a 60s) tendem a fornecer maior especificidade. Quanto aos componentes da reação da PCR, a concentração de magnésio representa uma das variáveis chave, sendo relevante tanto para a especificidade do primer quanto para a quantidade do produto amplificado. $O$ magnésio influencia a atividade da DNA polimerase, a qual pode afetar a quantidade de produto amplificado e também 0 anelamento do primer. Este, por sua vez, pode interferir na especificidade da reação. Além disso, os dNTPs podem quelar o magnésio reduzindo a quantidade disponível para a atividade da enzima (Bogetto et al., 2000). Neste trabalho foi possível determinar uma concentração de magnésio para a qual a quantidade de produto amplificado e a 
especificidade da reação foram adequadas, considerando todas as demais variáveis da reação constantes.

Na Tabela 2 são apresentados as condições de amplificação utilizadas para os 30 locos de microssatélites avaliados.

Tabela 2. Locos de microssatélites, cromossomo (Bin), condições de amplificação (Programa), tempo de anelamento (s) e concentração de magnésio (mM) utilizados na reação de PCR.

\begin{tabular}{ccccc}
\hline Primer & Bin & Programa* & $\begin{array}{c}\text { Tempo } \\
\text { para anelamento }\end{array}$ & $\begin{array}{c}\text { Concentração de } \\
\text { magnésio- }\end{array}$ \\
\hline Bnlg 109 & 1.02 & 1 & 60 & 2.0 \\
Phi 001 & 1.03 & 4 & 30 & 2.0 \\
Bnlg 176 & 1.03 & 1 & 60 & 2.0 \\
Bnlg 131 & 1.11 & 6 & 40 & 1.0 \\
Bnlg 125 & 2.02 & 2 & 60 & 2.0 \\
Bnlg 108 & 2.04 & 1 & 60 & 2.0 \\
MAGEO5 & 2.05 & 4 & 30 & 2.0 \\
Bnlg 602 & 3.04 & 1 & 60 & 2.0 \\
Bnlg 197 & 3.07 & 1 & 60 & 2.5 \\
MTTGO2 & 4.06 & 4 & 30 & 2.0 \\
Bnlg 589 & 4.11 & 6 & 60 & 2.0 \\
Bnlg 143 & 5.01 & 1 & 60 & 2.0 \\
Phi 113 & 5.03 & 1 & 60 & 2.0 \\
Phi 48 & 5.07 & 1 & 60 & 2.0 \\
Bnlg 238 & 6.00 & 1 & 60 & 2.0 \\
Bnlg 161 & 6.01 & 4 & 30 & 2.0 \\
Phi 70 & 6.07 & 6 & 60 & 2.5 \\
Bnlg 657 & 7.02 & 1 & 60 & 2.0 \\
BNlg 155 & 7.04 & 3 & 60 & 1.0 \\
Bnlg 572 & 7.07 & 1 & 60 & 2.0 \\
Phi 115 & 8.03 & 1 & 60 & 2.0 \\
Bnlg 669 & 8.03 & 5 & 60 & 2.0 \\
Bnlg 666 & 8.05 & 1 & 60 & 2.0 \\
Bnlg 240 & 8.06 & 1 & 60 & 2.0 \\
MACTO2BO8 & 9.01 & 4 & 30 & 2.5 \\
Phi 65 & 9.03 & 3 & 60 & 2.5 \\
Bnlg 127 & 9.04 & 1 & 60 & 2.0 \\
Bnlg 292 & 9.06 & 1 & 60 & 2.0 \\
Phi 59 & 10.02 & 1 & 60 & 2.5 \\
Phi 84 & 10.04 & 4 & 30 & 2.5 \\
\hline
\end{tabular}

* A descrição dos programas está no item 3.2.1.4 (Figura 4). 
De modo geral, foi encontrado polimorfismo para os 94 pares de primers testados nas populações e nos sintéticos (Figura 6), sendo mais acentuado nas populações originais (Figura 7). Apenas o primer Bnlg 391 não apresentou nenhum produto de amplificação. Deste total, 30 pares de primers (30 locos), cerca de $32 \%$, geraram bons padrões de amplificação, permitindo com que genótipos fossem claramente identificados em todos 384 indivíduos pertencentes às populações e aos sintéticos.

\subsection{Variabilidade genética}

Na Tabela 3 são apresentados a seqüência dos motivos, o número e comprimento dos alelos (em pb) e o conteúdo de informação de polimorfismo referente aos 30 locos de microssatélites.

Considerando todos os materiais, o número de alelos variou de 2 a 7, com uma média de 4,16 alelos por loco. Os locos Phi 70, Phi 115, MACTO2BO8, Phi 65 e Bnlg 292 apresentaram o menor número, isto é, 2 alelos. O número máximo de alelos foi observado nos locos Bnlg 161 e Bnlg 669 (7 alelos).

Esses valores são expressivos comparativamente aqueles relatados por Senior et al. (1998) em 94 linhagens elites, representantes da diversidade genética das raças norte americanas do cinturão de milho dentado, as quais foram avaliadas para 70 locos de microssatélites em agarose metaphora $4 \%$. Foi encontrado um número médio de 5 alelos por loco, com amplitude de 2 a 23 alelos.

Em relação ao número observado de alelos, deve-se ressaltar que as populações e os sintéticos, foram genotipados em agarose metaphor, a qual apresenta um limite de resolução acima de $4 \mathrm{pb}$. Nestas circunstâncias, o número de alelos torna-se subestimado, comparativamente ao que seria obtido em géis de poliacrilamida. 0 poder de resolução dos géis de poliacrilamida permite a deteç̧ão de um número maior de alelos por loco, principalmente para os locos de repetições dinucleotídicas. Seqüências diferindo em 2 pb não podem ser resolvidas em géis de agarose (Senior et al., 1998; Smith et al., 1997). 


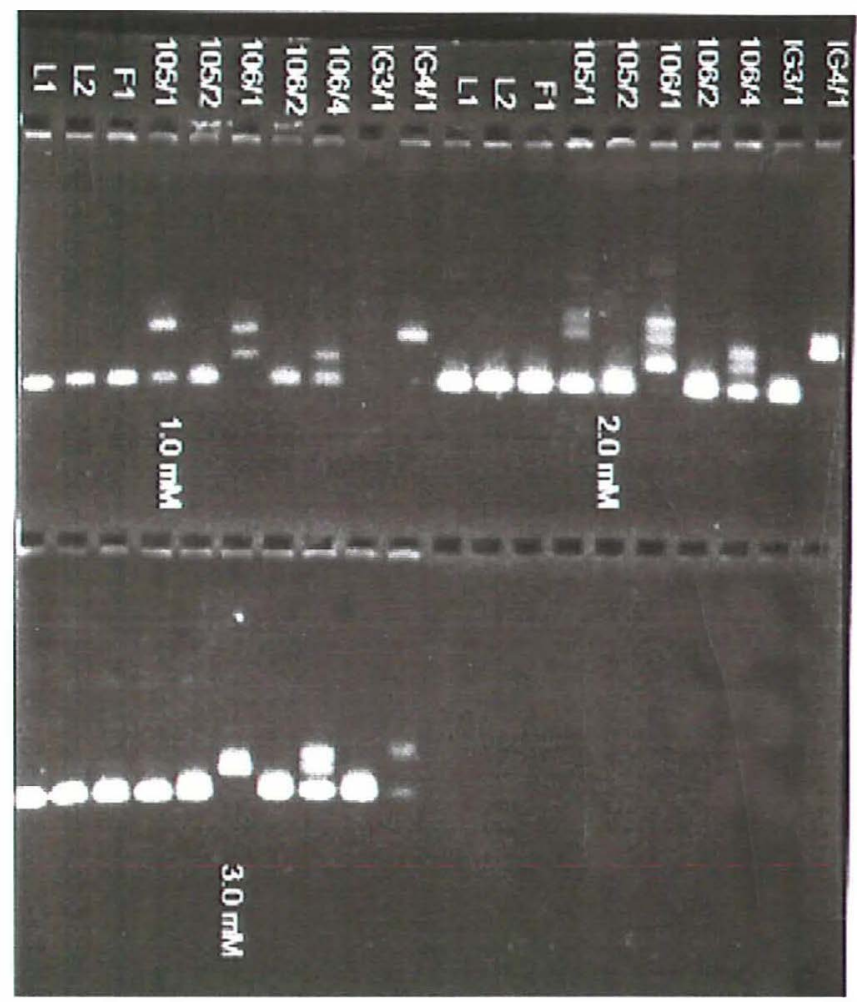

Figura 5- Reação de PCR com o primer Bnlg 155, sob diferentes concentrações de magnésio $(1,0 ; 2,0$ e $3,0 \mathrm{mM})$ e demais variáveis da reação constantes. 

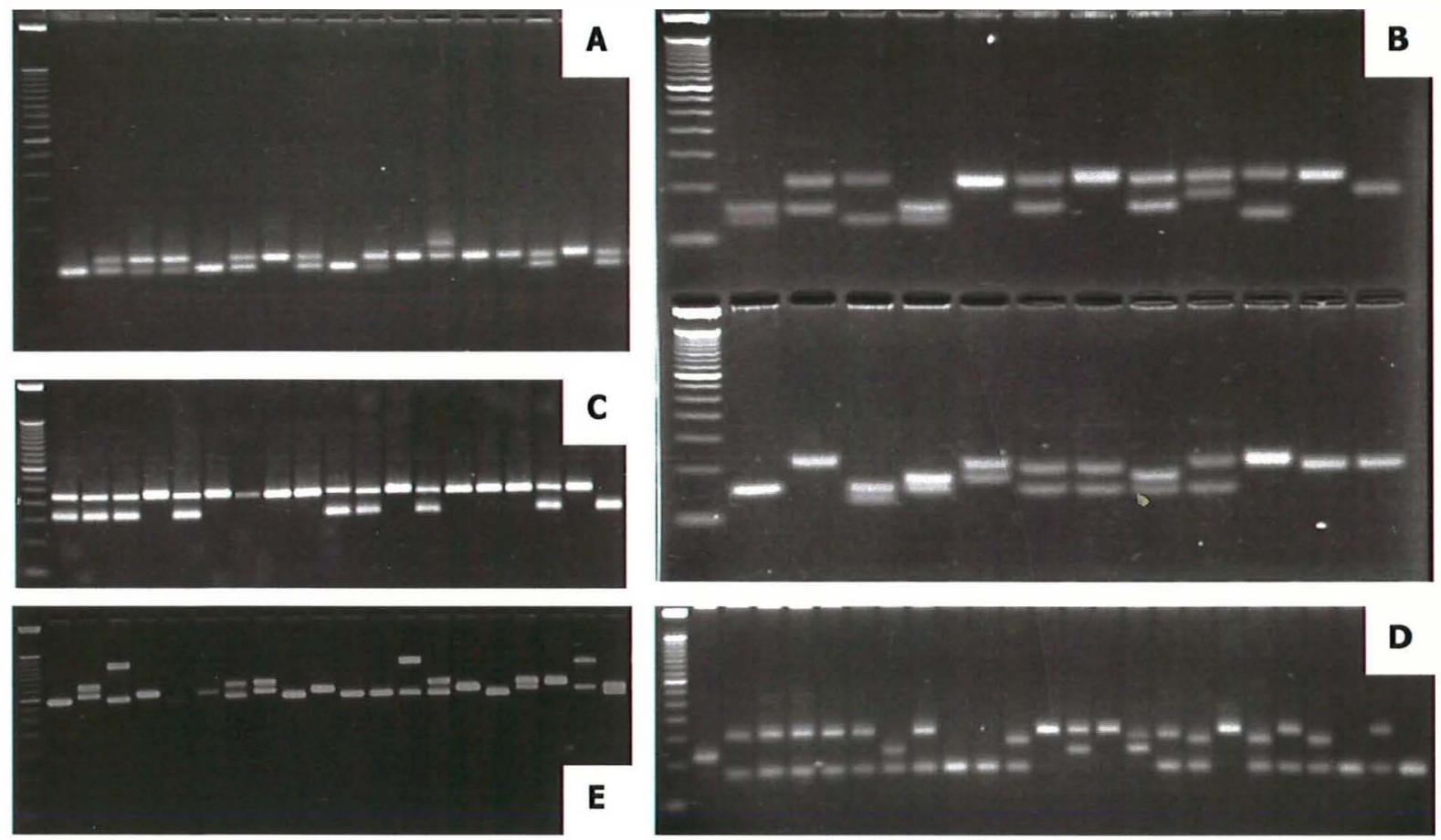

D

Figura 6- Polimorfismos detectados utilizando cinco marcadores microssatélites em populações de milho em géis de agarose metaphora 3\%. A) MAGE05 (BR-105), B) Bnlg 131 (BR-105), C) MTTGBO2 (BR-106), D) Bnlg 155 (IG-3) E) Bnlg 109 (IG-4). 



Figura 7- Padrões de amplificação para locos de microssatélites: primer Bnlg 197 na população BR-105 (A) e no sintético IG-3 (B); primer Bnlg 669 na população BR-106 (C) e no sintético IG-4 (D). 
Quanto aos tipos de repetições (motivos), 60\% dos locos foram constituídos de repetições dinucleotídicas, $13 \%$ de repetições imperfeitas (compostas e interrompidas), $10 \%$ de repetições trinucleotídicas, $10 \%$ de repetições tetranucleotídicas e $7 \%$ de repetições pentanucleotídicas. As repetições dinucleotídicas, aparentemente, apresentaram em média um número de alelos $(4,88)$ maior em relação às demais repetições (3,66 para tri e tetranucleotídicas; 2,00 para pentanucleotídicas e 2,75 para repetições imperfeitas). Em plantas, as repetições de dinucleotídios têm sido apontadas como a classe mais polimórfica de microssatélites enquanto as repetições imperfeitas, como menos polimórficas (Chin et al., 1996; Jarne \& Lagoda, 1996).

O comprimento dos fragmentos gerados, (alelos), foi estimado para cada loco a partir de uma equação de regressão obtida com base nos marcadores de peso molecular de 50 e $100 \mathrm{pb}$. A menor amplitude no comprimento dos alelos foi observada para o loco Phi 70 (10 pb) sendo a maior observada para o loco Bnlg 109 (288 pb).

A robustez característica dos locos de microssatélites permite a comparação de resultados entre laboratórios como também, no caso do milho, dos padrões de amplificação descritos para linhagens, os quais se encontram disponíveis no Maize Genome Database (http://www.agron.missouri.edu). Dos 70 locos de microssatélites utilizados na avaliação de 94 linhagens elites do cinturão de milho dentado, descrita por Senior et. al. (1998), 5 locos foram os mesmos utilizados neste estudo. A amplitude observada para os locos Phi 001, Phi 70, Phi 65, Phi 59 e Phi 84 foi praticamente a mesma observada nas linhagens elites (Tabela 4). Isto sugere que as populações BR105 e BR-106 e respectivos sintéticos provavelmente apresentam alelos em comum com as linhagens descritas por aqueles autores.

Os fragmentos (alelos) detectados nas populações e nos sintéticos, em geral, apresentaram a mesma amplitude dos encontrados para a quase totalidade dos locos disponíveis no banco de dados do milho, referentes a linhagens elites. 
Tabela 3. Motivo, número de alelos, tamanho do alelo $(\mathrm{pb})$ e conteúdo de polimorfismo (PIC), referente a 30 locos de microssatélites.

\begin{tabular}{|c|c|c|c|c|}
\hline Loco (SSR) & Motivo & $\begin{array}{c}\text { Número de } \\
\text { alelos }\end{array}$ & $\begin{array}{l}\text { Tamanho do } \\
\text { alelo (pb) }\end{array}$ & PIC \\
\hline Bnlg 109 & $\overline{A G}$ & 4 & 344 a 632 & 0,494 a 0,717 \\
\hline Phi001 & AG & 6 & 76 a 154 & 0,395 a 0,815 \\
\hline Bnlg 176 & CT & 4 & 134 a 244 & 0,010 a 0,477 \\
\hline Bnlg 131 & AG & 6 & 60 a 138 & 0,541 a 0,768 \\
\hline Bnlg 125 & $(C T)(G T)(A G)$ & 5 & 234 a 348 & 0,605 a 0,775 \\
\hline Bnlg 108 & $A G$ & 4 & 78 a 116 & 0,110 a 0,645 \\
\hline MAGE05 & AG & 3 & 98 a 126 & 0,275 a 0,506 \\
\hline Bnlg 602 & AG & 4 & 148 a 172 & 0,445 a 0,745 \\
\hline Bnlg 197 & GA & 6 & 84 a 132 & 0,286 a 0,635 \\
\hline MTTBO2 & TTG & 5 & 150 a 228 & 0,396 a 0,766 \\
\hline Bnlg 589 & CT & 5 & 154 a 232 & 0,292 a 0,743 \\
\hline Bnlg 143 & CA & 3 & 242 a 280 & 0,245 a 0,530 \\
\hline Phi 113 & GTCT & 4 & 96 a 316 & 0,526 a 0,746 \\
\hline Phi 048 & ATCG & 3 & 188 a 220 & 0,314 a 0,500 \\
\hline Bnlg 238 & AG & 6 & 134 a 228 & 0,535 a 0,749 \\
\hline Bnlg 161 & AG & 7 & 120 a 224 & 0,635 a 0,794 \\
\hline Phi 070 & GAGCT & 2 & 80 a 90 & 0,475 a 0,501 \\
\hline Bnlg 657 & AG & 5 & 84 a 116 & 0,656 a 0,763 \\
\hline Bnlg 155 & CT & 6 & 92 a 188 & 0,403 a 0,711 \\
\hline Bnlg 572 & CT & 3 & 84 a 102 & 0,529 a 0,659 \\
\hline Phi 115 & $(T A)(A T A C)$ & 2 & 90 a 120 & 0,500 a 0,503 \\
\hline Bnlg 669 & GA & 7 & 108 a 200 & 0,304 a 0,687 \\
\hline Bnlg 666 & GA & 5 & 84 a 186 & 0,557 a 0,742 \\
\hline Bnlg 240 & TC & 4 & 112 a 158 & 0,553 a 0,690 \\
\hline МСТО2В08 & $(C A)(A)(C A)$ & 2 & 95 a 125 & 0,374 a 0,498 \\
\hline Phi 065 & CACTT & 2 & 130 a 150 & 0,326 a 0,460 \\
\hline Bnlg 127 & GTCT & 4 & 240 a 276 & 0,416 a 0,656 \\
\hline Bnlg 292 & $(C T)(C)(C T)(T)(C T)$ & 2 & 120 a 152 & 0,000 a 0,430 \\
\hline Phi 059 & CCA & 3 & 144 a 171 & 0,335 a 0,480 \\
\hline Phi 084 & GAA & 3 & 150 a 198 & 0,092 a 0,525 \\
\hline
\end{tabular}


Nas populações BR-105 e BR-106, tanto o loco Bnlg 109 como o Phi 113 apresentaram alelos bem distantes dos demais observados nos respectivos locos. Para o loco Bnlg 109, o alelo de 632 pb se distanciou do alelo mais próximo (438 pb) em cerca de 194 pb. Para o loco Phi 113, o alelo de 316 pb se distanciou do alelo mais próximo (128 pb) em cerca de $189 \mathrm{pb}$. Fragmentos semelhantes a estes, provavelmente os mesmos, também foram observados no banco de dados do milho. Expansões deste tipo são observadas no genoma humano e, é provável que tais regiões repetitivas contenham algum tipo de inserto $\left(\right.$ Senior $\left.^{2}\right)$. Apesar do mecanismo do deslize da DNA polimerase ser considerado como preponderante na formação do microssatélite, pode ocorrer também permuta desigual na meiose, envolvendo um número maior de repetições, originando fragmentos maiores.

O conteúdo de polimorfismo (PIC) estimado para os 30 locos de microssatélites variou de 0,000 (Bnlg 292) a 0,815 (Phi001) com um valor médio de 0,514. Os valores de PIC observados se encontram dentro do intervalo de 0,40 a 0,89 relatados para milho por Powell et al. (1996) com 2 a 12 alelos por loco. São valores inferiores à média de 0,67 observada por Smith et al. (1997) em 58 linhagens de milho, genotipadas via seqüenciadores automáticos em géis de poliacrilamida.

Tabela 4. Comparação dos fragmentos (pb) de microssatélites obtidos nas populações e sintéticos com os relatados para linhagens elites.

\section{Amplitude (pb)}

Loco

Phi001

Phi 70

Phi 65

Phi 59

Phi 84
Presente estudo

76 a 154

80 a 90

130 a 150

144 a 171

150 a 198
Senior et al. (1998) 66 a 157 78 a 88 132 a 157

147 a 159

148 a 157

Fonte: Senior et al. (1998)

2. Senior, L.(USDA),Comunicação pessoal, 2001. 


\section{2.a Freqüências alélicas}

As freqüências alélicas apresentadas nas Tabelas 5 e 6 foram estimadas a partir das freqüências genotípicas observadas nas amostras retiradas de cada população e sintéticos. Os 30 locos forneceram um total de 125 alelos. Foram encontrados 116 alelos na população BR-106 e 111 na população BR-105. Foi observada uma perda de $23 \%$ dos alelos no sintético IG-3, o qual apresentou 86 alelos. Para o sintético IG-4 foi observada uma perda de 17\%, sendo observados 96 alelos.

A distribuição dos alelos nas populações e nos sintéticos encontra-se representada na Figura 8. Em relação as populações originais, tal distribuição evidência um aumento no número de alelos pertencentes às classes extremas de freqüências após a seleção. Na população BR-105, 33\% dos alelos apresentaram freqüências iguais ou menores que 0,1 (próximo à extinção). Após um ciclo de seleção, $38 \%$ dos alelos foram encontrados nesta classe. Na BR-106, 27\% dos alelos apresentaram freqüências menores ou iguais a 0,1 e no sintético IG4, $35 \%$. Nos sintéticos foram encontrados um número maior de alelos próximos à fixação (freqüências de 0,9 a 1,0 ), respectivamente, $7,21 \%$ e $5,17 \%$ comparativamente a BR-105 (1,80\%) e BR-106 $(0,86 \%)$.

Em relação às populações originais, os sintéticos apresentaram uma distribuição de freqüências alélicas mais uniforme nas classes intermediárias. Este padrão de distribuição é característico do processo dispersivo, em que as freqüênicias tendem a se distribuir uniformemente, entre os limites de zero (extinção) e um (fixação). A perda de alelos é esperada, naturalmente, em populações que passaram por um estreitamento de sua base genética. Os alelos que apresentam baixas freqüências são perdidos mais rapidamente, e os alelos mais freqüentes no início do processo dispersivo têm maior chance de se fixarem.

Os intervalos de confiança a $95 \%$ de probabilidade assumiram valores positivos para a maioria das freqüências alélicas estimadas. Nas populações e nos sintéticos, respectivamente, 3,6\%, 9,0\% e 7,0\% dos intervalos de confiança contiveram valores negativos. Conseqüentemente, os alelos poderão não ser amostrados em um próximo evento. 
Tabela 5. Locos, alelos $(\mathrm{pb})$, freqüências alélicas $\left(\hat{p}_{u}\right)$, intervalo de confiança a $95 \%$ de probabilidade ( $I C_{95 \%}$ ) e tamanho da amostra (n) referente à população BR-105 e ao sintético IG-3 para 30 locos de microssatélites.

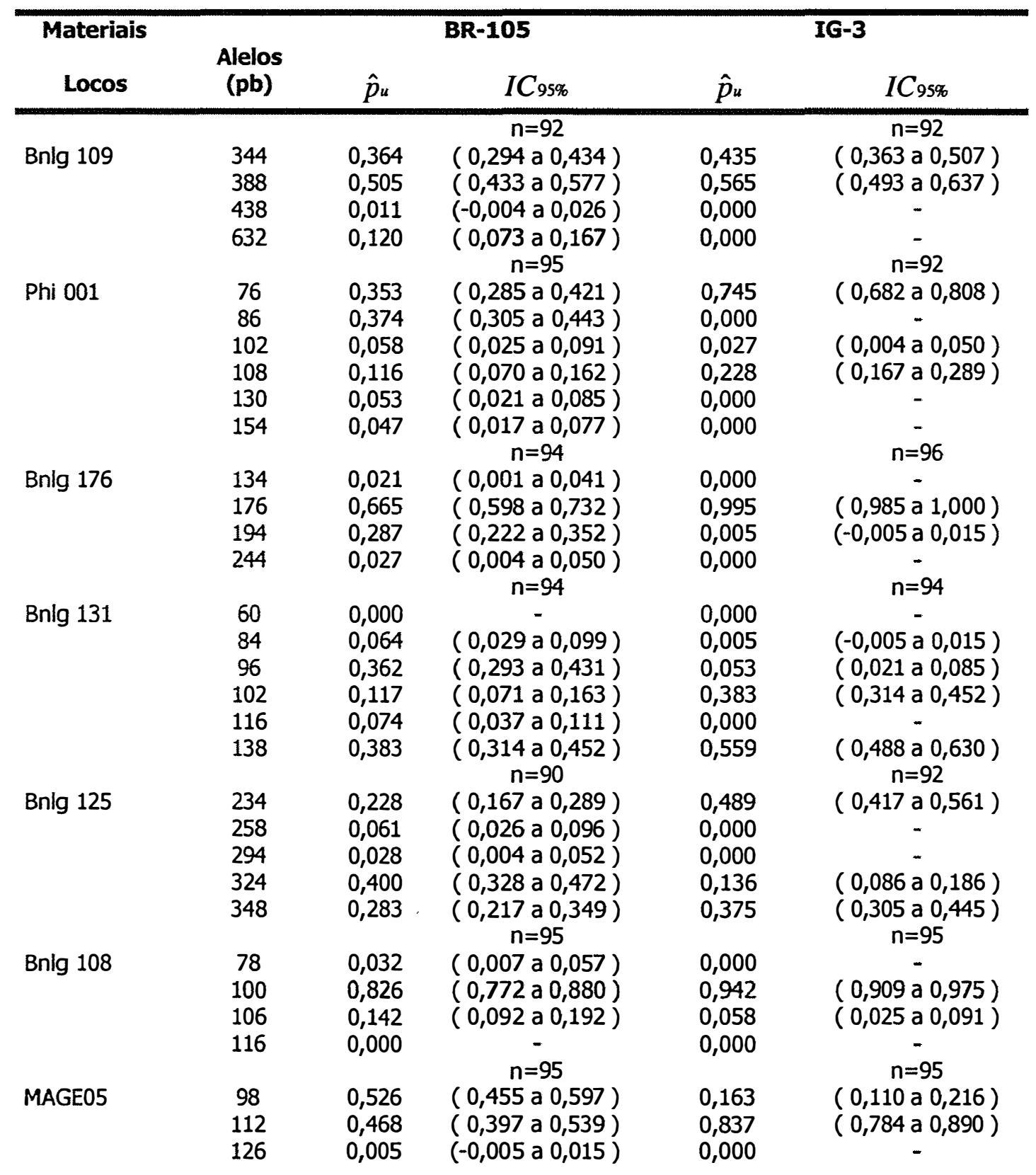


Tabela 5. Locos, alelos $(\mathrm{pb})$, freqüências alélicas $\left(\hat{p}_{u}\right)$, intervalo de confiança a $95 \%$ de probabilidade ( $I C_{95 \%}$ ) e tamanho da amostra (n) referente à população BR-105 e ao sintético IG-3 para 30 locos de microssatélites.

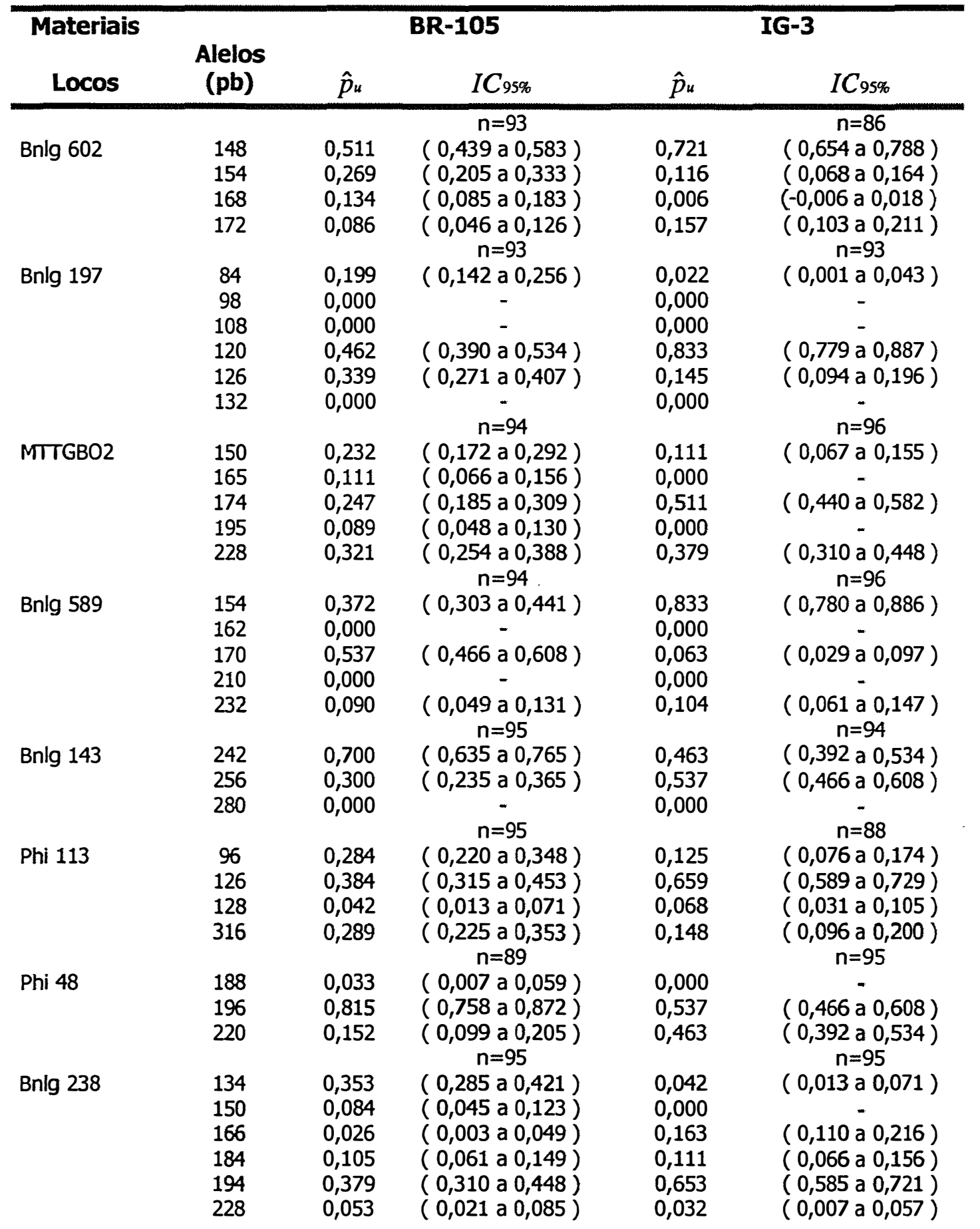


Tabela 5. Locos, alelos $(\mathrm{pb})$, freqüências alélicas $\left(\hat{p}_{u}\right)$, intervalo de confiança a 95\% de probabilidade ( $I C_{95 \%}$ ) e tamanho da amostra $(n)$ referente à população BR-105 e ao sintético IG-3 para 30 locos de microssatélites.

\begin{tabular}{|c|c|c|c|c|c|}
\hline \multirow{2}{*}{$\begin{array}{c}\text { Materiais } \\
\text { Locos }\end{array}$} & \multirow[b]{2}{*}{$\begin{array}{l}\text { Alelos } \\
\text { (pb) }\end{array}$} & \multicolumn{2}{|r|}{ BR-105 } & \multicolumn{2}{|c|}{ IG-3 } \\
\hline & & $\hat{p}_{u}$ & $I C_{95 \%}$ & $\hat{p}_{u}$ & $I C_{95 \%}$ \\
\hline \multirow{8}{*}{ Bnlg 161} & & & $n=95$ & & $n=94$ \\
\hline & 120 & 0,353 & $(0,285$ a 0,421$)$ & 0,000 & - \\
\hline & 138 & 0,063 & $(0,028$ a 0,098$)$ & 0,048 & $(0,017$ a 0,079$)$ \\
\hline & 150 & 0,058 & $(0,025$ a 0,091$)$ & 0,149 & $(0,098$ a 0,200$)$ \\
\hline & 168 & 0,111 & $(0,066$ a 0,156$)$ & 0,298 & $(0,233$ a 0,363$)$ \\
\hline & 176 & 0,379 & $(0,310$ a 0,448$)$ & 0,505 & $(0,434$ a 0,576$)$ \\
\hline & 202 & 0,037 & $(0,010$ a 0,064$)$ & 0,000 & - \\
\hline & 224 & 0,000 & $n=93$ & 0,000 & $\begin{array}{c}- \\
n=93\end{array}$ \\
\hline \multirow[t]{2}{*}{ Phi 70} & 80 & 0,548 & $(0,476$ a 0,620$)$ & 0,618 & $(0,548$ a 0,688$)$ \\
\hline & 90 & 0,452 & $\begin{array}{c}(0,380 \text { a } 0,524) \\
n=92\end{array}$ & 0,382 & $\begin{array}{c}(0,313 \text { a } 0,453) \\
n=94\end{array}$ \\
\hline \multirow[t]{5}{*}{ Bnlg 657} & 84 & 0,000 & - & 0,000 & - \\
\hline & 94 & 0,190 & $(0,133$ a 0,247$)$ & 0,298 & $(0,233$ a 0,363$)$ \\
\hline & 98 & 0,516 & $(0,444$ a 0,588$)$ & 0,202 & $(0,145$ a 0,259$)$ \\
\hline & 104 & 0,114 & $(0,068$ a 0,160$)$ & 0,202 & $(0,145$ a 0,259$)$ \\
\hline & 116 & 0,179 & $\begin{array}{c}(0,124 \text { a } 0,234) \\
n=95\end{array}$ & 0,298 & $\begin{array}{c}(0,233 \text { a } 0,363) \\
n=96\end{array}$ \\
\hline \multirow[t]{6}{*}{ Bnlg 155} & 92 & 0,763 & $(0,703$ a 0,823$)$ & 0,422 & $(0,352$ a 0,492$)$ \\
\hline & 108 & 0,026 & $(0,003$ a 0,049) & 0,000 & - \\
\hline & 120 & 0,032 & $(0,007$ a 0,057$)$ & 0,161 & $(0,109$ a 0,213$)$ \\
\hline & 142 & 0,079 & $(0,041$ a 0,117$)$ & 0,177 & $(0,123$ a 0,231$)$ \\
\hline & 168 & 0,095 & $(0,053$ a 0,137$)$ & 0,240 & $(0,180$ a 0,300$)$ \\
\hline & 188 & 0,005 & $\begin{array}{c}(-0,005 \text { a } 0,015) \\
n=90\end{array}$ & 0,000 & $n=95$ \\
\hline \multirow[t]{3}{*}{ Bnlg 572} & 84 & 0,261 & $(0,197$ a 0,325$)$ & 0,368 & $(0,299$ a 0,437$)$ \\
\hline & 90 & 0,328 & $(0,259$ a 0,397$)$ & 0,105 & $(0,061$ a 0,149$)$ \\
\hline & 102 & 0,411 & $\begin{array}{c}(0,339 \text { a } 0,483) \\
n=95\end{array}$ & 0,526 & $\begin{array}{c}(0,455 \text { a } 0,597) \\
n=93\end{array}$ \\
\hline \multirow[t]{2}{*}{ Phi 115} & 90 & 0,505 & $(0,434$ a 0,576$)$ & 0,462 & $(0,390$ a 0,534$)$ \\
\hline & 120 & 0,495 & $\begin{array}{c}(0,424 \text { a } 0,566) \\
n=95\end{array}$ & 0,538 & $\begin{array}{c}(0,466 \text { a } 0,610) \\
n=96\end{array}$ \\
\hline \multirow[t]{7}{*}{ Bnlg 669} & 108 & 0,368 & $(0,299$ a 0,437$)$ & 0,807 & $(0,751$ a 0,863$)$ \\
\hline & 114 & 0,047 & $(0,017$ a 0,077$)$ & 0,000 & - \\
\hline & 128 & 0,405 & $(0,335$ a 0,475$)$ & 0,182 & $(0,127$ a 0,237$)$ \\
\hline & 144 & 0,095 & $(0,053$ a 0,137$)$ & 0,000 & - \\
\hline & 160 & 0,074 & $(0,037$ a 0,111$)$ & 0,000 & - \\
\hline & 180 & 0,000 & - & 0,000 & - \\
\hline & 200 & 0,011 & $\begin{array}{c}(-0,004 \text { a } 0,026) \\
n=92\end{array}$ & 0,010 & $\begin{array}{c}(-0,004 \text { a } 0,024) \\
n=93\end{array}$ \\
\hline \multirow[t]{5}{*}{ Bnlg 666} & 84 & 0,288 & $(0,223$ a 0,353$)$ & 0,258 & $(0,195$ a 0,321$)$ \\
\hline & 126 & 0,288 & $(0,223$ a 0,353$)$ & 0,199 & $(0,142$ a 0,256$)$ \\
\hline & 138 & 0,092 & $(0,050$ a 0,134$)$ & 0,124 & $(0,077$ a 0,171$)$ \\
\hline & 166 & 0,293 & $(0,227$ a 0,359$)$ & 0,419 & $(0,348$ a 0,490$)$ \\
\hline & 186 & 0,038 & $(0,010$ a 0,066$)$ & 0,000 & - \\
\hline
\end{tabular}


Tabela 5. Locos, alelos $(\mathrm{pb})$, freqüências alélicas $\left(\hat{p}_{u}\right)$, intervalo de confiança a $95 \%$ de probabilidade ( $I C_{95 \%}$ ) e tamanho da amostra (n) referente à população BR-105 e ao sintético IG-3 para 30 locos de microssatélites.

\begin{tabular}{|c|c|c|c|c|c|}
\hline \multirow{2}{*}{$\begin{array}{c}\text { Materiais } \\
\text { Locos }\end{array}$} & \multirow{2}{*}{$\begin{array}{c}\text { Alelos } \\
\text { (pb) }\end{array}$} & \multicolumn{2}{|r|}{ BR-105 } & \multicolumn{2}{|c|}{ IG-3 } \\
\hline & & $\hat{p}_{u}$ & $I C_{95 \%}$ & $\hat{p}_{\boldsymbol{u}}$ & $I C_{95 \%}$ \\
\hline \multirow{4}{*}{ Bnlg 240} & 112 & 0.100 & $\begin{array}{c}n=95 \\
(0.057\end{array}$ & 0068 & $\begin{array}{c}n=95 \\
\text { nas }\end{array}$ \\
\hline & 126 & 0,332 & $(0,265$ a 0,399$)$ & $\begin{array}{l}0,008 \\
0,389\end{array}$ & $(0,320$ a 0,458$)$ \\
\hline & 140 & 0,516 & $(0,445$ a 0,587$)$ & 0,542 & $(0,471$ a 0,613$)$ \\
\hline & 158 & 0,053 & $\begin{array}{c}(0,021 \text { a } 0,085) \\
n=96\end{array}$ & 0,000 & $n=96$ \\
\hline \multirow[t]{2}{*}{ МАCTO2BO8 } & 95 & 0,548 & $(0,478$ a 0,618$)$ & 0,753 & $(0,692$ a 0,814$)$ \\
\hline & 125 & 0,452 & $\begin{array}{c}(0,382 \text { a } 0,522) \\
n=91\end{array}$ & 0,247 & $\begin{array}{c}(0,186 \text { a } 0,308) \\
n=94\end{array}$ \\
\hline \multirow[t]{2}{*}{ Phi 65} & $\begin{array}{l}130 \\
150\end{array}$ & $\begin{array}{l}0,797 \\
0,203\end{array}$ & $\begin{array}{l}(0,739 \text { a } 0,855) \\
(0,145 \text { a } 0,261)\end{array}$ & $\begin{array}{l}0,346 \\
0,654\end{array}$ & $\begin{array}{l}(0,278 \text { a } 0,414) \\
(0,586 \text { a } 0,722)\end{array}$ \\
\hline & & & $n=93$ & & $n=94$ \\
\hline \multirow[t]{4}{*}{ Bnlg 127} & $\begin{array}{l}240 \\
252\end{array}$ & $\begin{array}{l}0,425 \\
0.575\end{array}$ & $(0,354$ a 0,496$)$ & $\begin{array}{l}0,707 \\
0,293\end{array}$ & $\begin{array}{l}(0,642 \text { a } 0,772) \\
(0,228 \text { a } 0,358)\end{array}$ \\
\hline & 264 & 0,000 & $(0,0070,070)$ & 0,000 & $(0,2<0$ a 0,530$)$ \\
\hline & 276 & 0,000 & - & 0,000 & - \\
\hline & & & $n=95$ & & $n=96$ \\
\hline \multirow[t]{2}{*}{ Bnlg 292} & 120 & 0,689 & $(0,623$ a 0,755$)$ & 0,984 & $(0,966$ a 0,999$)$ \\
\hline & 152 & 0,311 & $\begin{array}{c}(0,245 \text { a } 0,377) \\
n=96\end{array}$ & 0,016 & $\begin{array}{c}(-0,002 \text { a } 0,034) \\
n=90\end{array}$ \\
\hline \multirow[t]{3}{*}{ Phi 59} & 144 & 0,000 & - & 0,000 & - \\
\hline & 162 & 0,321 & $(0,255$ a 0,387$)$ & 0,395 & $(0,324$ a 0,466$)$ \\
\hline & 171 & 0,679 & $\begin{array}{c}(0,613 \text { a } 0,745) \\
n=91\end{array}$ & 0,605 & $\begin{array}{c}(0,534 \text { a } 0,676) \\
n=94\end{array}$ \\
\hline \multirow[t]{3}{*}{ Phi 84} & 150 & 0,703 & $(0,637$ a 0,769$)$ & 0,952 & $(0,921$ a 0,983$)$ \\
\hline & 171 & 0,258 & $(0,194$ a 0,322$)$ & 0,005 & $(-0,005$ a 0,015$)$ \\
\hline & 198 & 0,038 & $(0,010$ a 0,066$)$ & 0,043 & $(0,014$ a 0,072$)$ \\
\hline${ }^{*}(\mathrm{TA})$ & & (111) & & (86) & \\
\hline
\end{tabular}

*TA: número total de alelos 
Tabela 6. Locos, alelos $(\mathrm{pb})$, freqüências alélicas $\left(\hat{p}_{u}\right)$, intervalo de confiança a $95 \%$ de probabilidade ( $I C_{95 \%}$ ) e tamanho da amostra (n) referente à população BR-106 e ao sintético IG-4 para 30 locos de microssatélites.

\begin{tabular}{|c|c|c|c|c|c|}
\hline \multirow{2}{*}{$\begin{array}{c}\text { Materiais } \\
\text { Locos }\end{array}$} & \multirow[b]{2}{*}{$\begin{array}{c}\text { Alelos } \\
\text { (pb) }\end{array}$} & \multicolumn{2}{|r|}{ BR-106 } & \multicolumn{2}{|c|}{ IG-4 } \\
\hline & & $\hat{p}_{u}$ & $I C_{95 \%}$ & $\hat{p}_{u}$ & $I C_{95 \%}$ \\
\hline \multirow{5}{*}{ Bnlg 109} & & & $n=90$ & & $n=94$ \\
\hline & 344 & 0,222 & $(0,161$ a 0,283$)$ & 0,271 & $(0,207$ a 0,335$)$ \\
\hline & 388 & 0,661 & $(0,592$ a 0,730$)$ & 0,367 & $(0,298$ a 0,436$)$ \\
\hline & 438 & 0,111 & $(0,065$ a 0,157$)$ & 0,261 & $(0,198$ a 0,324$)$ \\
\hline & 632 & 0,006 & $\begin{array}{c}(-0,005 \text { a } 0,017) \\
n=87\end{array}$ & 0,101 & $\begin{array}{c}(0,058 \text { a } 0,144) \\
n=93\end{array}$ \\
\hline \multirow[t]{6}{*}{ Phi 001} & 76 & 0,126 & $(0,077$ a 0,175$)$ & 0,183 & $(0,127$ a 0,239$)$ \\
\hline & 86 & 0,184 & $(0,126$ a 0,242$)$ & 0,075 & $(0,037$ a 0,113$)$ \\
\hline & 102 & 0,132 & $(0,082$ a 0,182$)$ & 0,000 & - \\
\hline & 108 & 0,178 & $(0,121$ a 0,235$)$ & 0,220 & $(0,160$ a 0,280$)$ \\
\hline & 130 & 0,092 & $(0,049$ a 0,135$)$ & 0,075 & $(0,037$ a 0,113$)$ \\
\hline & 154 & 0,287 & $\begin{array}{c}(0,220 \text { a } 0,354) \\
n=96\end{array}$ & 0,446 & $\begin{array}{c}(0,375 \text { a } 0,517) \\
n=96\end{array}$ \\
\hline \multirow[t]{5}{*}{ Bnlg 176} & 134 & 0,010 & $(-0,004$ a 0,024$)$ & 0,005 & $(-0,005$ a 0,015$)$ \\
\hline & 176 & 0,854 & $(0,804$ a 0,904$)$ & 0,984 & $(0,966$ a 1,000$)$ \\
\hline & 194 & 0,135 & $(0,087$ a 0,183$)$ & 0,010 & $(-0,004$ a 0,024$)$ \\
\hline & 244 & 0,000 & - & 0,000 & - \\
\hline & & & $n=95$ & & $\mathrm{n}=96$ \\
\hline \multirow[t]{6}{*}{ Bnlg 131} & 60 & 0,368 & $(0,299$ a 0,437$)$ & 0,651 & $(0,584$ a 0,718$)$ \\
\hline & 84 & 0,137 & $(0,088$ a 0,186$)$ & 0,125 & $(0,078$ a 0,172$)$ \\
\hline & 96 & 0,084 & $(0,045$ a 0,123$)$ & 0,000 & - \\
\hline & 102 & 0,195 & $(0,139$ a 0,251$)$ & 0,125 & $(0,078$ a 0,172$)$ \\
\hline & 116 & 0,026 & $(0,003$ a 0,049$)$ & 0,000 & - \\
\hline & 138 & 0,189 & $\begin{array}{c}(0,133 \text { a } 0,245) \\
n=94\end{array}$ & 0,099 & $\begin{array}{c}(0,057 \text { a } 0,141) \\
n=94\end{array}$ \\
\hline \multirow[t]{5}{*}{ Bnlg 125} & 234 & 0,394 & $(0,324$ a 0,464$)$ & 0,340 & $(0,272$ a 0,408$)$ \\
\hline & 258 & 0,452 & $(0,381$ a 0,523$)$ & 0,218 & $(0,159$ a 0,277$)$ \\
\hline & 294 & 0,048 & $(0,017$ a 0,079$)$ & 0,122 & $(0,075$ a 0,169$)$ \\
\hline & 324 & 0,032 & $(0,007$ a 0,057$)$ & 0,149 & $(0,098$ a 0,200$)$ \\
\hline & 348 & 0,074 & $\begin{array}{c}(0,037 \text { a } 0,111) \\
n=96\end{array}$ & 0,170 & $\begin{array}{c}(0,116 \text { a } 0,224) \\
n=96\end{array}$ \\
\hline \multirow[t]{4}{*}{ Bnlg 108} & 78 & 0,214 & $(0,156$ a 0,272$)$ & 0,271 & $(0,208$ a 0,334$)$ \\
\hline & 100 & 0,464 & $(0,393$ a 0,535$)$ & 0,401 & $(0,332$ a 0,470$)$ \\
\hline & 106 & 0,313 & $(0,247$ a. 0,379$)$ & 0,328 & $(0,262$ a 0,394$)$ \\
\hline & 116 & 0,010 & $\begin{array}{c}(-0,004 \text { a } 0,024) \\
n=95\end{array}$ & 0,000 & $n=91$ \\
\hline \multirow[t]{3}{*}{ MAGE05 } & 98 & 0,758 & $(0,697$ a 0,819$)$ & 0,813 & $(0,756$ a 0,870$)$ \\
\hline & 112 & 0,242 & $(0,181$ a 0,303$)$ & 0,187 & $(0,130$ a 0,244$)$ \\
\hline & 126 & 0,000 & - & 0,000 & - \\
\hline
\end{tabular}


Tabela 6. Locos, alelos $(\mathrm{pb})$, freqüências alélicas $\left(\hat{p}_{u}\right)$, intervalo de confiança a $95 \%$ de probabilidade ( $I C_{95 \%}$ ) e tamanho da amostra (n) referente à população BR-106 e ao sintético IG-4 para 30 locos de microssatélites.

\begin{tabular}{|c|c|c|c|c|c|}
\hline \multirow{2}{*}{$\begin{array}{c}\text { Materiais } \\
\text { Locos }\end{array}$} & \multirow[b]{2}{*}{$\begin{array}{c}\text { Alelos } \\
\text { (pb) }\end{array}$} & \multicolumn{2}{|r|}{ BR-106 } & \multicolumn{2}{|c|}{ IG-4 } \\
\hline & & $\hat{p}_{u}$ & $I C_{95 \%}$ & $\hat{p}_{u}$ & $I C_{95 \%}$ \\
\hline Bnlg 602 & $\begin{array}{l}148 \\
154 \\
168 \\
172\end{array}$ & $\begin{array}{l}0,370 \\
0,307 \\
0,198 \\
0,125\end{array}$ & $\begin{array}{c}n=96 \\
(0,302 \text { a } 0,438) \\
(0,242 \text { a } 0,372) \\
(0,142 \text { a } 0,254) \\
(0,078 \text { a } 0,172) \\
n=95\end{array}$ & $\begin{array}{l}0,275 \\
0,287 \\
0,169 \\
0,270\end{array}$ & $\begin{array}{c}n=89 \\
(0,209 \text { a } 0,341) \\
(0,221 \text { a } 0,353) \\
(0,114 \text { a } 0,224) \\
(0,205 \text { a } 0,335) \\
n=94\end{array}$ \\
\hline Bnlg 197 & $\begin{array}{c}84 \\
98 \\
108 \\
120 \\
126 \\
132\end{array}$ & $\begin{array}{l}0,016 \\
0,179 \\
0,089 \\
0,674 \\
0,026 \\
0,016\end{array}$ & $\begin{array}{l}(-0,002 \text { a } 0,034) \\
(0,124 \text { a } 0,234) \\
(0,049 \text { a } 0,129) \\
(0,607 \text { a } 0,741) \\
(0,003 \text { a } 0,049) \\
(-0,002 \text { a } 0,034)\end{array}$ & $\begin{array}{c}0,011 \\
0,005 \\
0,000 \\
0,91 \\
0,074 \\
0,000\end{array}$ & $\begin{array}{c}(-0,004 \text { a } 0,026) \\
(-0,005 \text { a } 0,015) \\
- \\
(0,869 \text { a } 0,951) \\
(0,037 \text { a } 0,111) \\
-\end{array}$ \\
\hline MTTGBO2 & $\begin{array}{l}150 \\
165 \\
174 \\
195 \\
228\end{array}$ & $\begin{array}{l}0,128 \\
0,000 \\
0,144 \\
0,000 \\
0,729\end{array}$ & $\begin{array}{c}n=95 \\
(0,080 \text { a } 0,176) \\
- \\
(0,094 \text { a } 0,194) \\
- \\
(0,666 \text { a } 0,792) \\
n=95\end{array}$ & $\begin{array}{l}0,224 \\
0,000 \\
0,031 \\
0,000 \\
0,745\end{array}$ & $\begin{array}{c}n=95 \\
(0,165 \text { a } 0,283) \\
- \\
(0,006 \text { a } 0,056) \\
- \\
(0,683 \text { a } 0,807) \\
n=96\end{array}$ \\
\hline Bnlg 589 & $\begin{array}{l}154 \\
162 \\
170 \\
210\end{array}$ & $\begin{array}{l}0,226 \\
0,321 \\
0,179 \\
0,274\end{array}$ & $\begin{array}{l}(0,167 \text { a } 0,285) \\
(0,255 \text { a } 0,387) \\
(0,124 \text { a } 0,234) \\
(0,211 \text { a } 0,337)\end{array}$ & $\begin{array}{l}0,672 \\
0,000 \\
0,182 \\
0,146\end{array}$ & $\begin{array}{r}(0,606 \text { a } 0,738) \\
- \\
(0,127 \text { a } 0,237) \\
(0,096 \text { a } 0,196)\end{array}$ \\
\hline & 232 & 0,000 & $n=95$ & 0,000 & $n=81$ \\
\hline Bnlg 143 & $\begin{array}{l}242 \\
256 \\
280\end{array}$ & $\begin{array}{l}0,611 \\
0,084 \\
0,305\end{array}$ & $\begin{array}{c}(0,542 \text { a } 0,680) \\
(0,045 \text { a } 0,123) \\
(0,240 \text { a } 0,370) \\
n=93\end{array}$ & $\begin{array}{l}0,858 \\
0,000 \\
0,142\end{array}$ & $\begin{array}{c}(0,804 \text { a } 0,912) \\
- \\
(0,088 \text { a } 0,196) \\
n=91\end{array}$ \\
\hline Phi 113 & $\begin{array}{c}96 \\
116 \\
128 \\
316\end{array}$ & $\begin{array}{l}0,263 \\
0,194 \\
0,317 \\
0,226\end{array}$ & $\begin{array}{c}(0,200 \text { a } 0,326) \\
(0,137 \text { a } 0,251) \\
(0,250 \text { a } 0,384) \\
(0,166 \text { a } 0,286) \\
n=95\end{array}$ & $\begin{array}{l}0,000 \\
0,121 \\
0,599 \\
0,280\end{array}$ & $\begin{array}{c}(0,074 \text { a } 0,168) \\
(0,528 \text { a } 0,670) \\
(0,215 \text { a } 0,345) \\
n=94\end{array}$ \\
\hline Phi 48 & $\begin{array}{l}188 \\
196 \\
220\end{array}$ & $\begin{array}{l}0,000 \\
0,347 \\
0,653\end{array}$ & $\begin{array}{c}(0,279 \text { a } 0,415) \\
(0,585 \text { a } 0,721) \\
n=95\end{array}$ & $\begin{array}{l}0,000 \\
0,431 \\
0,569\end{array}$ & $\begin{array}{c}(0,360 \text { a } 0,502) \\
(0,498 \text { a } 0,640) \\
n=94\end{array}$ \\
\hline Bnlg 238 & $\begin{array}{l}134 \\
150 \\
166 \\
184 \\
194 \\
228\end{array}$ & $\begin{array}{l}0,005 \\
0,147 \\
0,063 \\
0,300 \\
0,347 \\
0,137\end{array}$ & $\begin{array}{l}(-0,005 \text { a } 0,015) \\
(0,097 \text { a } 0,197) \\
(0,028 \text { a } 0,098) \\
(0,235 \text { a } 0,365) \\
(0,279 \text { a } 0,415) \\
(0,088 \text { a } 0,186)\end{array}$ & $\begin{array}{l}0,000 \\
0,101 \\
0,053 \\
0,309 \\
0,138 \\
0,399\end{array}$ & $\begin{array}{c}(0,058 \text { a } 0,144) \\
(0,021 \text { a } 0,085) \\
(0,243 \text { a } 0,375) \\
(0,089 \text { a } 0,187) \\
(0,329 \text { a } 0,469)\end{array}$ \\
\hline
\end{tabular}


Tabela 6. Locos, alelos $(\mathrm{pb})$, freqüências alélicas $\left(\hat{p}_{u}\right)$, intervalo de confiança a $95 \%$ de probabilidade ( $I C_{95 \%}$ ) e tamanho da amostra (n) referente à população BR-106 e ao sintético IG-4 para 30 locos de microssatélites.

\begin{tabular}{|c|c|c|c|c|c|}
\hline \multirow{2}{*}{$\begin{array}{c}\text { Materiais } \\
\text { Locos }\end{array}$} & \multirow[b]{2}{*}{$\begin{array}{c}\text { Alelos } \\
\text { (pb) }\end{array}$} & \multicolumn{2}{|r|}{ BR-106 } & \multicolumn{2}{|c|}{ IG-4 } \\
\hline & & $\hat{p}_{u}$ & $I C_{95 \%}$ & $\hat{p}_{u}$ & $I C_{95 \%}$ \\
\hline & & & $n=91$ & & $n=93$ \\
\hline \multirow[t]{7}{*}{ Bnlg 161} & 120 & 0,000 & - & 0,000 & - \\
\hline & 138 & 0,000 & - & 0,000 & - \\
\hline & 150 & 0,159 & $(0,106$ a 0,212$)$ & 0,086 & $(0,046$ a 0,126$)$ \\
\hline & 168 & 0,214 & $(0,154$ a 0,274$)$ & 0,070 & $(0,033$ a 0,107$)$ \\
\hline & 176 & 0,258 & $(0,194$ a 0,322$)$ & 0,360 & $(0,291$ a 0,429$)$ \\
\hline & 202 & 0,231 & $(0,170$ a 0,292$)$ & 0,091 & $(0,050$ a 0,132$)$ \\
\hline & 224 & 0,137 & $\begin{array}{c}(0,087 \text { a } 0,187) \\
n=96\end{array}$ & 0,392 & $\begin{array}{c}(0,322 \text { a } 0,462) \\
n=95\end{array}$ \\
\hline \multirow[t]{2}{*}{ Phi 70} & 80 & 0,557 & $(0,487$ a 0,627$)$ & 0,526 & $(0,455$ a 0,597$)$ \\
\hline & 90 & 0,443 & $\begin{array}{c}(0,373 \text { a } 0,513) \\
n=96\end{array}$ & 0,474 & $\begin{array}{c}(0,403 \text { a } 0,545) \\
n=96\end{array}$ \\
\hline \multirow[t]{5}{*}{ Bnlg 657} & 84 & 0,094 & $(0,053$ a 0,135$)$ & 0,375 & $(0,307$ a 0,443$)$ \\
\hline & 94 & 0,292 & $(0,228$ a 0,356$)$ & 0,151 & $(0,100$ a 0,202$)$ \\
\hline & 98 & 0,302 & $(0,237$ a 0,367$)$ & 0,120 & $(0,074$ a 0,166$)$ \\
\hline & 104 & 0,214 & $(0,156$ a 0,272$)$ & 0,182 & $(0,127$ a 0,237$)$ \\
\hline & 116 & 0,099 & $\begin{array}{c}(0,057 \text { a } 0,141) \\
n=95\end{array}$ & 0,172 & $\begin{array}{c}(0,119 \text { a } 0,225) \\
n=95\end{array}$ \\
\hline \multirow[t]{6}{*}{ Bnlg 155} & 92 & 0,442 & $(0,371$ a 0,513$)$ & 0,511 & $(0,440$ a 0,582$)$ \\
\hline & 108 & 0,289 & $(0,225$ a 0,353$)$ & 0,000 & - \\
\hline & 120 & 0,084 & $(0,045$ a 0,123$)$ & 0,000 & - \\
\hline & 142 & 0,032 & $(0,007$ a 0,057$)$ & 0,000 & - \\
\hline & 168 & 0,142 & $(0,092$ a 0,192$)$ & 0,484 & $(0,413$ a 0,555$)$ \\
\hline & 188 & 0,011 & $\begin{array}{c}(-0,004 \text { a } 0,026) \\
n=86\end{array}$ & 0,005 & $\begin{array}{c}(-0,005 \text { a } 0,015) \\
n=92\end{array}$ \\
\hline \multirow[t]{3}{*}{ Bnlg 572} & 84 & 0,541 & $(0,467$ a 0,615$)$ & 0,815 & $(0,759$ a 0,871$)$ \\
\hline & 90 & 0,035 & $(0,008$ a 0,062$)$ & 0,011 & $(-0,004$ a 0,026$)$ \\
\hline & 102 & 0,424 & $\begin{array}{c}(0,350 \text { a } 0,498) \\
n=93\end{array}$ & 0,174 & $\begin{array}{c}(0,119 \text { a } 0,229) \\
n=96\end{array}$ \\
\hline \multirow[t]{2}{*}{ Phi 115} & 90 & 0,435 & $(0,364$ a 0,506$)$ & 0,578 & $(0,508$ a 0,648$)$ \\
\hline & 120 & 0,565 & $\begin{array}{c}(0,494 \text { a } 0,636) \\
n=94\end{array}$ & 0,422 & $\begin{array}{c}(0,352 \text { a } 0,492) \\
n=92\end{array}$ \\
\hline \multirow[t]{7}{*}{ Bnlg 669} & 108 & 0,559 & $(0,488$ a 0,630$)$ & 0,826 & $(0,771$ a 0,881$)$ \\
\hline & 114 & 0,043 & $(0,014$ a 0,072$)$ & 0,000 & - \\
\hline & 128 & 0,011 & $(-0,004$ a 0,026$)$ & 0,043 & $(0,014$ a 0,072$)$ \\
\hline & 144 & 0,005 & $(-0,005$ a 0,015$)$ & 0,000 & - \\
\hline & 160 & 0,261 & $(0,198$ a 0,324$)$ & 0,016 & $(-0,002$ a 0,034$)$ \\
\hline & 180 & 0,021 & $(0,001$ a 0,041$)$ & 0,000 & - \\
\hline & 200 & 0,101 & $\begin{array}{c}(0,058 \text { a } 0,144) \\
n=95\end{array}$ & 0,114 & $\begin{array}{c}(0,068 \text { a } 0,160) \\
n=95\end{array}$ \\
\hline \multirow[t]{5}{*}{ Bnlg 666} & 84 & 0,632 & $(0,563$ a 0,701$)$ & 0,274 & $(0,211$ a 0,337$)$ \\
\hline & 126 & 0,100 & $(0,057$ a 0,143$)$ & 0,205 & $(0,148$ a 0,262$)$ \\
\hline & 138 & 0,111 & $(0,066$ a 0,156$)$ & 0,095 & $(0,053$ a 0,137$)$ \\
\hline & 166 & 0,158 & $(0,106$ a 0,210$)$ & 0,426 & $(0,356$ a 0,496$)$ \\
\hline & 186 & 0,000 & - & 0,000 & - \\
\hline
\end{tabular}


Tabela 6. Locos, alelos $(\mathrm{pb})$, freqüências alélicas $\left(\hat{p}_{u}\right)$, intervalo de confiança a $95 \%$ de probabilidade ( $I C_{95 \%}$ ) e tamanho da amostra (n) referente à população BR-106 e ao sintético IG-4 para 30 locos de microssatélites.

\begin{tabular}{|c|c|c|c|c|c|}
\hline \multirow{2}{*}{$\begin{array}{c}\text { Materiais } \\
\text { Locos }\end{array}$} & \multirow[b]{2}{*}{$\begin{array}{c}\text { Alelos } \\
\text { (pb) }\end{array}$} & \multicolumn{2}{|r|}{ BR-106 } & \multicolumn{2}{|c|}{ IG-4 } \\
\hline & & $\hat{p}_{u}$ & $I C_{95 \%}$ & $\hat{p}_{u}$ & $I C_{95 \%}$ \\
\hline \multirow{4}{*}{ Bnlg 240} & & & $\begin{array}{c}n=96 \\
047\end{array}$ & & 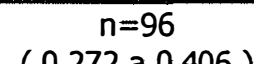 \\
\hline & $\begin{array}{l}112 \\
126\end{array}$ & $\begin{array}{l}0,313 \\
0,042\end{array}$ & $\begin{array}{l}(0,247 \text { a } 0,379) \\
(0,014 \text { a } 0,070)\end{array}$ & $\begin{array}{l}0,339 \\
0,031\end{array}$ & $\begin{array}{l}(0,2 / 2 \text { a } 0,406) \\
(0,006 \text { a } 0.056)\end{array}$ \\
\hline & 140 & 0,375 & $(0,307$ a 0,443$)$ & 0,557 & $(0,487$ a 0,627$)$ \\
\hline & 158 & 0,271 & $\begin{array}{c}(0,208 \text { a } 0,334) \\
n=96\end{array}$ & 0,073 & $\begin{array}{c}(0,036 \text { a } 0,110) \\
n=96\end{array}$ \\
\hline \multirow[t]{2}{*}{ МАСТО2В08 } & 95 & 0,635 & $(0,567$ a 0,703$)$ & 0,578 & $(0,508$ a 0,648$)$ \\
\hline & 125 & 0,365 & $\begin{array}{c}(0,297 \text { a } 0,433) \\
n=91\end{array}$ & 0,422 & $\begin{array}{c}(0,352 \text { a } 0,492) \\
n=96\end{array}$ \\
\hline \multirow[t]{2}{*}{ Phi 65} & 130 & 0,626 & $(0,556$ a 0,696$)$ & 0,646 & $(0,578$ a 0,714$)$ \\
\hline & 150 & 0,374 & $(0,304$ a 0,444$)$ & 0,354 & $(0,286$ a 0,422$)$ \\
\hline \multirow{5}{*}{ Bnlg 127} & & & $n=91$ & & $n=90$ \\
\hline & 240 & 0,434 & $(0,362$ a 0,506$)$ & 0,433 & $(0,361$ a 0,505$)$ \\
\hline & 252 & 0,346 & $(0,277$ a 0,415$)$ & 0,567 & $(0,495$ a 0,639$)$ \\
\hline & 264 & 0,198 & $(0,140$ a 0,256$)$ & 0,000 & - \\
\hline & 276 & 0,022 & $\begin{array}{c}(0,001 \text { a } 0,043) \\
n=95\end{array}$ & 0,000 & $\begin{array}{c}- \\
n=96\end{array}$ \\
\hline \multirow[t]{2}{*}{ Bnlg 292} & 120 & 0,921 & $(0,883$ a 0,959$)$ & 1,000 & - \\
\hline & 152 & 0,079 & $\begin{array}{c}(0,041 \text { a } 0,117) \\
n=96\end{array}$ & 0,000 & $\begin{array}{c}- \\
n=90\end{array}$ \\
\hline \multirow[t]{3}{*}{ Phi 059} & 144 & 0,031 & $(0,006$ a 0,056$)$ & 0,000 & - \\
\hline & 162 & 0,318 & $(0,252$ a 0,384$)$ & 0,211 & $(0,151$ a 0,271$)$ \\
\hline & 171 & 0,651 & $\begin{array}{c}(0,584 \text { a } 0,718) \\
n=95\end{array}$ & 0,789 & $\begin{array}{c}(0,729 \text { a } 0,849) \\
n=92\end{array}$ \\
\hline \multirow[t]{3}{*}{ Phi 84} & 150 & 0,705 & $(0,640$ a 0,770$)$ & 0,598 & $(0,527$ a 0,669$)$ \\
\hline & 171 & 0,284 & $(0,220$ a 0,348$)$ & 0,342 & $(0,273$ a 0,411$)$ \\
\hline & 198 & 0,011 & $(-0,004$ a 0,026$)$ & 0,060 & $(0,026$ a 0,094$)$ \\
\hline (TA) & & (116) & & (96) & \\
\hline
\end{tabular}

*TA: número total de alelos 
A)

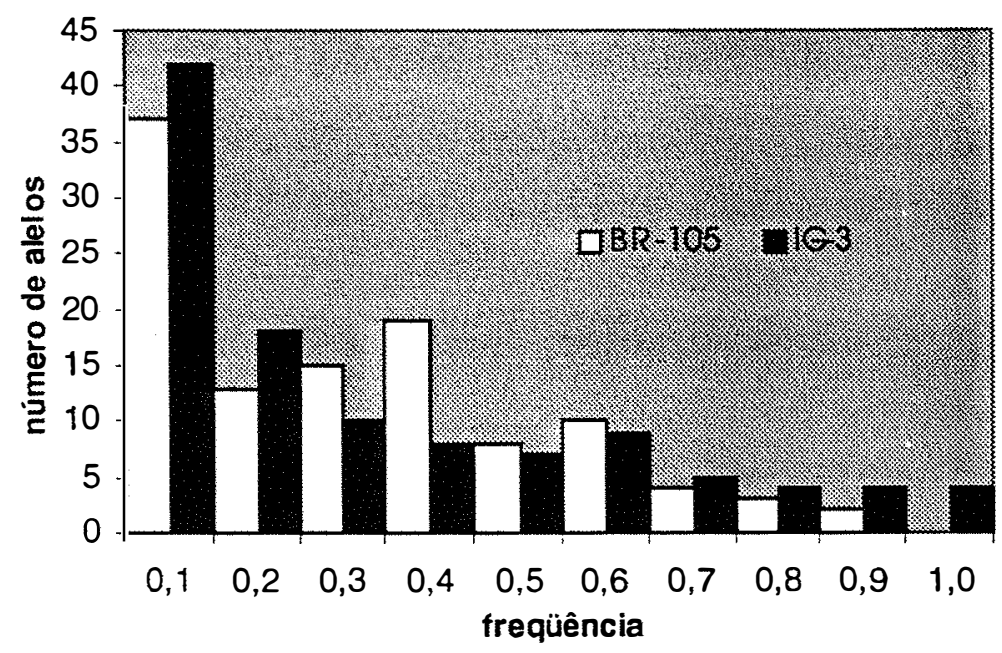

B)

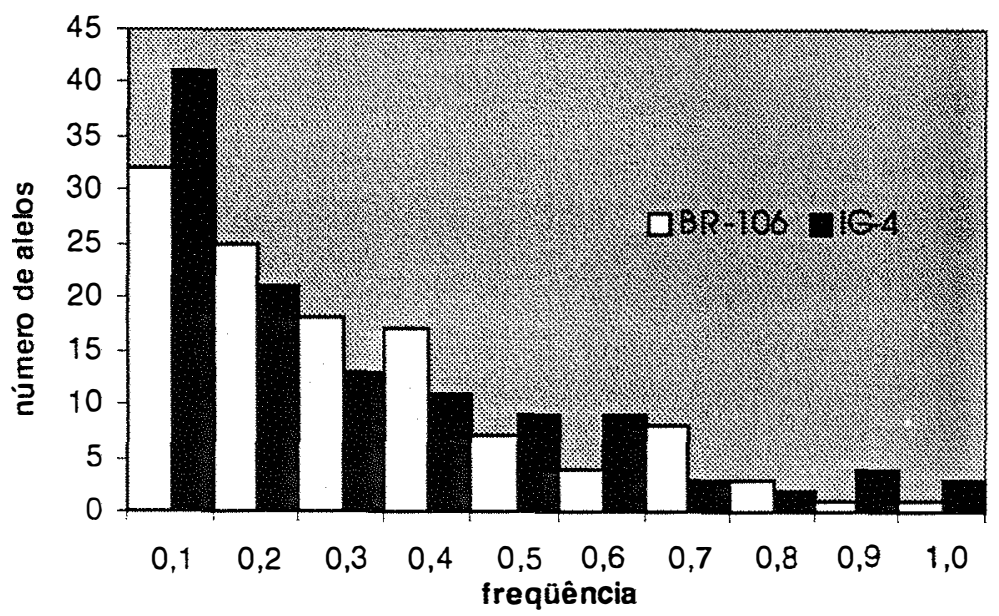

Figura 8 - Distribuição das freqüências alélicas na população BR-105 e respectivo sintético IG-3 (A) e na população BR-106 e respectivo sintético IG-4 (B). 
De acordo com Grossa (1989), o tamanho da amostra depende da freqüência do alelo ou genótipo menos comum. Genótipos ou alelos que ocorrem em freqüências maiores que $10 \%$ podem ser preservados com um tamanho de amostra de 40 indivíduos. Amostras de 100 indivíduos preservam alelos que ocorrem a freqüências de $5 \%$. Por outro lado, se a freqüência de alelos raros for menor que $5 \%$, amostras bem maiores são requeridas. Amostras de 300 a 400 indivíduos são necessárias quando se deseja preservar alelos com freqüência de $1 \%$.

Com base no intervalo de confiança a $95 \%$ de probabilidade, foram constatados diferenças significativas nas freqüências alélicas entre as populações originais e os sintéticos, da ordem de $67 \%$ entre BR-105 e IG3 e $51 \%$ entre BR-106 e IG-4 (Tabelas 5 e 6).

Nas populações foi observado um alto índice de alelos exclusivos ( 23 alelos), isto é, alelos característicos, encontrados em apenas uma população (Tabela 7). Destes, $14(61 \%)$ foram exclusivos à BR-106. Cerca de $61 \%$ apresentaram frequências baixas, menores que $0,100,0$ que contribui para que estes alelos se tornem alvo dos efeitos da deriva. Nos sintéticos foram observados 30 alelos exclusivos, dos quais $33 \%$ estavam presentes em IG-3 e $67 \%$ em IG-4. Do total, $43 \%$ apresentaram freqüências menores que 0,100 .

Comparando o número de alelos exclusivos encontrados nas populações e respectivos sintéticos (Tabela 8), nota-se um número maior para a BR-105 e IG-3 (25 alelos), em relação a BR-106 e IG-4 (20 alelos).

Os testes de diferenciação das freqüências alélicas entre as populações, e entre os sintéticos (Tabela 9) e entre as populações originais e respectivos sintéticos (Tabela 10) mostraram que a hipótese sob teste, isto é, de que a distribuição das freqüências dos alelos é idêntica nas populações, foi rejeitada $(P<0,05)$ para a maioria dos 30 locos de microssatélites. Analisando os locos em conjunto, a distribuição das freqüências dos alelos entre os grupos comparados foi altamente significativa, evidenciando que as populações são geneticamente diferentes quanto a este aspecto. 
Tabela 7. Alelos exclusivos e freqüência com que ocorrem nas populações e nos sintéticos.

\begin{tabular}{|c|c|c|c|}
\hline Loco & Alelo (pb) & Frequiência & Poopulaçōes \\
\hline \multicolumn{4}{|c|}{ BR-105 e BR-106 } \\
\hline Bnlg 589 & 232 & 0,090 & BR-105 \\
\hline Phi 48 & 188 & 0,033 & $B R-105$ \\
\hline MTTGBO2 & 165 & 0,111 & BR-105 \\
\hline MTTGBO2 & 195 & 0,089 & BR-105 \\
\hline MAGEO5 & 126 & 0,005 & BR-105 \\
\hline Bnig 161 & 138 & 0,063 & BR-105 \\
\hline Bnlg 161 & 120 & 0,353 & BR-105 \\
\hline Bnlg 176 & 244 & 0,027 & BR-105 \\
\hline Bnlg 666 & 186 & 0,038 & BR-105 \\
\hline Bnlg 197 & 108 & 0,089 & BR-106 \\
\hline Bnlg 197 & 132 & 0,016 & BR-106 \\
\hline Bnlg 197 & 98 & 0,179 & $B R-106$ \\
\hline Bnlg 108 & 116 & 0,010 & BR-106 \\
\hline Bnlg 131 & 60 & 0,368 & BR-106 \\
\hline Phi 59 & 144 & 0,031 & BR-106 \\
\hline Bnig 161 & 224 & 0,137 & BR-106 \\
\hline Bnlg 143 & 280 & 0,305 & BR-106 \\
\hline Bnlg 127 & 276 & 0,022 & BR-106 \\
\hline Bnlg 127 & 264 & 0,198 & BR-106 \\
\hline Bnlg 657 & 84 & 0,094 & BR-106 \\
\hline Bnlg 669 & 180 & 0,021 & BR-106 \\
\hline Bnlg 589 & 210 & 0,274 & BR-106 \\
\hline Bnlg 589 & 161 & 0,321 & BR-106 \\
\hline \multicolumn{4}{|c|}{ IG-3 e IG-4 } \\
\hline Bnlg 155 & 120 & 0,161 & IG-3 \\
\hline Bnlg 155 & 142 & 0,177 & IG-3 \\
\hline Bnig 589 & 232 & 0,104 & IG-3 \\
\hline Phi 001 & 102 & 0,027 & IG-3 \\
\hline Bnlg 238 & 134 & 0,042 & IG-3 \\
\hline Bnlg 292 & 152 & 0,016 & IG-3 \\
\hline Bnlg 131 & 96 & 0,053 & IG-3 \\
\hline Bnlg 161 & 138 & 0,048 & IG-3 \\
\hline Bnlg 143 & 256 & 0,537 & IG-3 \\
\hline Phi 113 & 96 & 0,125 & IG-3 \\
\hline Bnlg 669 & 160 & 0,016 & IG-4 \\
\hline Bnlg 155 & 188 & 0,005 & IG-4 \\
\hline Bnlg 589 & 210 & 0,146 & IG-4 \\
\hline Bnlg 125 & 258 & 0,218 & IG-4 \\
\hline Bnlg 125 & 294 & 0,122 & IG-4 \\
\hline Phi 001 & 130 & 0,075 & IG-4 \\
\hline Phi 001 & 154 & 0,446 & IG-4 \\
\hline Phi 001 & 86 & 0,075 & IG-4 \\
\hline Bnlg 238 & 150 & 0,101 & IG-4 \\
\hline Bnlg 109 & 438 & 0,261 & IG-4 \\
\hline Bnlg 109 & 632 & 0,101 & IG-4 \\
\hline Bnlg 197 & 98 & 0,005 & IG-4 \\
\hline Bnlg 108 & 78 & 0,271 & IG-4 \\
\hline Bnlg 176 & 134 & 0,005 & IG-4 \\
\hline Bnlg 131 & 60 & 0,651 & IG-4 \\
\hline Bnlg 161 & 224 & 0,392 & IG-4 \\
\hline Bnlg 161 & 202 & 0,091 & IG-4 \\
\hline Bnlg 143 & 280 & 0,142 & IG-4 \\
\hline Bnlg 240 & 158 & 0,073 & IG-4 \\
\hline Bnlg 657 & 84 & 0,375 & IG-4 \\
\hline
\end{tabular}


Tabela 8. Alelos exclusivos e freqüência com que ocorrem nas populações originais e respectivos sintéticos.

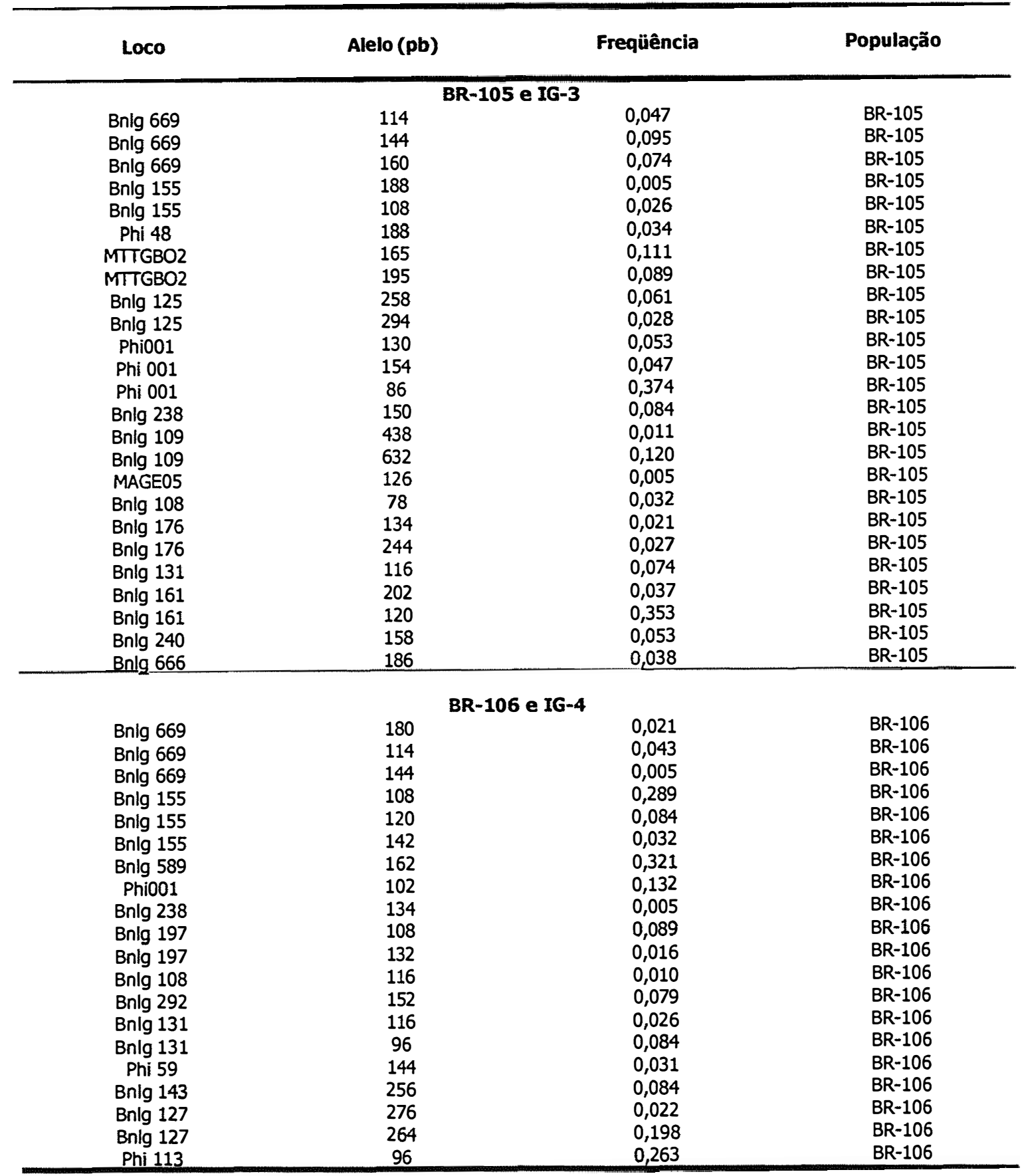


Tabela 9. Diferenciação das freqüências alélicas por loco, entre as populações BR-105 e BR-106 e entre os sintéticos IG-3 e IG-4. $\chi^{2}$ para grupos com graus de liberdade $(\mathrm{gl})$ e desvio padrão.

BR-105 e BR-106

IG-3 e IG-4

\begin{tabular}{|c|c|c|c|c|}
\hline Loco & $\begin{array}{c}\text { Probabilidade } \\
\text { Exata }\end{array}$ & $\begin{array}{l}\text { Desvio } \\
\text { Padrão }\end{array}$ & $\begin{array}{c}\text { Probabilidade } \\
\text { Exata }\end{array}$ & $\begin{array}{l}\text { Desvio } \\
\text { padrão }\end{array}$ \\
\hline Bnlg 109 & 0,000 & 0,000 & 0,000 & 0,000 \\
\hline Phi 001 & 0,000 & 0,000 & 0,000 & 0,000 \\
\hline Bnlg 176 & 0,000 & 0,000 & 0,622 & 0,003 \\
\hline Bnlg 131 & 0,000 & 0,000 & 0,000 & 0,000 \\
\hline Bnlg 125 & 0,000 & 0,000 & 0,000 & 0,000 \\
\hline Bnlg 108 & 0,000 & 0,000 & 0,000 & 0,000 \\
\hline MAGE05 & 0,000 & 0,000 & 0,000 & 0,000 \\
\hline Bnlg 602 & 0,036 & 0,005 & 0,000 & 0,000 \\
\hline Bnlg 197 & 0,000 & 0,000 & 0,057 & 0,007 \\
\hline MTTGBO2 & 0,000 & 0,000 & 0,000 & 0,000 \\
\hline Bnlg 589 & 0,000 & 0,000 & 0,000 & 0,000 \\
\hline Bnlg 143 & 0,000 & 0,000 & 0,000 & 0,000 \\
\hline Phi 113 & 0,000 & 0,000 & 0,000 & 0,000 \\
\hline Phi 48 & 0,000 & 0,000 & 0,042 & 0,005 \\
\hline Bnlg 238 & 0,000 & 0,000 & 0,000 & 0,000 \\
\hline Bnlg 161 & 0,000 & 0,000 & 0,000 & 0,000 \\
\hline Phi 70 & 0,912 & 0,003 & 0,085 & 0,007 \\
\hline Bnlg 657 & 0,000 & 0,000 & 0,000 & 0,000 \\
\hline Bnlg 155 & 0,000 & 0,000 & 0,198 & 0,008 \\
\hline Bnlg 572 & 0,000 & 0,000 & 0,000 & 0,000 \\
\hline Phi 115 & 0,180 & 0,010 & 0,034 & 0,005 \\
\hline Bnlg 669 & 0,000 & 0,000 & 0,000 & 0,000 \\
\hline Bnlg 666 & 0,000 & 0,000 & 0,839 & 0,008 \\
\hline Bnlg 240 & 0,000 & 0,000 & 0,000 & 0,000 \\
\hline MACTO2BO8 & 0,089 & 0,006 & 0,000 & 0,000 \\
\hline Phi 65 & 0,000 & 0,000 & 0,000 & 0,000 \\
\hline Bnlg 127 & 0,000 & 0,000 & 0,000 & 0,000 \\
\hline Bnlg 292 & 0,000 & 0,000 & 0,123 & 0,002 \\
\hline Phi 059 & 0,052 & 0,006 & 0,000 & 0,000 \\
\hline Phi 84 & 0,209 & 0,009 & 0,000 & 0,000 \\
\hline $\begin{array}{c}\text { Grupo } \\
\text { gl } \\
\chi^{2}\end{array}$ & $\begin{array}{c}0,000 \\
60 \\
539,87\end{array}$ & & $\begin{array}{c}0,000 \\
60 \\
515,24\end{array}$ & \\
\hline
\end{tabular}


Tabela 10. Diferenciação das freqüências alélicas por loco, entre as populações e entre os sintéticos. $\chi^{2}$ para grupos com graus de liberdade $(g l) e$ desvio padrão.

BR-105 e IG-3

BR-106 e IG-4

\begin{tabular}{|c|c|c|c|c|}
\hline Loco & $\begin{array}{c}\text { Probabilidade } \\
\text { exata }\end{array}$ & $\begin{array}{l}\text { Desvio } \\
\text { Padrão }\end{array}$ & $\begin{array}{c}\text { Probabilidade } \\
\text { exata }\end{array}$ & $\begin{array}{l}\text { Desvio } \\
\text { Padrão }\end{array}$ \\
\hline Bnlg 109 & 0,000 & 0,000 & 0,000 & 0,000 \\
\hline Phi 001 & 0,000 & 0,000 & 0,000 & 0,000 \\
\hline Bnlg 176 & 0,000 & 0,000 & 0,000 & 0,000 \\
\hline Bnlg 131 & 0,000 & 0,000 & 0,000 & 0,000 \\
\hline Bnlg 125 & 0,000 & 0,000 & 0,000 & 0,000 \\
\hline Bnlg 108 & 0,000 & 0,000 & 0,267 & 0,013 \\
\hline MAGE05 & 0,000 & 0,000 & 0,201 & 0,010 \\
\hline Bnlg 602 & 0,000 & 0,000 & 0,007 & 0,003 \\
\hline Bnlg 197 & 0,000 & 0,000 & 0,000 & 0,000 \\
\hline MTTGBO2 & 0,000 & 0,000 & 0,000 & 0,000 \\
\hline Bnlg 589 & 0,000 & 0,000 & 0,000 & 0,000 \\
\hline Bnig 143 & 0,000 & 0,000 & 0,000 & 0,000 \\
\hline Phi 113 & 0,000 & 0,000 & 0,000 & 0,000 \\
\hline Phi 48 & 0,000 & 0,000 & 0,115 & 0,009 \\
\hline Bnlg 238 & 0,000 & 0,000 & 0,000 & 0,000 \\
\hline Bnlg 161 & 0,000 & 0,000 & 0,000 & 0,000 \\
\hline Phi 70 & 0,185 & 0,010 & 0,603 & 0,009 \\
\hline Bnlg 657 & 0,000 & 0,000 & 0,000 & 0,000 \\
\hline Bnlg 155 & 0,000 & 0,000 & 0,000 & 0,000 \\
\hline Bnlg 572 & 0,000 & 0,000 & 0,000 & 0,000 \\
\hline Phi 115 & 0,394 & 0,012 & 0,005 & 0,001 \\
\hline Bnlg 669 & 0,000 & 0,000 & 0,000 & 0,000 \\
\hline Bnlg 666 & 0,003 & 0,000 & 0,000 & 0,000 \\
\hline Bnlg 240 & 0,005 & 0,001 & 0,000 & 0,000 \\
\hline МАCTO2BO8 & 0,000 & 0,000 & 0,287 & 0,012 \\
\hline Phi 65 & 0,000 & 0,000 & 0,749 & 0,006 \\
\hline Bnlg 127 & 0,000 & 0,000 & 0,000 & 0,000 \\
\hline Bnlg 292 & 0,000 & 0,000 & 0,000 & 0,000 \\
\hline Phi 059 & 0,149 & 0,008 & 0,001 & 0,000 \\
\hline Phi 84 & 0,000 & 0,000 & 0,008 & 0,002 \\
\hline Grupo & 0,000 & & 0,000 & \\
\hline Gl & 60 & & 60 & \\
\hline$\chi^{2}$ & 561,01 & & 489,74 & \\
\hline
\end{tabular}


Pelo exposto, em relação aos testes exatos de diferenciação de freqüências alélicas e ao número de alelos exclusivos, verifica-se que, embora as populações compartilhem a maior parte dos alelos, existe uma divergência significativa nas freqüências alélicas, como também há um número expressivo de alelos característicos de cada população.

A variabilidade dos sintéticos IG-3 e IG-4 é estreitamente dependente da amostra de alelos trazida, respectivamente, pelas 8 e 10 linhagens $S_{3}$ (fundadoras) extraídas das populações. Este efeito fundador, contribuiu para à significância das diferenças entre as freqüências alélicas nas populações originais e para àquelas encontradas nos sintéticos recém-formados. A perda de alelos, juntamente com as alterações nas freqüências alélicas, contribuíram para aumentar a divergência genética entre os sintéticos.

\section{2.b Número médio de alelos por loco, porcentagem de locos polimórficos e número efetivo de alelos}

Na Tabela 11 são apresentados o tamanho médio da amostra por loco, o número médio de alelos por loco, o número efetivo de alelos e a porcentagem de locos polimórficos (sob os critérios de 95, 99 e 100\%)

Tabela 11. Variabilidade genética em 30 locos de microssatélites presentes nas Populações BR-105 e BR-106 e nos sintéticos IG-3 e IG-4.

\begin{tabular}{ccccrrrr} 
Materiais & $\begin{array}{c}\text { Tamanho } \\
\text { médio } \\
\text { da amostra } \\
\text { por loco }\end{array}$ & $\begin{array}{c}\text { Número médio } \\
\text { de } \\
\text { alelos por } \\
\text { loco }\end{array}$ & $\begin{array}{c}\text { Número } \\
\text { efetivo } \\
\text { de alelos }\end{array}$ & \multicolumn{2}{c}{$\begin{array}{c}\text { Porcentagem de } \\
\text { locos polimórficos }\end{array}$} \\
\hline BR-105 & 93,5 & $3,70 \pm 0,26$ & 2,28 & 100,00 & 100,00 & 100,00 \\
IG-3 & 93,8 & $2,90 \pm 0,16$ & 1,78 & 90,00 & 96,70 & 100,00 \\
BR-106 & 93,9 & $3,90 \pm 0,27$ & 2,33 & 100,00 & 100,00 & 100,00 \\
IG-4 & 93,5 & $3,20 \pm 0,21$ & 1,96 & 93,3 & 96,70 & 96,70 \\
\hline
\end{tabular}


Em média, para cada loco, foram genotipados cerca de 93 indivíduos tanto nas populações como nos sintéticos, tornando comparáveis os valores das estimativas do número médio de alelos por loco. Amostras de tamanhos semelhantes fornecem comparações mais confiáveis em relação a determinados índices de diversidade, como por exemplo, o número médio de alelos por loco. Este, é influenciado pelo tamanho da amostra, e não representa uma medida satisfatória de variabilidade genética na comparação de amostras de tamanhos diferentes (Nei, 1987). Na estimativa do número médio de alelos por loco foram considerados tanto os locos monomórficos como os polimórficos. Os valores desta estimativa não se mostraram significativamente diferentes entre as populações BR-105 $(3,70 \pm 0,26)$ e BR-106 $(3,90 \pm 0,27)$. Entretanto, considerando-se populações e respectivos sintéticos houve uma redução no número médio de alelos por loco, a qual foi bem mais pronunciada para o sintético IG-3 $(2,90 \pm 0,16)$ do que para o sintético IG-4 $(3,20 \pm 0,21)$. Isto indica que a população BR-105, em média, sofreu uma perda maior de alelos.

As populações apresentaram praticamente o mesmo valor para o número efetivo de alelos por loco, respectivamente de 2,28 e 2,33. A redução do número efetivo de alelos por loco também foi mais pronunciada sobre a BR-105 em relação à BR-106 proporcionando os valores de 1,78 e 1,96 para os sintéticos IG-3 e IG-4, respectivamente.

De maneira geral, tanto as populações como os sintéticos mostraram-se altamente polimórficos sob os três critérios avaliados (95, 99 e 100\%). Pequenas reduções dos níveis de polimorfismo foram observados nos sintéticos, mais notadamente sob o critétio de 0,95 sob o qual a freqüência do alelo mais comum não pode exceder $95 \%$. 
4.2.c Heterozigosidade observada ( $H o$ ), esperada ( $\hat{H} e$ ) e aderência às proporções de Hardy-Weinberg

Na Tabela 12 estão apresentadas as heterozigosidades observadas e esperadas (diversidade gênica), bem como o índice de fixação de Wright $(\hat{f})$ estimados para quantificar o excesso ou deficiência de homozigotos, respectivamente, nas populações e sintéticos. Os intervalos de confiança a $95 \%$ de probabilidade referentes às heterozigosidade observadas para cada loco encontra-se no anexo $A$.

Excluindo-se os locos fixados, os valores das heterozigosidades observadas variaram de 0,01 para o loco Bnlg 176 (IG-3) a 0,84 no loco Bnlg 125 (IG-4). Em relação às heterozigosidades esperadas, foram observados valores de 0,01 para o loco Bnlg 176 (IG-3) a 0,815 no loco Phi 001 (BR-106). Para os índices de fixação, foram encontrados tanto valores positivos $(\hat{f}>0)$ como negativos $(\hat{f}<0)$. Aproximadamente, $17 \%$ dos locos avaliados mostraram valores negativos para o índice de fixação $(\hat{f}<0)$ na população BR-105, e 33\% para o sintético IG-3. Na população BR-106, 20\% dos locos apresentaram valores negativos para o índice de fixação, enquanto no sintético IG-4, 43\% dos locos apresentaram valores negativos. No geral, para os 30 locos avaliados, foi observado excesso de homozigotos $(\hat{f}>0,05)$. Valores bem elevados quanto ao excesso de homozigotos foram observados na população BR-106 e no sintético IG-4 no (loco Bnlg 572), respectivamente, iguais a 0,44 e 0,43. Este mesmo loco, na população BR-105 e no sintético IG-3 revelou índices de fixação com valores mais baixos, respectivamente iguais a 0,12 e 0,05. 
Tabela 12. Heterozigosidade observada ( $H o$ ), esperada ( $\hat{H} e)$ e índice de fixação de Wright $(\hat{f})$ para 30 locos de microssatélites.

\begin{tabular}{|c|c|c|c|c|c|c|c|c|}
\hline \multirow{3}{*}{$\begin{array}{c}\text { Materiais } \\
\text { Loco }\end{array}$} & \multicolumn{2}{|c|}{ BR-105 } & \multicolumn{2}{|c|}{ IG-3 } & \multicolumn{2}{|c|}{ BR-106 } & \multicolumn{2}{|c|}{ IG-4 } \\
\hline & Ho & $\hat{f}$ & Ho & $\hat{f}$ & Ho & & Ho & $\hat{f}$ \\
\hline & $\hat{H} e$ & & $\hat{H} e$ & & $\hat{H} e$ & & $\hat{H} e$ & \\
\hline \multirow[t]{2}{*}{ Bnlg109 } & 0,522 & 0,13 & 0,587 & $-0,18$ & 0,411 & 0,18 & 0,691 & 0,04 \\
\hline & 0,601 & & 0,494 & & 0,504 & & 0,717 & \\
\hline Phi001 & $\begin{array}{l}0,558 \\
0,718\end{array}$ & 0,22 & $\begin{array}{l}0,402 \\
0,395\end{array}$ & $-0,01$ & $\begin{array}{l}0,759 \\
0,815\end{array}$ & 0,07 & $\begin{array}{l}0,677 \\
0,711\end{array}$ & 0,05 \\
\hline \multirow[t]{2}{*}{ Bnig176 } & 0,468 & 0,02 & 0,010 & 0,00 & 0,292 & $-0,15$ & 0,031 & 0,00 \\
\hline & 0,477 & & 0,010 & & 0,253 & & 0,031 & \\
\hline \multirow[t]{2}{*}{ Bnlg131 } & 0,585 & 0,17 & 0,500 & 0,07 & 0,600 & 0,21 & 0,344 & 0,36 \\
\hline & 0,703 & & 0,541 & & 0,768 & & 0,538 & \\
\hline \multirow[t]{2}{*}{ Bnlg125 } & 0,622 & 0,12 & 0,500 & 0,17 & 0,617 & 0,02 & 0,840 & $-0,08$ \\
\hline & 0,707 & & 0,605 & & 0,635 & & 0,775 & \\
\hline \multirow[t]{2}{*}{ Bnlg108 } & 0,263 & 0,12 & 0,095 & 0,13 & 0,750 & $-0,16$ & 0,656 & 0,01 \\
\hline & 0,298 & & 0,110 & & 0,645 & & 0,662 & \\
\hline \multirow[t]{2}{*}{ MAGE05 } & 0,432 & 0,15 & 0,242 & 0,12 & 0,274 & 0,25 & 0,264 & 0,13 \\
\hline & 0,506 & & 0,275 & & 0,369 & & 0,306 & \\
\hline \multirow[t]{2}{*}{ Bnlg602 } & 0,634 & 0,02 & 0,407 & 0,085 & 0,750 & $-0,04$ & 0,831 & $-0,11$ \\
\hline & 0,645 & & 0,445 & & 0,718 & & 0,745 & \\
\hline \multirow[t]{2}{*}{ Bnlg197 } & 0,527 & 0,17 & 0,247 & 0,14 & 0,432 & 0,15 & 0,181 & $-0,07$ \\
\hline & 0,635 & & 0,286 & & 0,508 & & 0,168 & \\
\hline \multirow[t]{2}{*}{ MTTGBO2 } & 0,800 & $-0,04$ & 0,579 & 0,01 & 0,394 & 0,09 & 0,417 & $-0,05$ \\
\hline & 0.766 & & 0,587 & & 0,434 & & 0,396 & \\
\hline \multirow[t]{2}{*}{ Bnlg 589} & 0,511 & 0,10 & 0,323 & $-0,10$ & 0,611 & 0,17 & 0,344 & 0,30 \\
\hline & 0,568 & & 0,292 & & 0,743 & & 0,497 & \\
\hline \multirow[t]{2}{*}{ Bnlg143 } & 0,347 & 0,18 & 0,415 & 0,17 & 0,547 & $-0,03$ & 0,259 & $-0,06$ \\
\hline & 0,422 & & 0,500 & & 0,530 & & 0,245 & \\
\hline \multirow[t]{2}{*}{ Phi113 } & 0,674 & 0,02 & 0,500 & 0,05 & 0,699 & 0,06 & 0,549 & 0,00 \\
\hline & 0,690 & & 0,526 & & 0,746 & & 0,551 & \\
\hline \multirow[t]{2}{*}{ Phi48 } & 0,303 & 0,03 & 0,505 & $-0,01$ & 0,442 & 0,03 & 0,457 & 0,07 \\
\hline & 0,314 & & 0,500 & & 0,456 & & 0,493 & \\
\hline \multirow[t]{2}{*}{ Bnlg238 } & 0,663 & 0,07 & 0,558 & $-0,04$ & 0,716 & 0,04 & 0,628 & 0,12 \\
\hline & 0,714 & & 0,535 & & 0,749 & & 0,717 & \\
\hline \multirow[t]{2}{*}{ Bnlg161 } & 0,642 & 0,10 & 0,617 & 0,03 & 0,670 & 0,15 & 0,602 & 0,13 \\
\hline & 0,715 & & 0,635 & & 0,794 & & 0,699 & \\
\hline
\end{tabular}


Tabela 12. Heterozigosidade observada ( $H o$ ), esperada $(\hat{H} e)$ e índice de fixação de Wright $(\hat{f})$ para 30 locos de microssatélites.

\begin{tabular}{|c|c|c|c|c|c|c|c|c|}
\hline \multirow{2}{*}{$\begin{array}{c}\text { Materiais } \\
\text { Loco }\end{array}$} & \multicolumn{2}{|c|}{ BR-105 } & \multicolumn{2}{|c|}{ IG-3 } & \multicolumn{2}{|c|}{ BR-106 } & \multicolumn{2}{|c|}{ IG-4 } \\
\hline & $\begin{array}{l}\text { Ho } \\
\hat{H} e\end{array}$ & $\hat{f}$ & $\begin{array}{l}H o \\
\hat{H} e\end{array}$ & $\hat{f}$ & $\begin{array}{l}H o \\
\hat{H} e\end{array}$ & $\hat{f}$ & $\begin{array}{l}H o \\
\hat{H} e\end{array}$ & $\hat{f}$ \\
\hline Phi70 & $\begin{array}{l}0,430 \\
0,498\end{array}$ & 0,14 & $\begin{array}{l}0,419 \\
0,475\end{array}$ & 0,17 & $\begin{array}{l}0,406 \\
0,496\end{array}$ & 0,18 & $\begin{array}{l}0,421 \\
0,501\end{array}$ & 0,16 \\
\hline Bnlg657 & $\begin{array}{l}0,511 \\
0,656\end{array}$ & 0,22 & $\begin{array}{l}0,755 \\
0,745\end{array}$ & $-0,01$ & $\begin{array}{l}0,677 \\
0,763\end{array}$ & 0,11 & $\begin{array}{l}0,740 \\
0,763\end{array}$ & 0,03 \\
\hline Bnlg155 & $\begin{array}{l}0 ; 284 \\
0,403\end{array}$ & 0,29 & $\begin{array}{l}0,667 \\
0,711\end{array}$ & 0,06 & $\begin{array}{l}0,653 \\
0,696\end{array}$ & 0,06 & $\begin{array}{l}0,516 \\
0,508\end{array}$ & $-0,01$ \\
\hline Bnlg572 & $\begin{array}{l}0,578 \\
0,659\end{array}$ & 0,12 & $\begin{array}{l}0,547 \\
0,579\end{array}$ & 0,05 & $\begin{array}{l}0,291 \\
0,529\end{array}$ & 0,44 & $\begin{array}{l}0,174 \\
0,307\end{array}$ & 0,43 \\
\hline Phi115 & $\begin{array}{l}0,547 \\
0,503\end{array}$ & $-0,08$ & $\begin{array}{l}0,473 \\
0,500\end{array}$ & 0,05 & $\begin{array}{l}0,462 \\
0,494\end{array}$ & 0,06 & $\begin{array}{l}0,510 \\
0,490\end{array}$ & $-0,04$ \\
\hline Bnlg669 & $\begin{array}{l}0,516 \\
0,687\end{array}$ & 0,25 & $\begin{array}{l}0,260 \\
0,317\end{array}$ & 0,18 & $\begin{array}{l}0,468 \\
0,611\end{array}$ & 0,23 & $\begin{array}{l}0,326 \\
0,304\end{array}$ & $-0,07$ \\
\hline Bnlg666 & $\begin{array}{l}0,707 \\
0,742\end{array}$ & 0,05 & $\begin{array}{l}0,710 \\
0,706\end{array}$ & $-0,005$ & $\begin{array}{l}0,442 \\
0,557\end{array}$ & 0,20 & $\begin{array}{l}0,705 \\
0,696\end{array}$ & $-0,013$ \\
\hline Bnlg240 & $\begin{array}{l}0,495 \\
0,614\end{array}$ & 0,19 & $\begin{array}{l}0,505 \\
0,553\end{array}$ & 0,08 & $\begin{array}{l}0,698 \\
0,690\end{array}$ & $-0,01$ & $\begin{array}{l}0,667 \\
0,571\end{array}$ & $-0,16$ \\
\hline МСТО2ВО8 & $\begin{array}{l}0,457 \\
0,498\end{array}$ & 0,08 & $\begin{array}{l}0,347 \\
0,374\end{array}$ & 0,07 & $\begin{array}{l}0,500 \\
0,466\end{array}$ & $-0,07$ & $\begin{array}{l}0,573 \\
0,490\end{array}$ & $-0,16$ \\
\hline Phi65 & $\begin{array}{l}0,363 \\
0,326\end{array}$ & $-0,11$ & $\begin{array}{l}0,521 \\
0,455\end{array}$ & $-0,14$ & $\begin{array}{l}0,418 \\
0,471\end{array}$ & 0,11 & $\begin{array}{l}0,479 \\
0,460\end{array}$ & $-0,04$ \\
\hline Bnlg127 & $\begin{array}{l}0,527 \\
0,491\end{array}$ & $-0,07$ & $\begin{array}{l}0,372 \\
0,416\end{array}$ & 0,17 & $\begin{array}{l}0,593 \\
0,656\end{array}$ & 0,09 & $\begin{array}{l}0,422 \\
0,494\end{array}$ & 0,14 \\
\hline Bnlg292 & $\begin{array}{l}0,389 \\
0,430\end{array}$ & 0,09 & $\begin{array}{l}0,032 \\
0,031\end{array}$ & $-0,03$ & $\begin{array}{l}0,116 \\
0,146\end{array}$ & 0,20 & $\begin{array}{l}0,000 \\
0,000\end{array}$ & 1,00 \\
\hline Phi59 & $\begin{array}{l}0,368 \\
0,438\end{array}$ & 0,16 & $\begin{array}{l}0,453 \\
0,480\end{array}$ & 0,05 & $\begin{array}{l}0,427 \\
0,477\end{array}$ & 0,10 & $\begin{array}{c}0,333 \\
0,335\end{array}$ & 0,00 \\
\hline Phi84 & $\begin{array}{l}0,505 \\
0,440\end{array}$ & $-0,15$ & $\begin{array}{l}0,096 \\
0,092\end{array}$ & $-0,04$ & $\begin{array}{l}0,379 \\
0,424\end{array}$ & 0,10 & $\begin{array}{l}0,630 \\
0,525\end{array}$ & $-0,20$ \\
\hline $\begin{array}{l}\overline{H o} \\
\hat{H} e\end{array}$ & $\begin{array}{r}0 \\
(0,410 \\
0 \\
(0,491\end{array}$ & $\begin{array}{l}606) \\
633)\end{array}$ & $\begin{array}{r}(0,32) \\
(0,36\end{array}$ & $\begin{array}{l}2 \\
0,514) \\
9 \\
0,510)\end{array}$ & $\begin{array}{r}0 \\
(0,420 \\
0 \\
(0,500\end{array}$ & $\begin{array}{l}\text { 512) } \\
\text { 541) }\end{array}$ & $\begin{array}{r}0 \\
(0,385 \\
0 \\
(0,419\end{array}$ & ,567) \\
\hline $\begin{array}{c}\hat{\bar{f}} \\
* I C_{95 \%}\end{array}$ & $\begin{array}{r}0 \\
(0,058\end{array}$ & 131) & $(0,003$ & $\begin{array}{l}9 \\
0,068)\end{array}$ & $\begin{array}{r}0 \\
(0,054\end{array}$ & 140) & $\begin{array}{r}0 \\
(-0,02\end{array}$ & ,083) \\
\hline
\end{tabular}

*Intervalo de confiança gerado por bootstrap com 10.000 repetições. 
A diferença entre duas unidades de repetições dinucleotídicas (4 pb) se encontra no limite inferior da resolução de géis de agarose, e portanto, a distinção entre indivíduos heterozigóticos, cujos alelos diferem em apenas 2 pb, é muito difícil (Taramino \& Tingey 1996). Considerando que o loco Bnlg 572 é composto por repetições de dinucleotídeos, no caso (CT), indivíduos heterozigóticos diferindo em alelos muito próximos podem ter sido genotipados como homozigotos na população BR-106 e no sintético IG-4. Entretanto, a deficiência de heterozigotos têm sido relatada para muitas espécies predominantemente de cruzamento (Brown, 1979). Embora, sob o ponto de vista estatístico, cada loco seja tratado como repetição, Murray (1996) ressalta que cada loco guarda uma estória independente, dependendo das quantidades de deriva genética, mutação e migração que ocorreram na população.

Comparando os valores das heterozigosidades médias observadas entre populações e sintéticos, houve uma redução de 16,93\% para a população BR-105, e de $7,75 \%$ para a população BR-106, conferindo aos respectivos sintéticos valores de 0,422 e 0,476 .

A heterozigosidade média esperada (diversidade gênica) para as populações não diferiu significativamente, da mesma forma que os valores referentes às heterozigosidades médias observadas. Nesse sentido, para os 30 locos de microssatélites, as populações mostraram os mesmos níveis de diversidade gênica.

As distribuições das heterozigosidades observadas e esperadas (Figura 9) mostraram para os sintéticos um aumento no número de locos referente às classes de menor valor $(0,1$ a 0,3$)$. Nos sintéticos, as heterozigosidades observadas foram mais próximas às esperadas do que entre as populações originais. Isto ilustra que os desvios de panmixia foram menos pronunciados nestes materiais. 

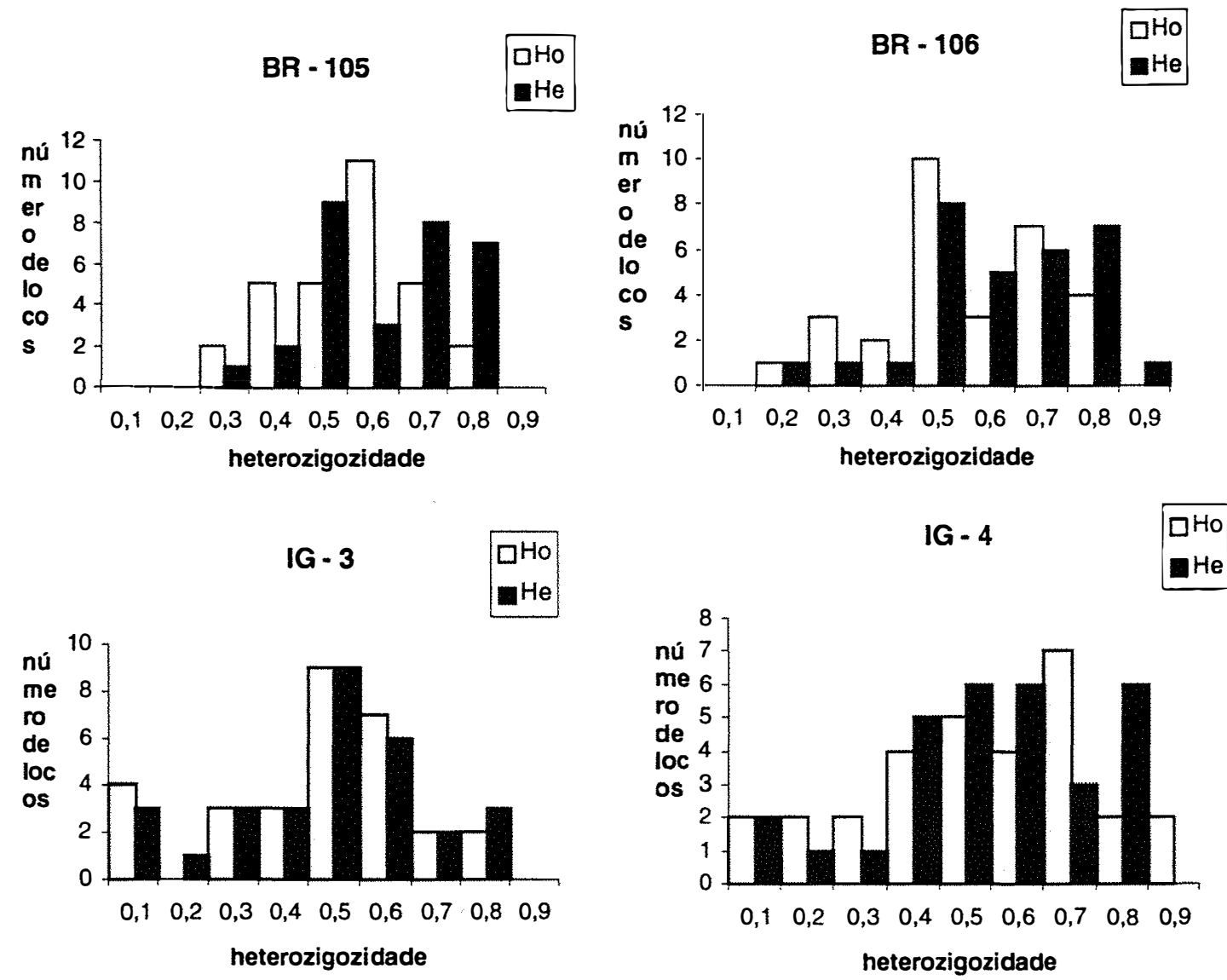

Figura 9- Distribuição das heterozigosidades observada ( $\mathrm{Ho}$ ) e esperada ( $\mathrm{He}$ ) ao longo dos locos de microssatélites para as populações e os sintéticos. 
Apesar da variação observada para os valores dos índices de fixação nos 30 locos analisados, os índices de fixação médios $(\hat{\bar{f}})$ observados nos sintéticos IG-3 $(0,039)$ e IG-4 $(0,028)$ foram menores que $5 \%(\hat{f}<0,05)$. As populações apresentaram índices de fixação médios maiores que $5 \%$, e equivalentes a 0,096 . Os intervalos de confiança a $95 \%$ de probabilidade, obtidos por bootstrap (10.000 repetições) revelaram que o valor verdadeiro para o índice de fixação médio $(\hat{\bar{f}})$ se encontra entre 0,058 a 0,131 para a população BR-105; entre 0,054 a 0,140 para a população BR-106; entre 0,003 a 0,068 para o sintético IG-3, e entre - 0,022 a 0,083 para o sintético IG-4. Em todos os casos mencionados, os intervalos de confiança acomodam um valor para o índice de fixação próximo a $5 \%$.

Para 53\% dos locos da população BR-105 e 57\% da BR-106 (Tabela 13), a hipótese de aderência às proporções de Hardy-Weinberg, aplicada sobre os 30 locos, revelou que os desvios das freqüências genotípicas em relação às do modelo não foram significativamente diferentes de zero $(P<0,05)$. A maioria $(93 \%)$ dos locos do sintético IG-3 apresentou aderência às proporções de Hardy-Weinberg em relação a $70 \%$ do locos do sintético IG-4 (Tabela 14). Os sintéticos apresentaram um maior número de locos em aderência às proporções de Hardy-Weinberg do que as respectivas populações originais. Segundo Rezende (1997), espera-se que os sintéticos estejam próximos do equilíbrio de ligação e em equilíbrio de Hardy-Weinberg em virtude das linhagens genitoras destes sintéticos terem sido inicialmente intercruzadas em um sistema dialélico, sendo o material recombinado por três gerações. 
Tabela 13. Aderência às proporções de Hardy-Weinberg para as populações BR-105 e BR-106 em 30 locos de microssatélites pelo teste exato.

\begin{tabular}{|c|c|c|c|c|}
\hline \multirow{3}{*}{ Loco } & \multicolumn{4}{|c|}{ Populações } \\
\hline & \multicolumn{2}{|c|}{ BR-105 } & \multicolumn{2}{|c|}{ BR-106 } \\
\hline & $\begin{array}{c}\text { Probabilidade } \\
\text { exata }\end{array}$ & $\begin{array}{l}\text { Desvio } \\
\text { padrão }\end{array}$ & $\begin{array}{c}\text { Probabilidade } \\
\text { exata }\end{array}$ & $\begin{array}{l}\text { Desvio } \\
\text { padrão }\end{array}$ \\
\hline Phi 65 & 0,348 & 0,008 & 0,372 & 0,009 \\
\hline Phi 84 & 0,199 & 0,010 & 0,368 & 0,011 \\
\hline МАСТО2В08 & 0,529 & 0,008 & 0,511 & 0,010 \\
\hline Bnlg 669 & 0,000 & 0,000 & 0,001 & 0,000 \\
\hline Bnlg 572 & 0,348 & 0,011 & 0,000 & 0,000 \\
\hline Bnlg 155 & 0,000 & 0,000 & 0,198 & 0,008 \\
\hline Phi 70 & 0,211 & 0,008 & 0,098 & 0,008 \\
\hline Phi 48 & 0,000 & 0,000 & 0,822 & 0,008 \\
\hline Bnlg 589 & 0,280 & 0,008 & 0,000 & 0,000 \\
\hline MTTGBO2 & 0,000 & 0,000 & 0,002 & 0,000 \\
\hline Bnlg 125 & 0,005 & 0,001 & 0,780 & 0,008 \\
\hline Phi 001 & 0,007 & 0,002 & 0,035 & 0,004 \\
\hline Bnlg 238 & 0,146 & 0,009 & 0,028 & 0,002 \\
\hline Bnlg 109 & 0,013 & 0,002 & 0,164 & 0,010 \\
\hline Bnlg 197 & 0,021 & 0,002 & 0,000 & 0,000 \\
\hline MAGE05 & 0,149 & 0,010 & 0,019 & 0,003 \\
\hline Bnlg 108 & 0,241 & 0,008 & 0,003 & 0,001 \\
\hline Bnig 176 & 0,257 & 0,011 & 0,408 & 0,014 \\
\hline Bnlg 292 & 0,472 & 0,011 & 0,097 & 0,007 \\
\hline Bnlg 131 & 0,043 & 0,004 & 0,001 & 0,000 \\
\hline Phi 59 & 0,155 & 0,007 & 0,163 & 0,006 \\
\hline Bnlg 161 & 0,031 & 0,002 & 0,004 & 0,001 \\
\hline Bnlg 143 & 0,094 & 0,006 & 0,573 & 0,009 \\
\hline Bnlg 127 & 0,525 & 0,009 & 0,347 & 0,007 \\
\hline Bnlg 240 & 0,049 & 0,006 & 0,424 & 0,007 \\
\hline Phì 115 & 0,418 & 0,011 & 0,668 & 0,010 \\
\hline Phi 113 & 0,027 & 0,004 & 0,861 & 0,007 \\
\hline Bnig 666 & 0,049 & 0,005 & 0,020 & 0,002 \\
\hline Bnlg 657 & 0,000 & 0,000 & 0,299 & 0,010 \\
\hline Bnlg 602 & 0,825 & 0,006 & 0,032 & 0,003 \\
\hline
\end{tabular}


Tabela 14. Aderência às proporções de Hardy-Weinberg para os sintéticos IG-3 e IG-4, em 30 locos de microssatélites pelo teste exato.

\begin{tabular}{|c|c|c|c|c|}
\hline \multirow{3}{*}{ Locos } & \multicolumn{4}{|c|}{ Populações } \\
\hline & \multicolumn{2}{|c|}{ IG-3 } & \multicolumn{2}{|l|}{ IG-4 } \\
\hline & $\begin{array}{c}\text { Probabilidade } \\
\text { exata }\end{array}$ & $\begin{array}{l}\text { Desvio } \\
\text { padrão }\end{array}$ & $\begin{array}{c}\text { Probabilidade } \\
\text { exata }\end{array}$ & $\begin{array}{l}\text { Desvio } \\
\text { padrão }\end{array}$ \\
\hline Phi 65 & 0,175 & 0,006 & 0,821 & 0,009 \\
\hline Phi 84 & 1,000 & 0,000 & 0,006 & 0,001 \\
\hline МАСТО2В08 & 0,584 & 0,012 & 0,139 & 0,008 \\
\hline Bnlg 669 & 0,141 & 0,008 & 0,919 & 0,007 \\
\hline Bnlg 572 & 0,893 & 0,005 & 0,000 & 0,000 \\
\hline Bnlg 155 & 0,073 & 0,008 & 1,000 & 0,000 \\
\hline Phi 70 & 0,277 & 0,009 & 0,151 & 0,009 \\
\hline Phi 48 & 1,000 & 0,000 & 0,528 & 0,010 \\
\hline Bnlg 589 & 0,894 & 0,006 & 0,000 & 0,000 \\
\hline MTTGBO2 & 0,857 & 0,006 & 0,921 & 0,005 \\
\hline Bnlg 125 & 0,133 & 0,007 & 0,000 & 0,000 \\
\hline Phi 001 & 0,705 & 0,011 & 0,145 & 0,007 \\
\hline Bnlg 238 & 0,123 & 0,007 & 0,168 & 0,009 \\
\hline Bnlg 109 & 0,091 & 0,005 & 0,063 & 0,006 \\
\hline Bnlg 197 & 0,000 & 0,000 & 1,000 & 0,000 \\
\hline MAGE05 & 0,260 & 0,008 & 0,290 & 0,008 \\
\hline Bnlg 108 & 0,265 & 0,008 & 0,000 & 0,000 \\
\hline Bnlg 176 & 1,000 & 0,000 & 1,000 & 0,000 \\
\hline Bnlg 292 & 1,000 & 0,000 & - & - \\
\hline Bnlg 131 & 0,000 & 0,000 & 0,000 & 0,000 \\
\hline Phi 59 & 0,668 & 0,011 & 1,000 & 0,000 \\
\hline Bnlg 161 & 0,950 & 0,004 & 0,008 & 0,002 \\
\hline Bnlg 143 & 0,143 & 0,007 & 1,000 & 0,000 \\
\hline Bnlg 127 & 0,325 & 0,011 & 0,199 & 0,006 \\
\hline Bnlg 240 & 0,284 & 0,008 & 0,122 & 0,005 \\
\hline Phi 115 & 0,678 & 0,011 & 0,833 & 0,007 \\
\hline Phi 113 & 0,106 & 0,006 & 0,850 & 0,008 \\
\hline Bnlg 666 & 0,991 & 0,002 & 0,075 & 0,006 \\
\hline Bnlg 657 & 0,282 & 0,009 & 0,235 & 0,008 \\
\hline Bnlg 602 & 0,063 & 0,005 & 0,000 & 0,000 \\
\hline
\end{tabular}

$(-)$ loco fixado. 


\subsection{Diversidade gênica (heterozigosidade esperada) sob ação da deriva genética e tamanho efetivo populacional ( $\hat{N} e)$}

Os valores de diversidade gênica (heterozigosidade esperada) estimados para cada um dos locos presentes nos sintéticos foram comparados com os valores teoricamente esperados sob deriva genética (Tabelas 15 e 16). Para a estimativa destes valores foram utilizados os valores de diversidade gênica estimados nas populações antes da seleção ( $\hat{D} o$ ), e os tamanhos efetivos populacionais teóricos esperados para os sintéticos IG-3 e IG-4, respectivamente iguais a 4,57 e 5,71.

No sintético IG-3, 8 locos (Bnlg 176, Bnlg 108, MAGEO5, Bnlg 197, Bnlg 589, Bnlg 669, Bnlg 292 e Phi 84) não aderiram ao modelo de deriva, considerando os intervalos de confiança a 95\% de probabilidade. Em relação ao sintético IG-4, 7 locos (Bnlg 176, Bnlg 197, Bnlg 589, Bnlg143, Bnlg 572, Bnlg 669 e Bnlg 292) mostraram valores menores e significativos em relação aos esperados sob deriva. Para estes locos, que representam aproximadamente $27 \%$ do total, a perda de diversidade gênica não pode ser atribuída somente aos efeitos da deriva genética.

Para os locos Phi 48 e Bnlg 155 (sintético IG-3) e para os locos Bnlg 109 e Bnlg 125 (sintético IG-4), as diversidades gênicas foram significativamente superiores às encontradas na população original, segundo o intervalo de confiança a 95\%.

Maruyama \& Fuerst (1985) ressaltam que populações nas quais ocorreram reduções significativas do tamanho populacional, bottlenecks, podem apresentar aumento da diversidade. Além disso, tem-se que os sintéticos IG-3 e IG-4 estão em equilíbrio de Hardy-Weinberg para a maioria dos locos. Isto colabora para que as diversidades gênicas dos sintéticos sejam maiores (Figura 9).

O valor de diversidade gênica total encontrado nos sintéticos não diferiu significativamente do esperado sob deriva genética. Desta forma, em média, a redução da diversidade gênica nos sintéticos se encontra à taxa predita pelo modelo de deriva genética. 


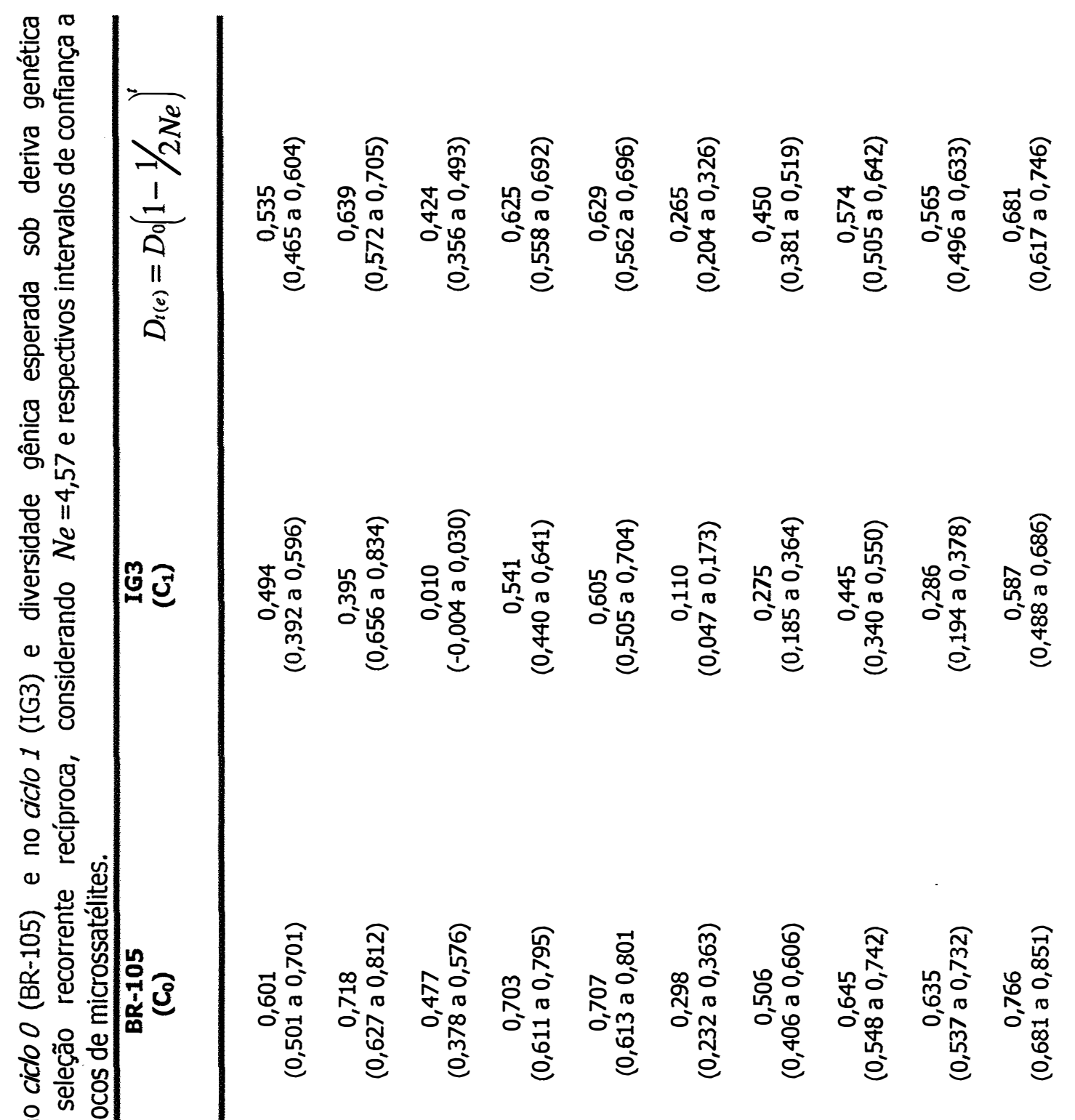




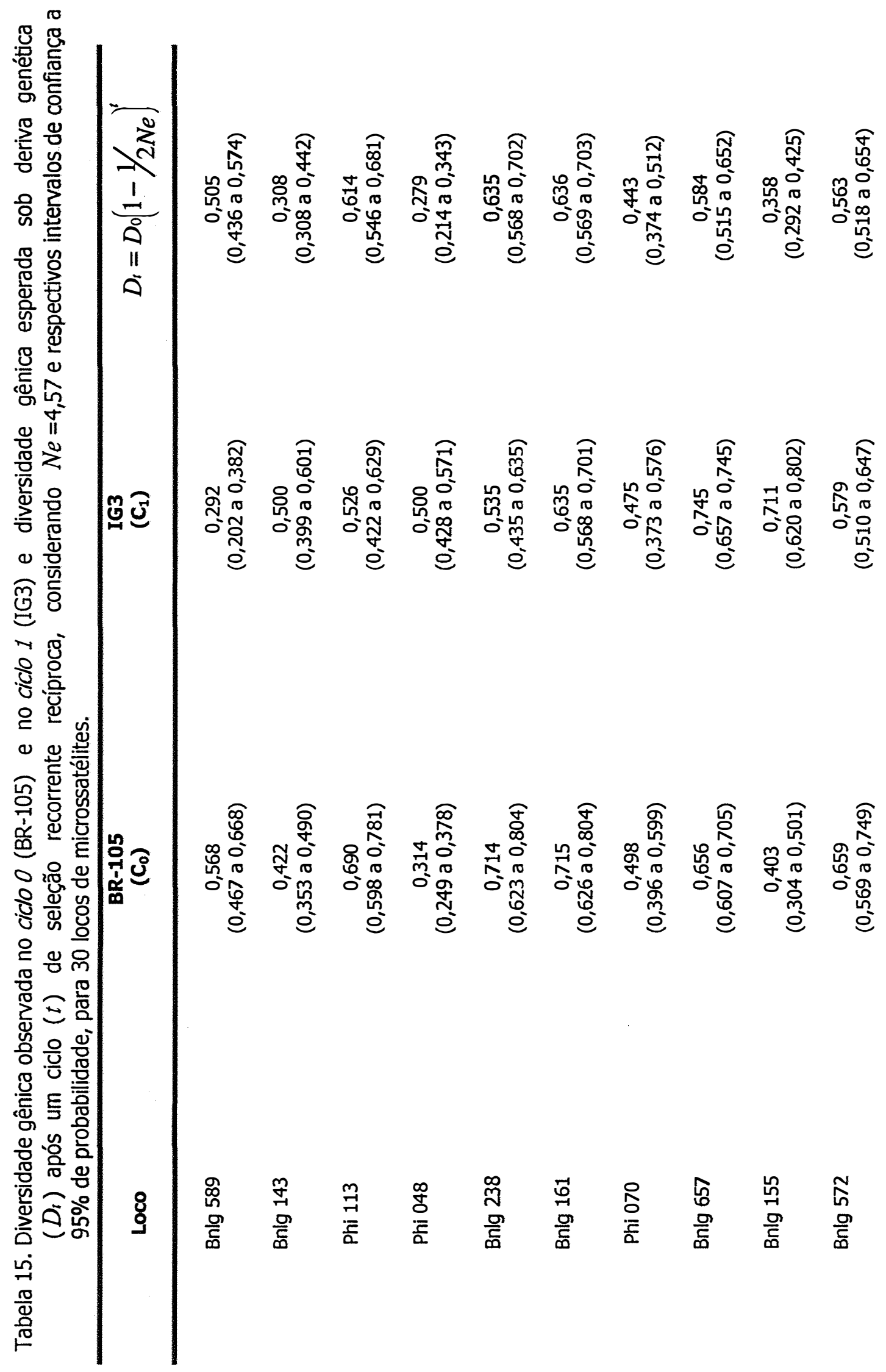




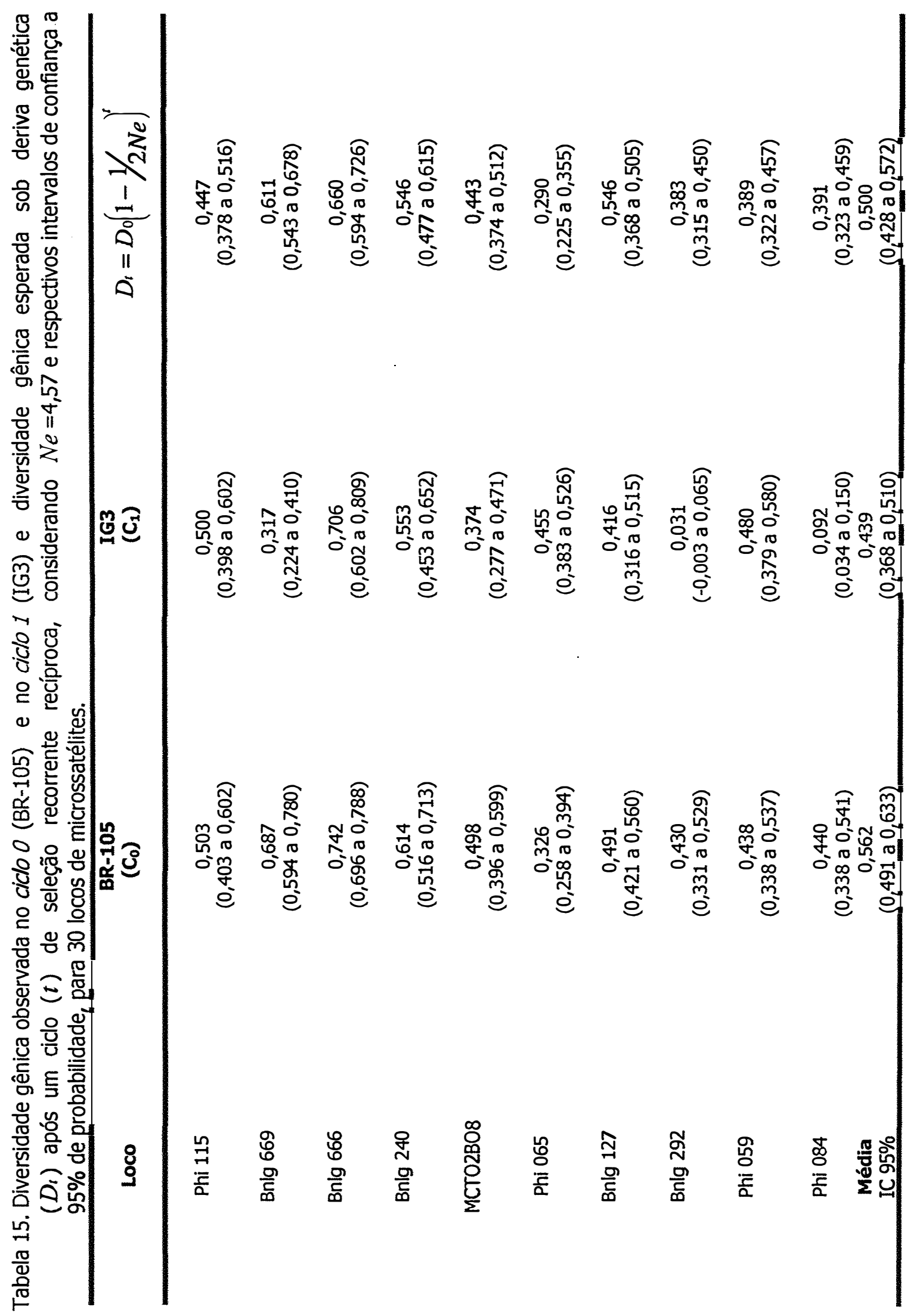




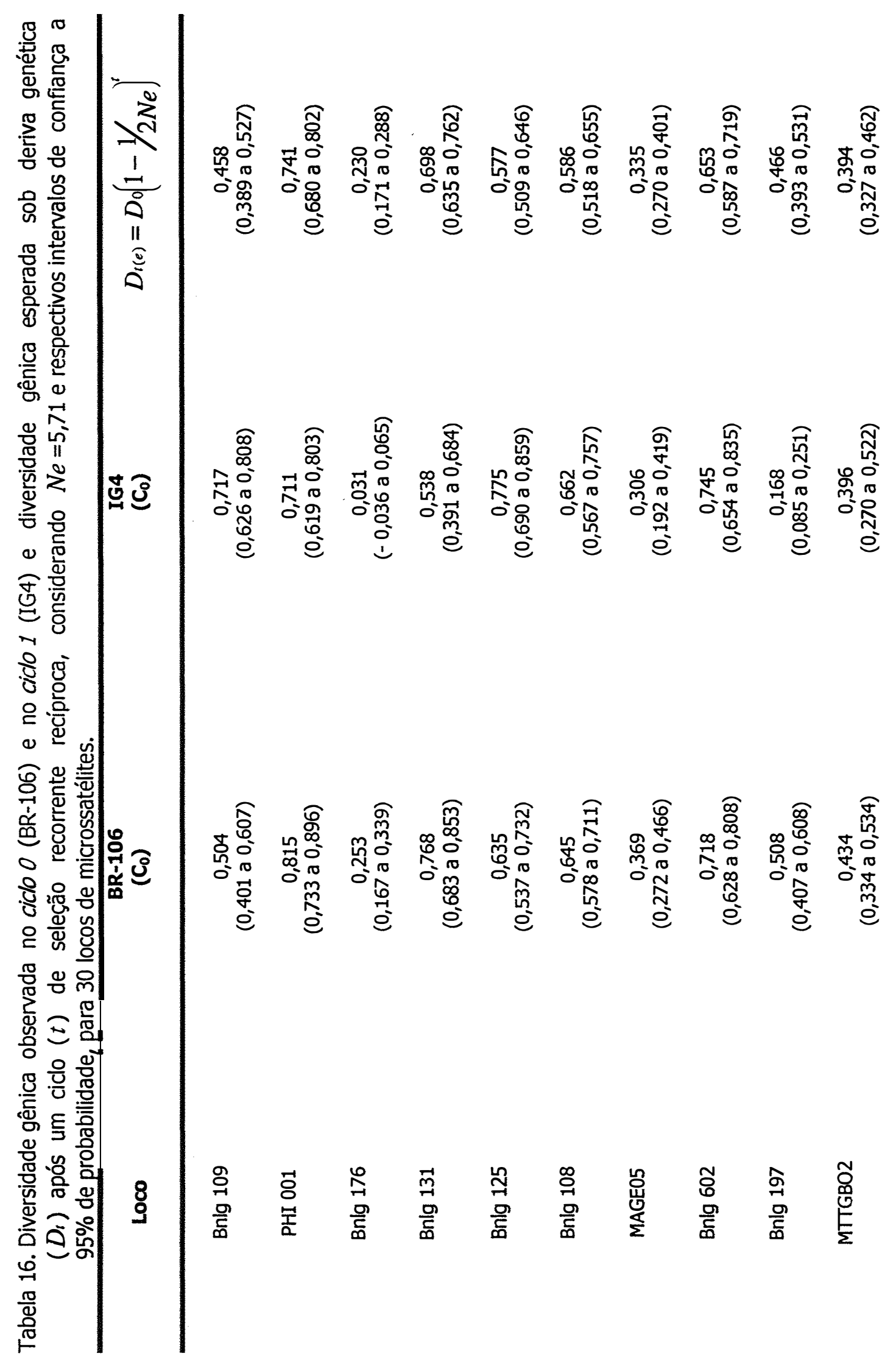




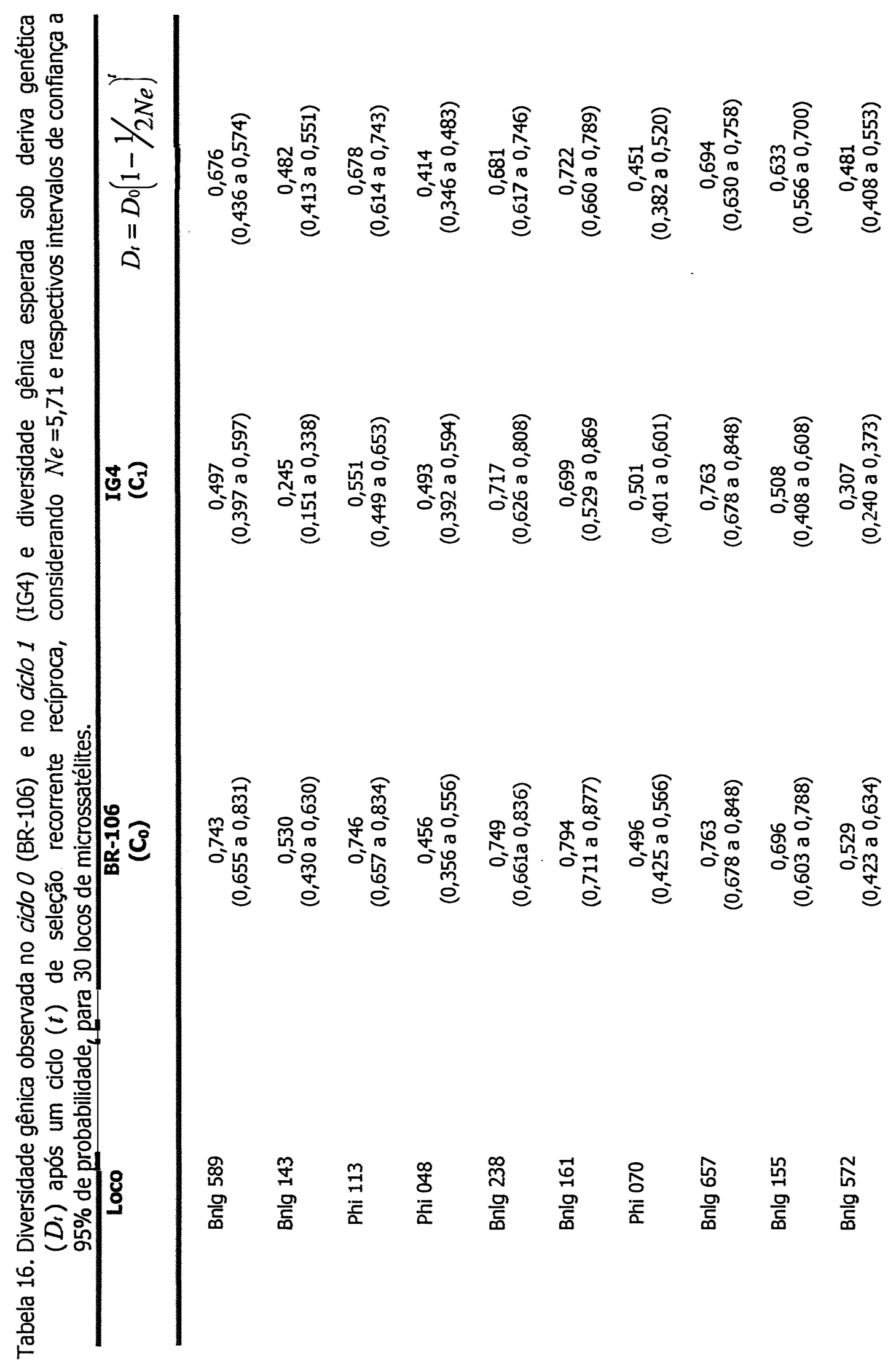




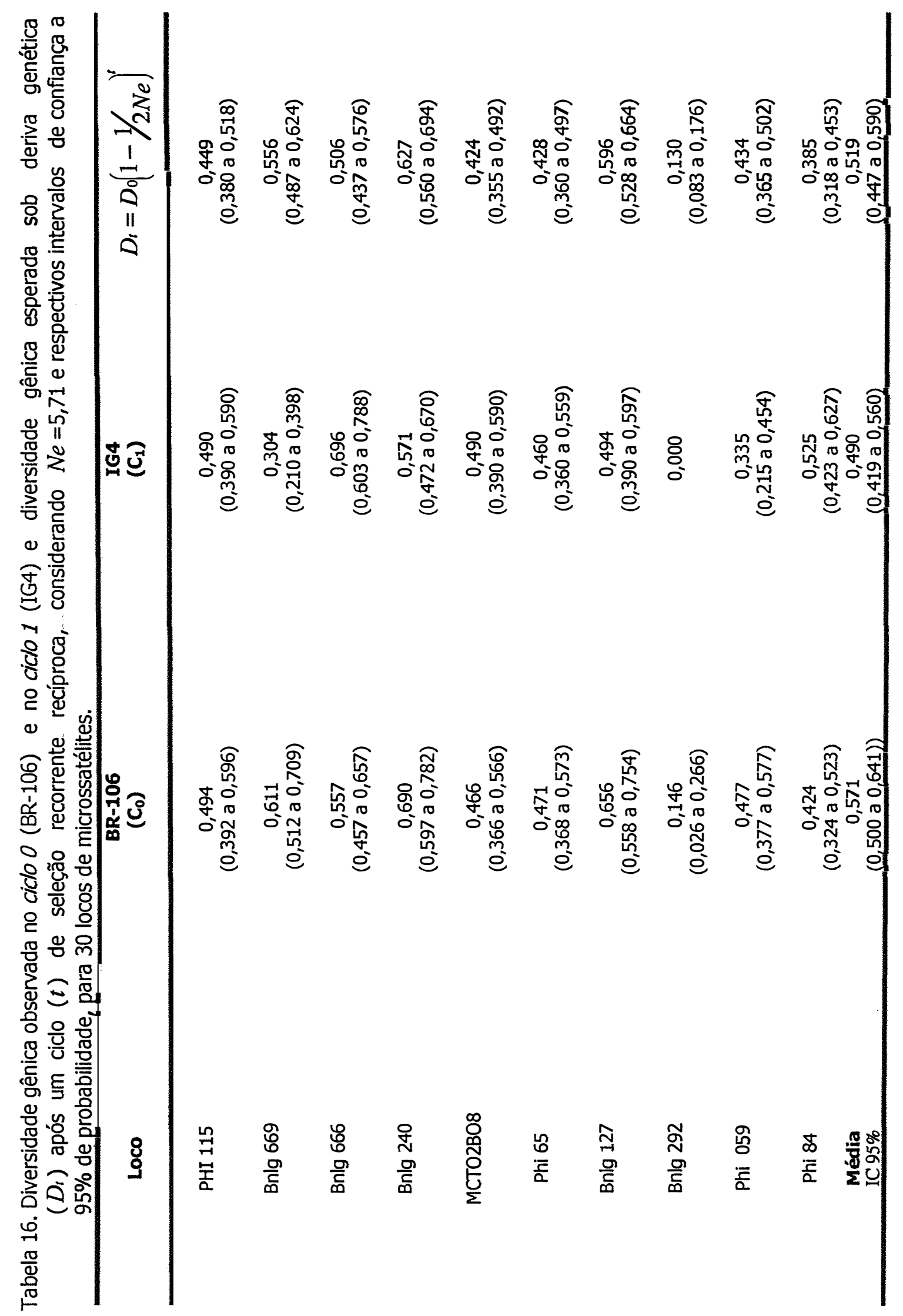


Na tabela 17 são apresentados os valores para os tamanhos efetivos populacionais. Foram obtidas estimativas dos tamanhos efetivos ( $\hat{N} e$ ) considerando os 30 locos de microssatélites e excluindo os locos supostamente "não neutros" pelo modelo de perda de diversidade gênica para alelos neutros.

Considerando as intensidades de seleção iguais a $2,0 \%$ e $2,5 \%$ praticadas, respectivamente, nas populações BR-105 e BR-106, bem como o tamanho efetivo populacional de uma linhagem $S_{3}$ como sendo igual a 0,57 , os valores dos tamanhos efetivos populacionais teóricos esperados para os sintéticos IG-3 e IG-4 equivalem a 4,57 e 5,71 , respectivamente. As estimativas de $\hat{N} e$ foram calculadas pelo método de Waples (1989), com base nas mudanças das freqüências alélicas para todos os locos, obtidas em dois eventos diferentes de amostragem, isto é, antes e após um ciclo de seleção recorrente recíproca.

Tabela 17. Estimativas do tamanho efetivo populacional $(\hat{N} e)$ e intervalo de confiança a $95 \%$ para os sintéticos IG-3 e IG-4.

IG-3 IG-4

Todos os locos

30 locos

$\hat{\bar{F} C}$

0,139

30 locos

$\left(S_{0} ; S_{1}\right)$

$(93,50 ; 93,80)$

3,87

$\hat{N} e$

2,90 a 5,42

0,086

IC $95 \%$

$(93,90 ; 93,50)$

6,62

5,01 a 9,14

Locos "neutros"

$\hat{\bar{F}} \mathrm{C}$

$\left(S_{0} ; S_{1}\right)$

$\hat{N} e$

IC $95 \%$

\section{2 locos}

0,123

$(93,42 ; 93,50)$

4,42

3,21 a 6,46
23 locos

0,079

$(94,00 ; 95,00)$

7,35

3,15 a 10,54

$\hat{\bar{F}} c$ - Variância média padronizada da freqüência alélica, poderada sobre locos.

$S_{0} ; S_{1}$ tamanho médio da amostra nos dois eventos de amostragem. 
Os tamanhos efetivos populacionais estimados para os sintéticos IG-3 e IG-4, calculados com 30 locos de microssatélites, mostraram valores equivalentes a 3,87 e 6,62 , respectivamente, e próximos aos teoricamente esperados, respectivamente iguais a 4,57 e 5,71. Os valores de $\hat{N} e$ eliminando os locos aparentemente "não neutros", isto é, os locos cujos valores de diversidade gênica diferiram significativamente dos esperados sob o modelo de deriva, forneceram estimativas numericamente maiores, respectivamente iguais a 4,42 e 7,35 para os sintéticos IG-3 e IG-4. Os intervalos de confiança a $95 \%$ de probabilidade contêm os valores teóricos esperados.

Ingvarsson \& Olsson (1997) ressaltam que o conhecimento detalhado do tamanho efetivo populacional é importante para determinar o quanto os níveis de diferenciação genética observados podem ser atribuídos exclusivamente à deriva genética, ou a outras causas como a seleção. A seleção direcional e por carona genética (genetic hitchhiking) deflacionam o tamanho efetivo populacional. $O$ efeito de carona genética é observado quando a seleção em um loco muda a freqüência de alelos neutros em locos que se encontram ligados ao loco sob seleção. Este efeito é condicionado pelo desequilíbrio inicial entre os locos (Kaplan et al., 1989; Wiehe, 1998; Labate et al., 1999).

A interpretação dos valores obtidos para os tamanhos efetivos populacionais, revela que a amostra física constituída, em média, pelos 93 indivíduos $(\mathrm{N})$ genotipados para os 30 locos de microssatélites, representa geneticamente, aproximadamente, 3,87 (IG-3) e 6,62 (IG-4) plantas de uma população panmítica ideal. Pode-se afirmar também que os tamanhos efetivos populacionais estimados correspondem, respectivamente, a 4,16 e 7,11\% do total amostrado de indivíduos nos sintéticos IG-3 e IG-4.

Os tamanhos efetivos populacionais estimados conferem coeficientes de endogamia, $\left(F=\frac{1}{2 N e}\right) 00$, respectivamente, de 12,91 e 7,55\% para os sintéticos IG3 e IG-4, valores estes próximos aos teóricos esperados iguais a 10,94 e 8,75\%. 


\subsection{Partição da diversidade}

A análise da estrutura genética das populações, considerando a distribuição da variabilidade entre as populações $\left(C_{0}\right)$, e entre os sintéticos $\left(C_{1}\right)$ está apresentada na Tabela 18.

A partição da diversidade gênica entre e dentro das populações mostrou que a maior parte da diversidade gênica total, avaliada por meio de locos de microssatélites, se apresenta distribuída dentro das populações ( $89 \%)$ do que entre elas ( $\hat{G}_{S T}=11 \%$ ). Para os sintéticos, $19,5 \%$ da variabilidade total está distribuída entre eles e cerca de $80,5 \%$ encontra-se dentro deles.

Tabela 18. Valores médios de diversidade nas populações originais $\left(C_{0}\right)$ e respectivos sintéticos $\left(C_{1}\right)$, com base em 30 locos de microssatélites.

\begin{tabular}{ccc}
\hline & Antes da seleç̃o & Após um ciclo de seleção \\
$\left(\mathbf{C}_{\mathbf{1}}\right)$ \\
\hline$\left.\hat{H} \mathbf{C}_{0}\right)$
\end{tabular}

*bootstrap com 10.000 repetiçōes.

Comparando os valores de diversidade total $\left(\hat{H}_{T}\right)$ entre as populações $\left(C_{0}\right)$ com os valores observados entre os sintéticos $\left(C_{1}\right)$, nota-se uma perda de $9,4 \%$. A heterozigosidade esperada dentro das populações originais $(\hat{H} s)$ decresceu cerca de $18 \%$ em relação à heterozigosidade esperada nos sintéticos $\left(C_{1}\right)$. Estas perdas contribuíram para o aumento da diferenciação entre as populações manifestada nos sintéticos. Contrastando os valores de $\hat{G} s T$ estimados antes da seleção $\left(\hat{G}_{S T}=0,11\right)$ e 
após um ciclo de seleção ( $\hat{G} s t=0,195$ ), nota-se um aumento de $77,3 \%$. Conseqüentemente, em relação às populações originais, os sintéticos tornaram-se mais divergentes entre si. É esperado que com o aumento da diferenciação genética entre populações ocorra também um aumento da distância genética.

De acordo com Rezende \& Souza Júnior (2000), o processo de seleção recorrente recíproca de alta intensidade aplicado sobre essas populações foi eficiente para melhorar significativamente a performance do cruzamento entre os respectivos sintéticos, sendo que as variâncias genéticas interpopulacionais não apresentaram mudanças significativas. Nesse sentido, ao nível molecular, a perda de diversidade gênica total $(9,4 \%)$ também foi pequena, face às intensidades de seleção aplicadas. Além disso, os valores de diversidade total $\left(\hat{H}_{T}\right)$ entre as populações e entre os sintéticos não diferem significativamente entre si, considerando os intervalos de confiança a 95\%. Entretanto, tal perda levou a valores de $\hat{G}_{s T}$ significativos contribuindo para um aumento expressivo da diferenciação genética entre os sintéticos (77,3\%).

Na Tabela 19, está apresentada a distribuição da diversidade gênica em relação às populações e respectivos sintéticos.

Tabela 19. Valores médios de diversidade presentes nas populações originais e respectivos sintéticos, com base em 30 locos de microssatélites.

\begin{tabular}{ccc}
\hline & BR-105 e IG-3 & BR-106 e IG-4 \\
\hline$\hat{H}_{s}$ & 0,501 & 0,531 \\
$I C_{95 \%}$ & $(0,429 \mathrm{a} 0,573)$ & $(0,459 \mathrm{a} 0,603)$ \\
$\hat{H}_{T}$ & 0,572 & 0,570 \\
$I C_{95 \%}$ & $(0,500 \mathrm{a} 0,643)$ & $(0,498 \mathrm{a} 0,641)$ \\
$\hat{D}_{s T}$ & 0,071 & 0,039 \\
$\hat{G}_{s T}$ & $12,40 \%$ & $6,80 \%$ \\
$\left({ }^{*} I C_{95 \%}\right)$ & $(0,084 \mathrm{a} 0,138)$ & $(0,142 \mathrm{a} 0,256)$ \\
$\hat{R}_{S T}$ & $11,00 \%$ & $6,6 \%$ \\
$\left({ }^{*} I C_{95 \%}\right)$ & $(0,093 \mathrm{a} 0,127)$ & $(0,056 \mathrm{a} 0,078)$ \\
\hline
\end{tabular}

*bootstrap com 10.000 repetiçōes. 
Analisando a partição da diversidade gênica total $(\hat{H} T)$, dentro $(\hat{H} s)$ e entre ( $\hat{D}_{S T}$ ) a população BR-105 e o sintético IG-3 e a população BR-106 e o sintético IG-4, respectivamente, nota-se que a diferenciação gênica total ( $\hat{G}_{S T}$ ) foi maior entre a população BR-105 e o sintético IG-3 (12,4\%) em relação à observada para a BR-106 e o sintético IG-4 (6,8\%). Considerando o intervalo de confiança obtido a $95 \%$ de probabilidade, as estimativas obtidas para o $\hat{G}_{s T}$ diferiram significativamente. Desta forma, a diferenciação gênica observada para o sintético IG-3 em relação à população original foi significativamente maior do que a observada para o sintético IG-4. A diversidade gênica média dentro da população BR-105 e IG-3 foi numericamente menor que a observada para a BR-106 e IG-4.

De acordo com Viard et al. (1996), tanto a autofecundação como o efeito de afunilamento (bottlenecks) podem reduzir drasticamente a variabilidade dentro das populações e aumentar a diferenciação entre elas. Parte da diferenciação entre a população original e o respectivo sintético pode ser atribuída também ao fato das populações BR-105 e BR-106 terem sido submetidas à seleção recorrente recíproca utilizando linhagens $S_{3}$, as quais foram desenvolvidas pelo método genealógico (pedigree).

As estimativas da estatística $\hat{R}_{S T}$, obtidas em todas as análises da partição da diversidade (Tabelas 18 e 19), apresentaram valores bem semelhantes aos do $\hat{G} s T$. O $R_{S T}$ representa uma medida de diferenciação genética semelhante ao $G_{S T}$, porém incorpora a história de mutação contida nos alelos sobre o modelo de mutação stepwise e, portanto, é mais adequado para análise com dados de microssatélites. Uma vez que a estatística se baseia na variância do tamanho dos alelos, ela pode ser utilizada como um indicativo da eficiência das genotipagens. Sob este aspecto, os valores estimados $\hat{R}_{S T}$ refletem que as genotipagens efetuadas sobre os 30 locos de microssatélites foram de adequadas. 


\subsection{Distância genética e análise de coordenadas principais}

A matriz da distância genética de Nei, obtida com base em 30 locos de microssatélites, encontra-se na Tabela 20.

Tabela 20. Identidade gênica (I), acima da diagonal, e distância genética ( $D=-\ln D$, abaixo da diagonal, para as populações BR-105, BR-106 e os sintéticos IG-3 e IG-4 com base em 30 locos de microssatélites.

\begin{tabular}{ccccc}
\hline & BR-105 & IG-3 & BR-106 & IG-4 \\
\hline BR-105 & - & 0,848 & 0,814 & 0,766 \\
IG-3 & 0,152 & - & 0,793 & 0,759 \\
BR-106 & 0,186 & 0,207 & - & 0,912 \\
IG-4 & 0,234 & 0,241 & 0,088 & - \\
\hline
\end{tabular}

A distância genética variou de 0,088 entre a população BR-106 e o sintético IG-4 a 0,241 entre os sintéticos IG-3 e IG-4. Em termos de porcentagem, a de Nei obtida entre as populações foi de $18,6 \%$, e entre os sintéticos IG-3 e IG-4, de $24,1 \%$. Isto representa um aumento de $29,57 \%$ em relação à distância observada entre as populações originais.

Entre a população BR-105 e o sintético correspondente foi observada uma distância de 15,2\%, e entre a população BR-106 e o sintético IG-4 de 8,8\%. A distância gerada entre a população BR-105 e o sintético IG-3 foi maior, em relação à distância entre a população BR-106 e o sintético IG-4. Tal observação pode ser atribuída, em parte, às magnitudes das intensidades de seleção respectivamente de 2,0\% e 2,5\%, aplicadas sobre as 400 linhagens $S_{3}$ provenientes das populações BR-105 e BR-106. Desta forma, considerando que o sintético IG-3 foi obtido pelo intercruzamento de 8 linhagens $S_{3}$, em relação às 10 linhagens $S_{3}$ que foram utilizadas para compor 0 sintético IG-4, era esperado que este se apresentasse mais distante da população BR105. 
$O$ valor do coeficiente de correlação cofenética $\left(r_{\text {cof }}=0,93, p=0,946\right)$ foi alto e significativo, e na escala proposta por Rholf (1992) pode ser interpretado como muito bom, indicando uma forte correlação entre os dados gerados na matriz de distâncias com o dendrograma obtido pela análise de agrupamento pelo método UPGMA. De acordo com o dendrograma apresentado na Figura 10, os materiais analisados foram separados em dois grupos, respectivamente, grupo I e grupo II. O grupo I incluiu a população BR-105 e seu sintético IG-3, enquanto o grupo II a população BR-106 e o sintético IG-4. O bootstrap com 10.000 repetições realizado sobre o dendrograma revelou uma freqüência de agrupamento de $94,25 \%$ para o grupo I e de $99,96 \%$ para o grupo II. Para o nó que une os grupos I e II foi obtida uma freqüência de $100 \%$.

Nas associações entre as populações e os sintéticos pela análise de coordenadas principais (Figura 12), os três primeiros componentes explicaram respectivamente $57,42 \%, 27,52 \%$ e $15,04 \%$ da variação total observada com os 30 locos. No gráfico, os sintéticos e as populações se apresentaram bem dispersos, com os sintéticos IG-3 e IG-4 mais afastados entre si em relação às populações originais. As associações revelaram um padrão semelhante ao obtido pelo dendrograma.

A distância genética $(\delta \mu)^{2}$ de Goodstein et al. (1995), a qual considera na análise o modelo de mutação (SMM) proposto para microssatélites, também foi estimada com base nos 30 locos (Tabela 21). De acordo com a matriz de distâncias foram observados valores variando de 0,142 entre o par formado pela população BR106 e o sintético IG-4 a 0,360 entre o par formado pelos sintéticos IG-3 e IG-4. A distância entre as populações BR-105 e BR-106 foi de $26,7 \%$ e entre os sintéticos IG-3 e IG-4 foi de $36,1 \%$. As distâncias das populações em relação aos sintéticos foram respectivamente de $23,1 \%$ e $14,2 \%$ entre BR-105 e IG-3 e entre BR-106 e IG-4. 
Tabela 21. Distância genética $\left(\delta^{2} \mu\right)$ de Goodstein et al. (1995), para as populações e os sintéticos, com base em 30 locos de microssatélites.

\begin{tabular}{ccccc}
\hline & BR-105 & IG-3 & BR-106 & IG-4 \\
\hline BR-105 & - & & & \\
IG-3 & 0,231 & - & & \\
BR-106 & 0,267 & 0,312 & - & \\
IG-4 & 0,312 & 0,361 & 0,142 & - \\
\hline
\end{tabular}

$O$ valor da correlação cofenética foi alta $\left(r_{\text {cof }}=0,91, p=0,94\right)$ e o dendrograma obtido com a distância $(\delta \mu)^{2}$, assim como o obtido com a distância de Nei mostrou a separação dos materiais em dois grupos. Grupo I, formado pela BR-105 e o sintético IG-3 e o grupo II formado pela população BR-106 e o seu sintético IG-4. Ambos (Figuras 10 e 11) separaram as populações e os sintéticos em grupos heteróticos distintos, de acordo com os resultados das performances destas populações em cruzamentos descritas anteriormente por Naspolini Filho et al. (1981).

Embora a distância de Nei e a de Goodstein apresentaram magnitudes diferentes (a primeira com valores de distâncias inferiores à Segunda), ambas revelam que os sintéticos encontram-se mais distantes entre si em relação às populações originais. O fato dos sintéticos e suas populações pertencerem a um mesmo grupo, confirma sua relação de identidade. No processo de seleção recorrente interpopulacional, os genótipos são avaliados em cruzamentos com a população recíproca, porém, a recombinação ocorre dentro das populações, fazendo com que as mesmas mantenham suas identidades.

As associações entre as populações e respectivos sintéticos reveladas pela análise de coordenadas principais, com dados gerados a partir da distância $(\delta \mu){ }^{2}$ encontram-se na Figura 13. A primeira coordenada explicou 52,08\% da variação total acessada com 30 locos, a segunda e a terceira coordenada explicaram 27,08 e 14,58\% da variação total, respectivamente. 
A análise das coordenadas principais também foi conduzida considerando-se os genótipos de forma individual (Figura 14). Cada ponto no gráfico representa uma amostra de aproximadamente 10 indivíduos da BR-105, BR-106, IG-3 e IG-4, separados em um espaço tridimensional. As três primeiras coordenadas explicaram, respectivamente, 70,17 e $6 \%$ da variação total observada. Todos os indivíduos agruparam-se de acordo com as respectivas populações ou sintéticos. Novamente, $\mathrm{Br}$ 105 e IG-3 apresentaram-se mais afastadas do que BR-106 e IG-4. Com base na primeira coordenada, nota-se que existe uma nítida separação entre BR-105/IG3 e BR106/IG-4. As associações obtidas foram coerentes com os dendrogramas obtidos. 


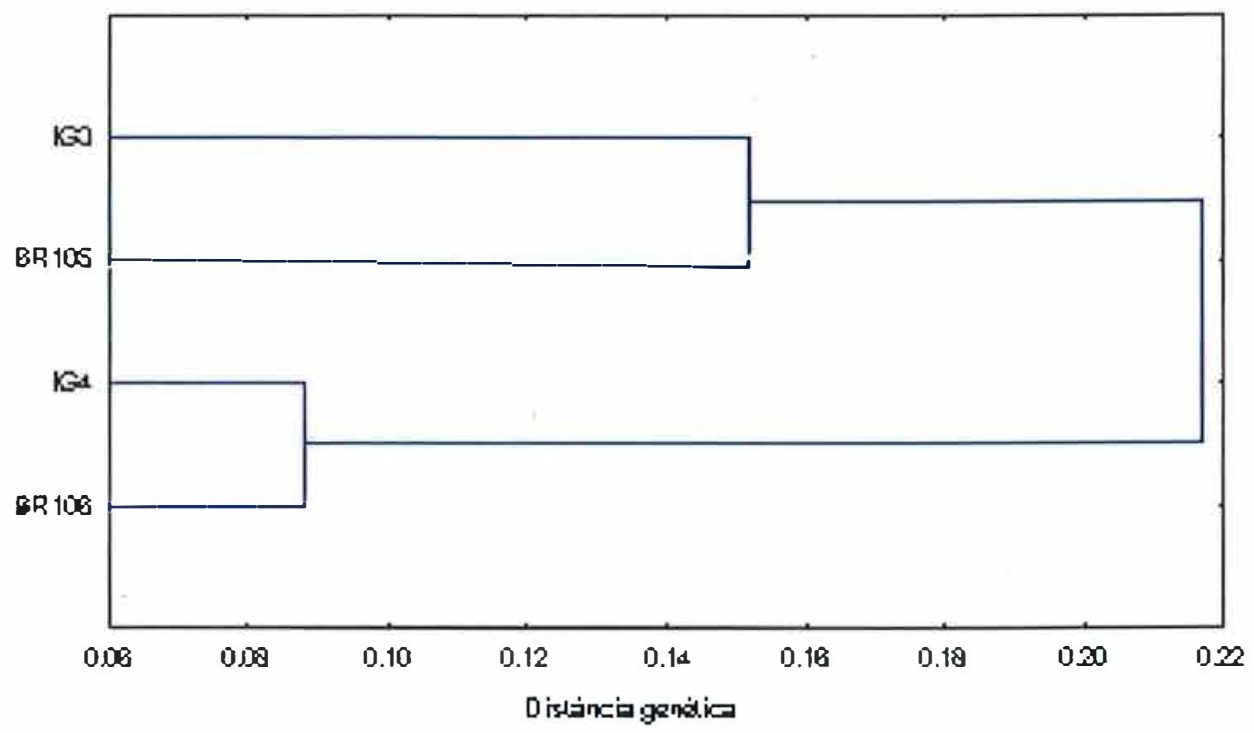

Figura 10 - Dendrograma das populações BR-105 e BR-106 e sintéticos IG-3 e IG-4 com base em 30 locos de microssatélites. 0 agrupamento foi realizado segundo o método UPGMA, considerando a matriz de distância genética de Nei. 


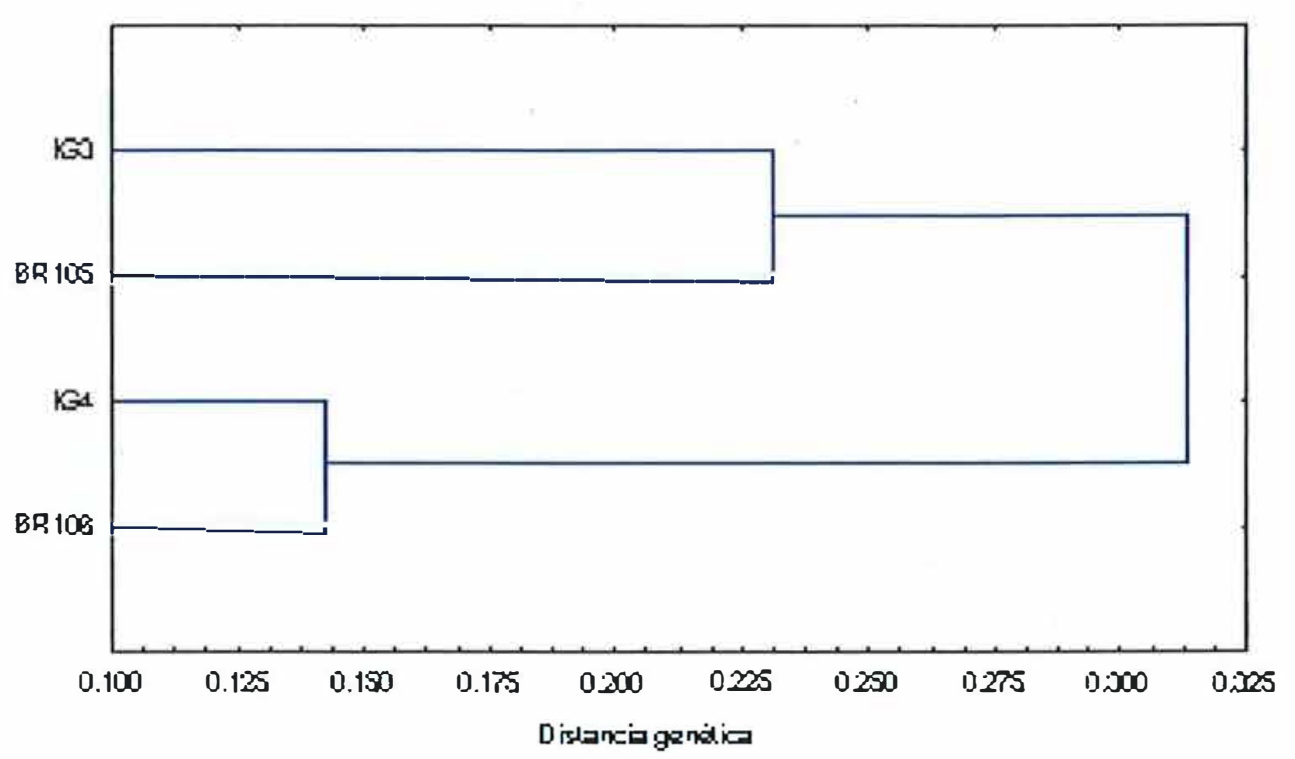

Figura 11-Dendrograma das populações BR-105 e BR-106 e sintéticos IG-3 e IG-4 com base em 30 locos de microssatélites. 0 agrupamento foi realizado segundo o método UPGMA, considerando a matriz de distância genética $(\delta \mu)^{2}$. 

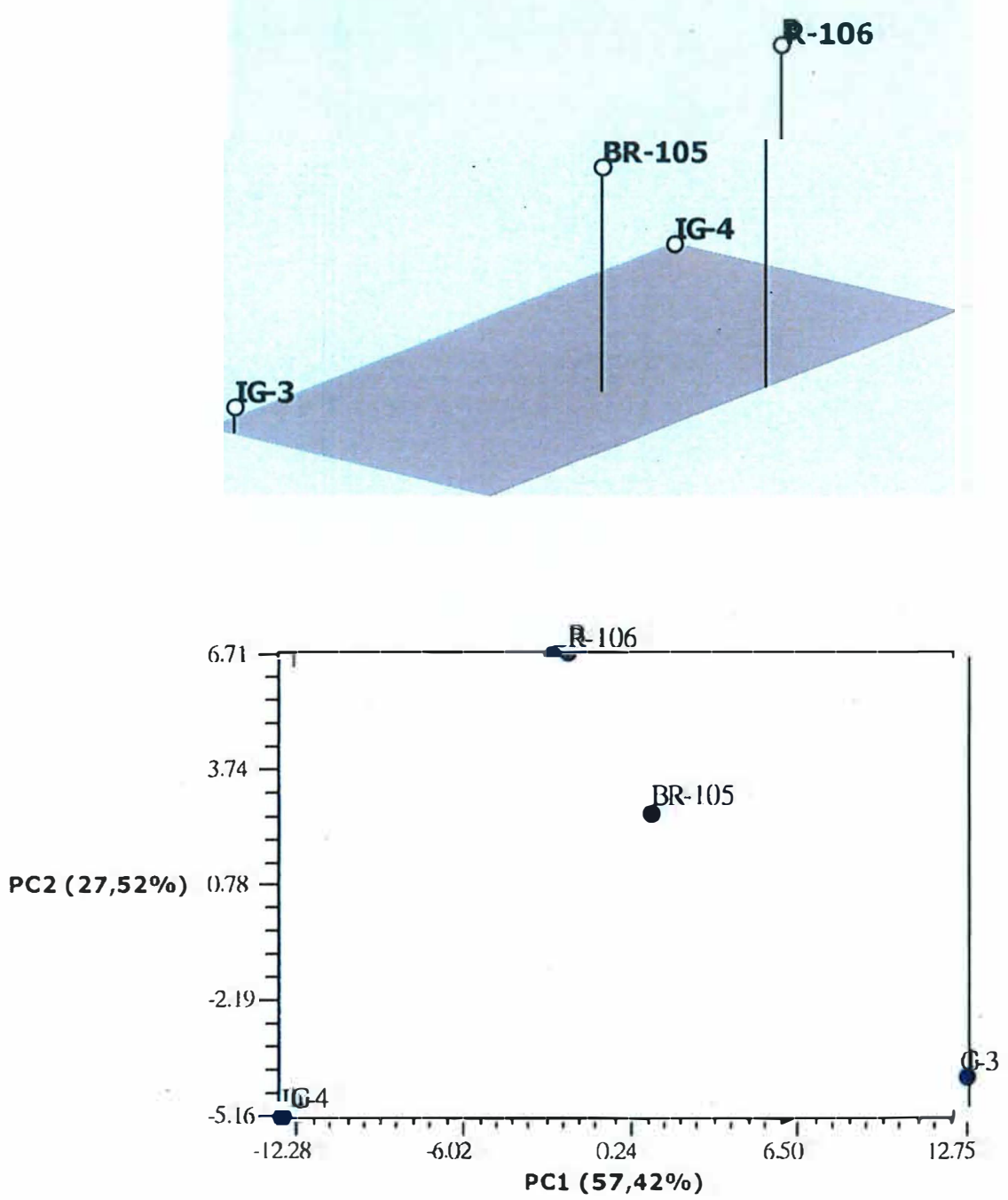

Figura 12- Associações entre as populações BR-105, BR-106 e os sintéticos IG-3 e IG-4 obtida pela análise de coordenadas principais (PCO). Distância de Nei (1978). 

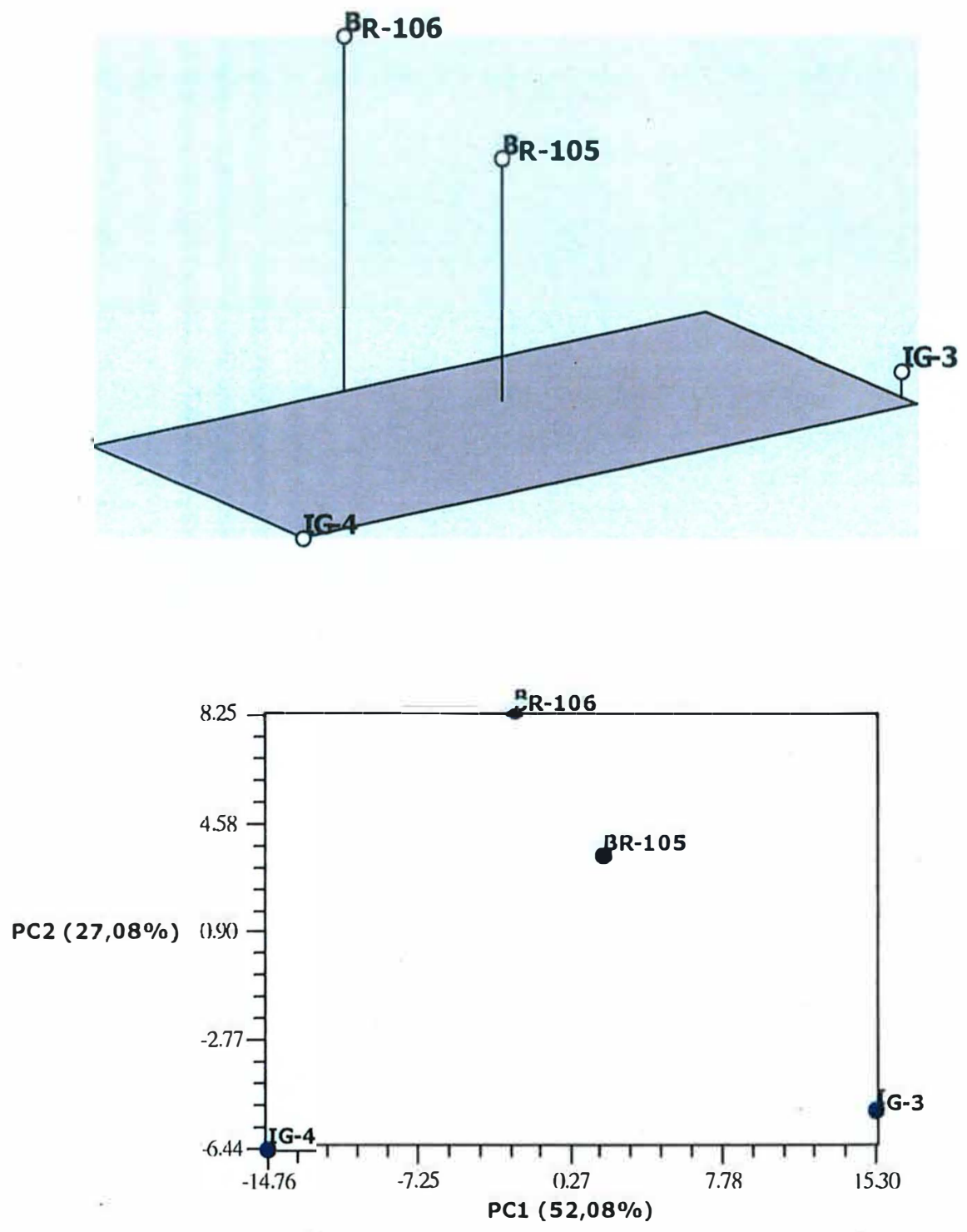

Figura 13- Associações entre as populações BR-105, BR-106 e os sintéticos IG-3 e IG- 4 obtida pela análise de coordenadas principais (PCO). Distância $(\delta \mu)^{2}$, Goodstein et al. (1995). 


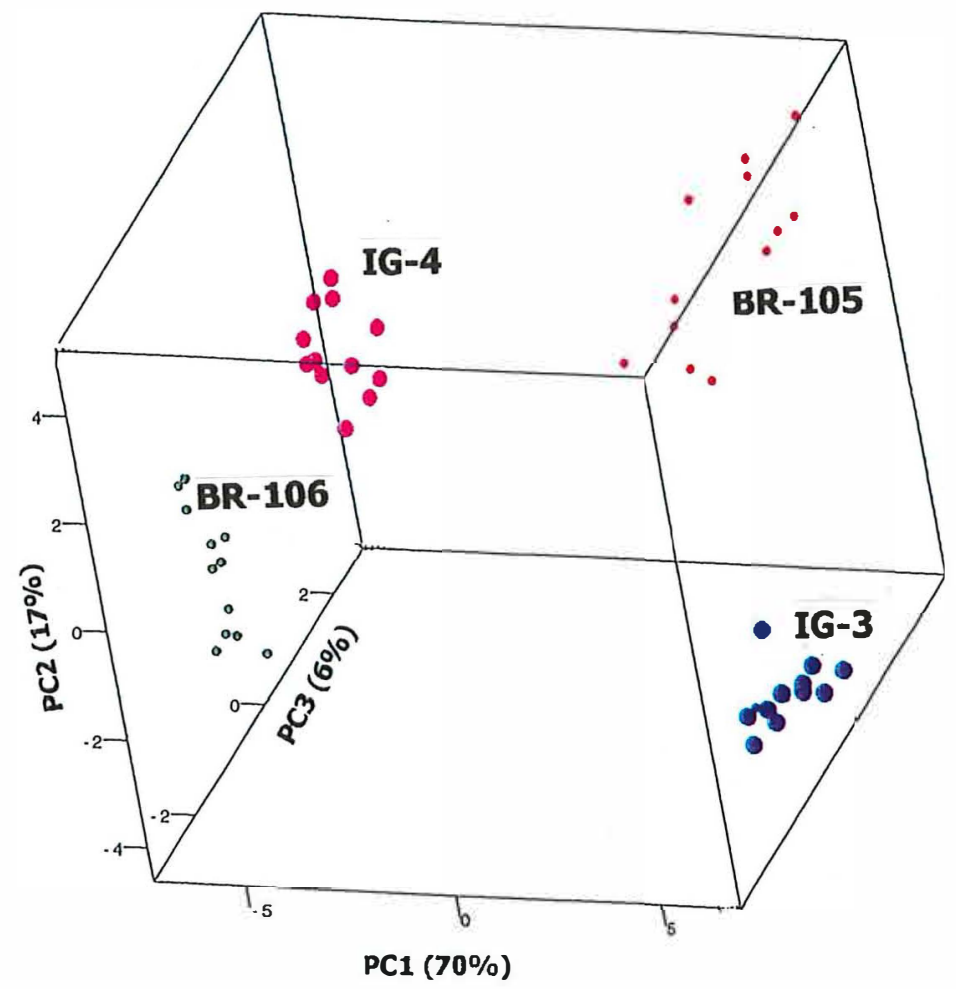

Figura 14- Associações entre populações e sintéticos com base na leitura dos genótipos individuais de 30 locos de microssatélites. BR-106 (verde), IG-4 (rosa), BR-105 (vermelho) e IG-3 (azul). 


\subsection{Considerações finais}

A avaliação da diversidade gênica é fundamental no melhoramento de plantas, principalmente nos casos em que pode ser lapidada pela seleção. As populações de milho BR-105 e BR-106 foram submetidas a um ciclo de seleção recorrente de alta intensidade. Os efeitos da seleção e da deriva genética sobre estas populações foram avaliados a campo, utilizando as populações originais, os sintéticos correspondentes e seus cruzamentos por Rezende \& Souza Júnior (2000).

A análise ao nível molecular da estrutura genética destas populações bem como das variedades sintéticas, condiz, em geral, com o que foi observado por esses autores. Apesar das populações BR-105 e BR-106 apresentarem níveis semelhantes e expressivos de variabilidade genética, estas populações diferem significativamente quanto à distribuição da freqüência de seus alelos, e também pela presença de alelos exclusivos. Tais diferenças, contribuem para a divergência genética inferida anteriormente com base nas performances dos cruzamentos interpopulacionais.

Considerando o número de genitores envolvidos na formação da população BR-106, era de se esperar um número maior de alelos por loco, em relação a BR-105. Provavelmente, os três ciclos de seleção para a redução da altura da planta e espiga praticados durante o processo de síntese da BR-106 podem ter contribuído para reduzir a variabilidade genética.

O grau de diferenciação gênica entre estas populações, ( $\hat{G}_{S T}=11 \%$ ), equivale aos valores relatados por Hamrick \& Godt (1990) com marcadores isoenzimáticos para espécies anuais (35,7\% com base em 146 espécies), monocotiledôneas (23\% com base em 81 espécies) e de polinização preferencialmente pelo vento ( $9,9 \%$ com base em 134 espécies). Além disso, é considerável frente ao valor de $30 \%$ obtido via marcadores RFLP em 65 acessos de milho de diversas origens: Europa, América do Norte, Argentina e China (Rebourg et al. 1999).

Do ponto de vista de estratégia de conservação, o valor obtido para $\hat{G}_{s T}$ entre as populações BR-105 e BR-106 indica que esforços devem ser concentrados para amostrar um maior número de indivíduos dentro de cada população, em virtude da maior parte da variabilidade genética estar alocada dentro destes materiais. 
Os polimorfismos gerados com os marcadores microssatélites revelaram que as diversidades gênicas totais observadas nas populações originais praticamente não se alteraram em relação às observadas após um ciclo de seleção recorrente recíproca, apesar do aumento da diferenciação gênica entre as populações e os sintéticos, medido pelo $\hat{G}_{s T}$, ter sido significativo. Para a expressão da variabilidade genética, Rezende \& Souza Júnior (2000) observaram que a interpopulação IG-3 x IG-4 apresentou diferenças pequenas e não significativas em relação a interpopulação BR-105 x BR-106. As variâncias genéticas decresceram $8,8 \%$ para produção, 13,5\% para altura da planta, $27,0 \%$ para altura da espiga e 4,0\% para prolificidade, sendo que apenas a variância genética para a altura da espiga diferiu significativamente entre um ciclo de seleção.

A manutenção da variabilidade genética tem sido relatada em vários programas de seleção recorrente a longo e curto prazo (Holthaus \& Lamkey, 1995; Bernardo, 1996; Guzman \& Lamkey, 1999) como também via marcadores de RFLP por Labate et al. (1999). Provavelmente, esta manutenção pode estar associada à variabilidade genética latente presente dentro de blocos poligênicos, a qual é liberada gradativamente pela permuta genética, do primeiro ciclo de seleção em diante (Rezende, 1997).

O aumento da diferenciação gênica e conseqüentemente da distância genética acessada com os locos de microssatélites é um reflexo de que alelos, em um mesmo loco, estão alcançando freqüências diferentes em cada um dos sintéticos. Neste sentido, o aumento da divergência genética pode estar contribuindo para aumentar a heterose, principalmente se estas mudanças complementares estiverem ocorrendo nas freqüências dos alelos que afetam a produção. Segundo Rezende \& Souza Júnior (2000), para o caráter produção de grãos, um ciclo de seleção recorrente recíproca provocou um aumento significativo da heterose, cerca de $25,7 \%$, e um decréscimo na depressão por endogamia em ambas populações.

A diversidade gênica total observada nos sintéticos IG-3 e IG-4 mostraram-se próximas às teoricamente esperadas sob o modelo de deriva genética. Entretanto, alguns locos apresentaram alterações significativas nas freqüências alélicas, considerando os intervalos de confiança a $95 \%$ de probabilidade, entre as populações originais e respectivos sintéticos. É provável que algumas destas alterações ocorridas 
nas freqüências dos alelos possam ser atribuídas aos efeitos exclusivos da seleção, porém tal fato deve ser analisado com cautela, principalmente no que se refere aos locos de microssatélites. Estes, representam regiões repetitivas e não codantes do DNA, as quais, à princípio, não estão sujeitas à fortes pressões de seleção. Entretanto, locos de microssatélites podem apresentar-se ligados a locos que estão sendo selecionados, e, neste caso, podem estar sujeitos à seleção por carona genética (genetic hitchhiking).

Os expressivos valores dos efeitos de oscilação genética observados por Rezende (1997) sobre as populações BR-105 e BR-106 foram atribuídos ao tamanho efetivo populacional excessivamente restrito dos sintéticos IG-3 e IG-4.

O tamanho efetivo populacional é um parâmetro muito importante a ser conhecido, uma vez que trata da representatividade genética da amostra. Em programas de melhoramento, o tamanho efetivo populacional delimita os limites da seleção como, por exemplo, a duração dos programas, e num contexto mais geral, a resposta total à seleção. Os tamanhos efetivos populacionais estimados com dados de microssatélites para os sintéticos IG-3 e IG-4 mostraram-se próximos aos teóricos esperados sob o esquema de seleção recorrente recíproca praticado nas populações BR-105 e BR-106.

Os parâmetros estimados com marcadores de DNA traçaram um esboço a respeito dos efeitos de um ciclo de seleção recorrente recíproca sobre a estrutura genética das populações BR-105 e BR-106. A análise mostrou-se consistente com o que é esperado teoricamente num processo de seleção recorrente interpopulacional, principalmente no que concerne à manutenção da variabilidade genética, em níveis satisfatórios, para que a seleção possa ser praticada em ciclos futuros.

Pelo exposto, pode-se afirmar que os objetivos inicialmente propostos nesse trabalho foram alcançados. 


\section{CONCLUSÕES}

a) As populações BR-105 e BR-106 apresentam níveis semelhantes de diversidade gênica, porém, diferem significativamente quanto à distribuição dos alelos, e a presença de alelos característicos, os quais se encontram em sua maioria em baixas freqüências.

b) Para determinados locos, as intensidades elevadas de seleção praticadas sobre as populações BR-105 e BR-106 provocaram alterações significativas nas freqüências alélicas entre a população original e o sintético.

c) Após um ciclo de seleção recorrente interpopulacional, os sintéticos IG-3 e IG-4 tornaram-se mais divergentes entre si do que as respectivas populações originais.

d) As perdas de diversidade gênica totais podem ser atribuídas aos efeitos da deriva genética devido ao tamanho reduzido dos sintéticos.

e) Os níveis de diversidade gênica, ao nível molecular encontrados nos sintéticos IG-3 e IG-4 sugerem que estes ainda apresentam variabilidade 
genética suficiente para ser explorada em futuros ciclos de seleção recorrente interpopulacional.

f) Locos de microssatélites apresentam potencial para serem utilizados com sucesso no monitoramento da variabilidade genética em programas de seleção, e também para fornecer estimativas do tamanho efetivo ( $\hat{N} e$ ) de populações que passaram por um estreitamento de sua base genética. 


\section{ANEXO}




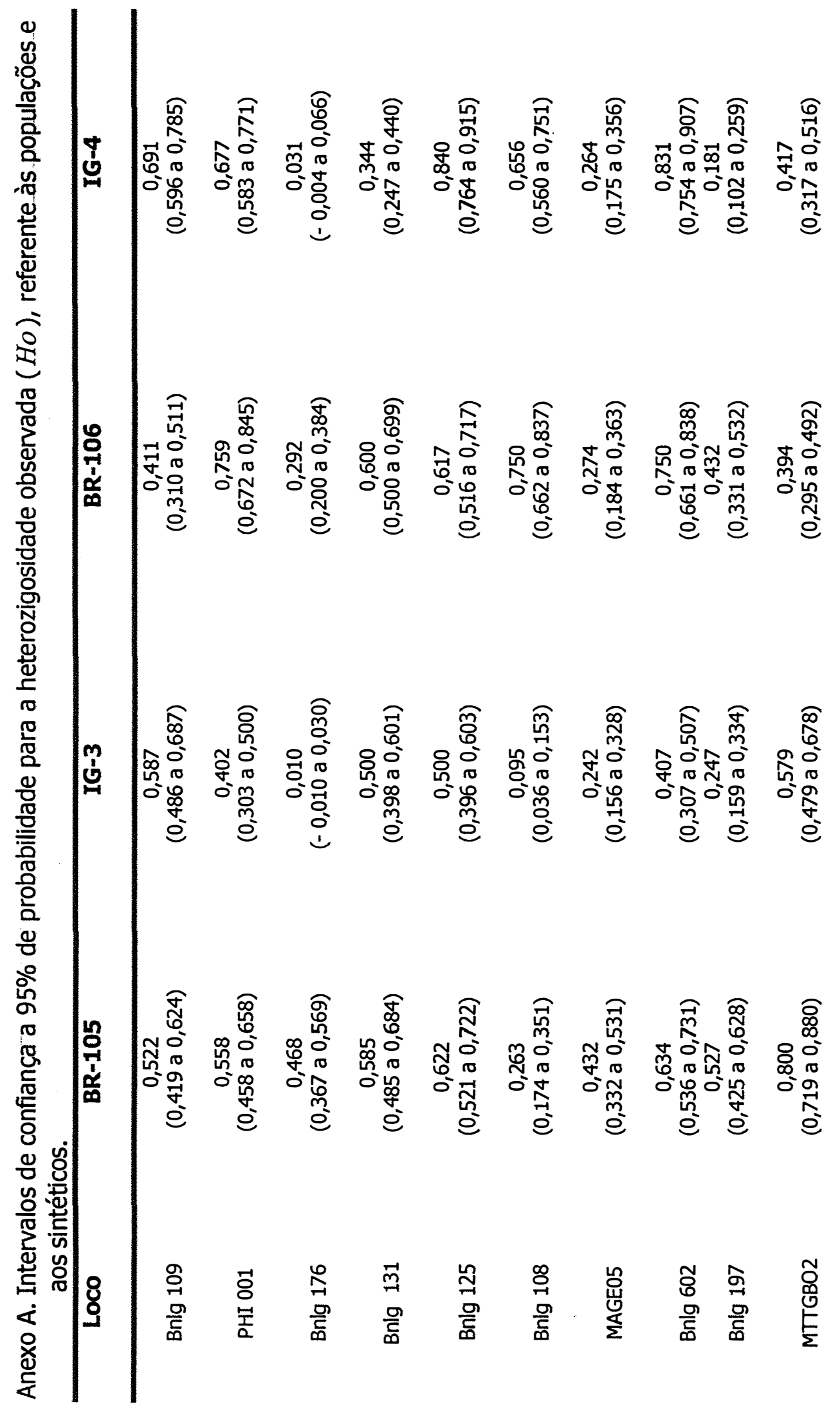




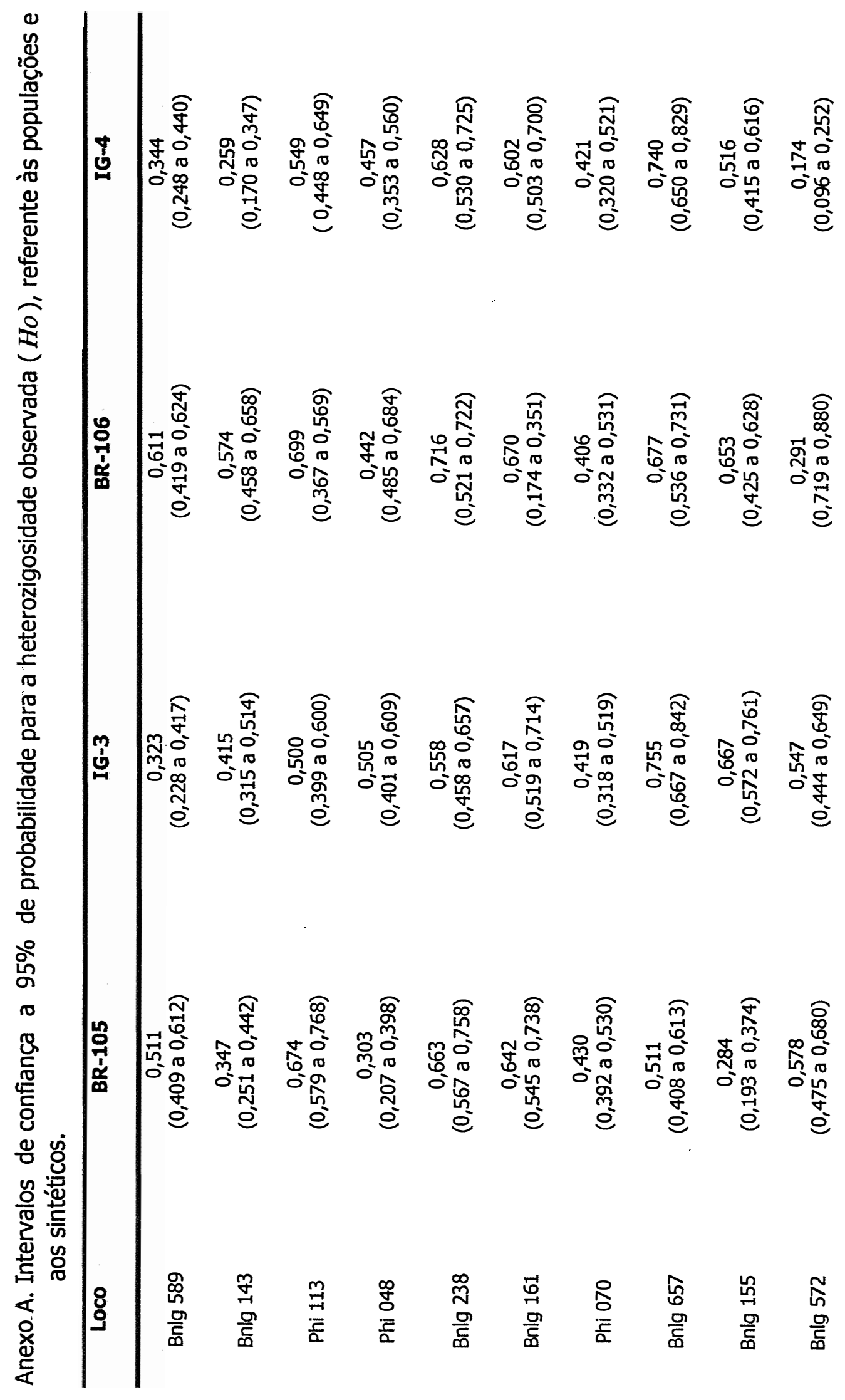




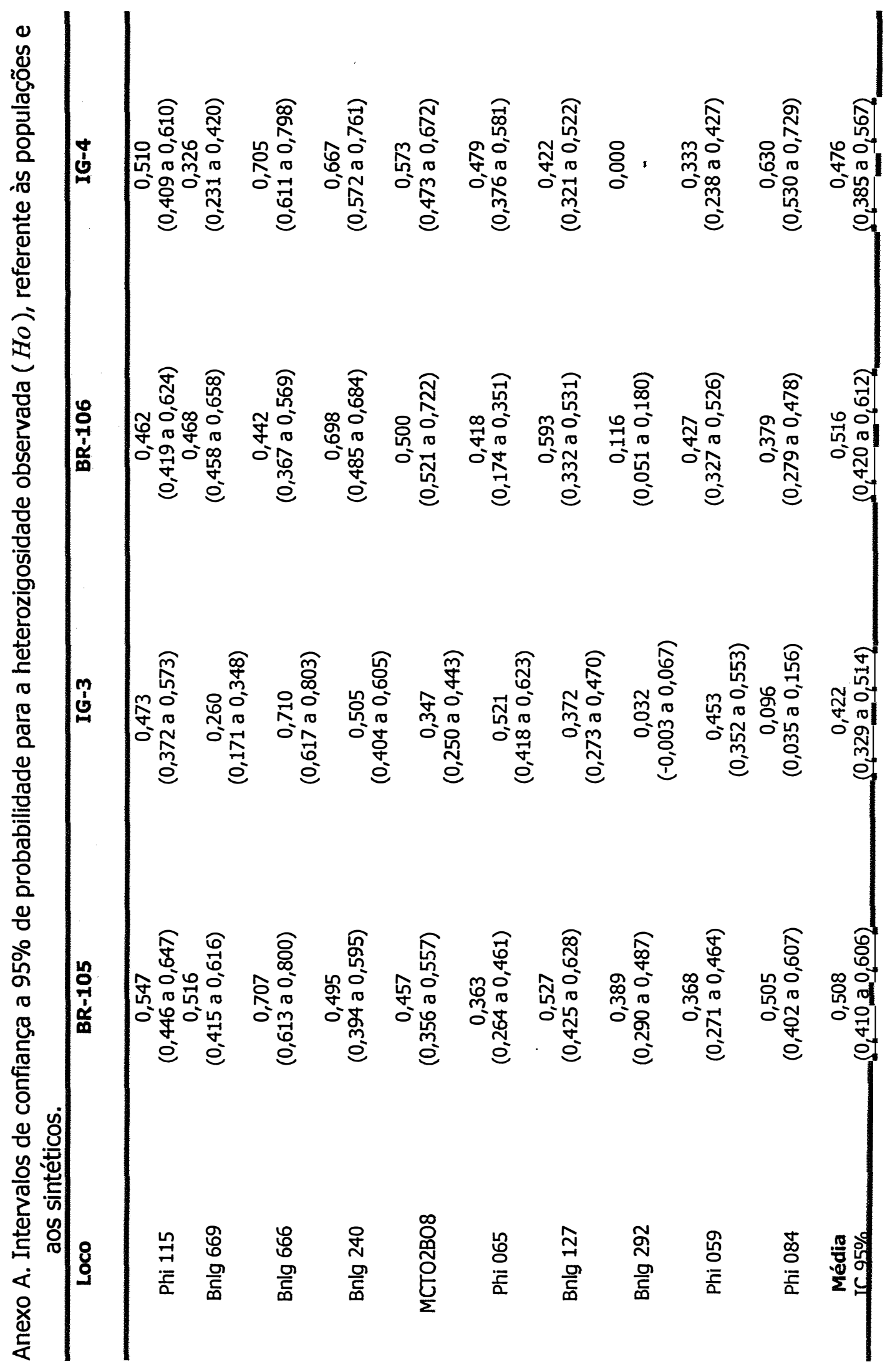




\section{REFERÊNCIAS BIBLIOGRÁFICAS}

ALFENAS, A.C. Eletroforese de isoenzimas e proteínas afins: fundamentos e aplicações em plantas e microrganismos. Viçosa: UFV, 1998. 574p.

ALKAMI BIOSYSTEMS. Alkami quick guide for PCR: a laboratory reference for the polymerase chain reaction. Miami,1999. 111p.

BEIGUELMAN, B. Dinâmica dos genes nas famílias e nas populações. Ribeirão Preto: Sociedade Brasileira de Genética, 1994. 472p.

BERNARDO, R. Testcross selection prior to further inbreeding in maize: mean performance and realized genetic variance. Crop Science, v.36, p. 867-871, 1996.

BOGETTO, P.; WAIDNER, L.; ANDERSON, H. Helpful tips for PCR. Focus, v.22, n.1, p.12, 2000.

BROWN, A.H.D. Enzyme polymorphism in plant populations. Theoretical Population Biology, v.15, p. 1-42, 1979.

BROWN, A.H.D.; ALLARD, R.W. Effect of Reciprocal Recurrent Selection for yield on Isozyme polymorphisms in maize (Zea mays L.). Crop Science, v.11, p.888-893, 1971. 
BROWN, A.H.D.; WEIR, B.S. Measuring genetic variability in plant populations. In: TANKSLEY, S.D.; ORTON, J.J. (Ed.) Isozymes in plant genetics and breeding; part A. Amsterdam: Elsevier Science, 1983, p.219-239.

CABALLERO, A. Developments in the prediction of effective population size. Heredity, v.73, p.657-679, 1994.

CARLINI, L.A. Estudo da estrutura genética populacional através do uso de marcadores moleculares. Piracicaba: ESALQ, Departamento de Genética, 1998. 93p.

CASACUBERTA, E.; PUIG-DOMENECH, P.; MONFORT, A. Distribution of microsatellites in relation to coding sequences within the Arabidopsis thaliana genome. Plant Science, v.157, p.97-104, 2000.

CHARLESWORTH, B.; SNIEGOWSKI, P.; STEPHAN, W. The evolutionary dynamics of repetitive DNA in eukaryotes. Nature, v.371, p.215-220, 1994.

CHIN, E.C.L.; SENIOR, M.L.; SHU, H.; SMITH, J.S.C. Maize simple repetitive DNA sequences: abundance and allellic variation. Genome, v.39, p.866-873, 1996.

CORDEIRO, G.M.; TAYLOR, G.O.; HENRY, R.J. Characterization of microsatellites markers from sugarcane (Saccharum sp.), a highly polyploid species. Plant Science, v.155, p.161-168, 2000.

DOEBLEY, J.F.; GOODMAN, M.M.; STUBER, C.W. Isozymes variation in the races of maize from Mexico. American Journal of Botany, v.72, n.5, p.629-639, 1985. 
EYHERABIDE, G.H.; HALLAUER, A.R. Reciprocal full-sib recurrent selection in maize: II. Contributions of additive, dominance, and genetic drift effects. Crop Science, v.31, p.1442-1448, 1991.

FALCONER, D.S.; MACKAY, T.F.C. Introduction to quantitative genetics. 4 ed. Edinburgh:1996. 464p.

FRASCAROLI, E.; LANDI, P. Allelic frequency change of P1 gene in a maize population after recurrent selection for grain yield. Crop Science, v.38, p.1391-1394, 1998.

FUTUYAMA, D.J. Biologia evolutiva. Ribeirão Preto: Sociedade Brasileira de Genética, 1992. 631p.

GOLDSTEIN, D.B.; LINARES, A.R.; CAVALLI-SFORZA, L.L.; FELDMAN, M.W. An evaluation of genetic distance for use with microsatellite loci. Genetics, v.139, p. 463-471, 1995.

GONZÁLEZ-CANDELAS, F.; PALACIOS, C. Analyzing molecular data for plant genetic resources. In: INTERNATIONAL PLANT GENETIC RESEARCH INSTITUTE WORKSHOP, Rome: IPGRI, 1995. p.55-81.

GOODMAN, S.J. RST Calc: a collection of computer programs for calculating estimates of genetic differentiation from microsatellite data and determining their significance. Molecular Ecology, v.6, p.881-885, 1997.

GOUDET, J. FSTAT (vers. 12): a computer program to calculate F-statistics. Journal of Heredity, v.86, p.485-486, 1995. 
GROSSA, J. Methodologies for estimating the sample size required for genetic conservation of outbreeding crops. Theoretical and Applied Genetics, v.77, p.153-161, 1989.

GUO, S.W.; THOMPSON, E.A. Performing the exact test of Hardy-Weinberg. Proportion for multiple alleles. Biometrics, v.48, p.361-371, 1992.

GUZMAN, P.S.; LAMKEY, K.R. Predicted gains from recurrent selection in the BS11 maize population. Maydica, v.44, p.93-99, 1999.

GUZMAN, P.S.; LAMKEY, K.R. Effective population size and genetic variability in the BS11 Maize population. Crop Science, v.40, p.338-346, 2000.

HALLAUER, A.R.; MIRANDA FILHO, J.B. Quantitative genetics in maize breeding. 2 ed. Ames: Iowa State University Press, 1988. 468p.

HALLAUER, A.R.; RUSSEL, W.A.; LAMKEY, K.R. Corn breeding. In: SPRAGUE, G.F.; DUDLEY, J.W. (Ed.) Corn and corn improvement. 3. ed. Madison: Iowa State University Press, 1988. p.453-464.

HAMRICK, J.L. Plant population genetics and evolution. American Journal of Botany, v.69, n.10, p.1685-1693, 1982.

HAMRICK, J.L.; GODT, M.J.W. Allozyme diversity in plant species. In: BROWN, A.H. D., CLEGG, M.T.; KAHLER, A.L.; WEIR, B.S. (Ed.) Plant population genetics, breeding and genetic resources. Sunderland: Sinauer Associates, 1990. p.43-63. 
HARTL, D.L.; CLARK, A.G. Principles of population genetics. Sunderland: Sinauer Associates,1989. 681p.

HEATH, D.D.; IWAMA, G.K.; DEVLIN, R.H. PCR primed with VNTR core sequences yields species specific patterns and hypervariable probes. Nucleic Acids Research, v.21, p.5782-5785, 1993.

HEREDIA-DÍAZ, O.H.; ALSIRT, A.; DARRAH, L.L.; COE, E.H. Allelic frequency changes in the MoSCSSS maize synthetic in response to bi-directional recurrent selection for rind penetrometer resistance. Maydica, v. 41, p.65-76, 1996.

HILLIS, D.M.; MORIZ, C.; MARBLE, B.K. Molecular systematics. 2. ed. Sunderland: Sinauer Associates,1996. 655p.

HOLTHAUS, J.F.; LAMKEY, K.R. Population means and genetic variances in selected and unselected Iowa Stiff Stalk synthetic maize populations. Crop Science, v.35, p.1581-1589, 1995.

INGVARSSON, P. K.; OLSSON, N. Hierarchical genetic structure and effective population sizes in Phalacrus substriatus. Heredity, v.79, p.153-161, 1997.

JARNE, P.; LAGODA, P.J.L. Microsatellites, from molecules to populations and back. Tree, v.11, n.10, p.424-429, 1996.

KAPLAN, N.L.; HUDSON, R. R.; LANGLEY, C. The hitchhiking effect revisited. Genetics, v.123, p.887-899, 1989.

LABATE, J.A.; LAMKEY, K.R.; LEE, M.; WOODMAN, W. L. Molecular genetic diversity after reciprocal recurrent selection in BSSS and BSCB1 maize populations. Crop Science, v.37, p.416-423, 1997 a. 
LABATE, J.A.; LAMKEY, K.R.; LEE, M.; WOODMAN,W.L. Population genetics increased hybrid performance between two maize populations under reciprocal recurrent selection. In: INTERNATIONAL SYMPOSIUM ON THE GENETICS AND EXPLOITATION OF HETEROSIS IN CROPS, Mexico, 1997. Proceedings. Madison: SSSA,ASA, CSSA, 1997b. p.127-137.

LABATE, J.A.; LAMKEY, K.R.; LEE, M.; WOODMAN, W. L. Temporal changes in allele frequencies in two reciprocally selected maize populations. Theoretical and Applied Genetics, v.99, p.1166-1178, 1999.

LAGERCRANTZ, U.; ELLEGREN, H.; ANDERSON, L. The abundance of various polymorphic microsatellite motifs differs between plants vertebrates. Nucleic Acids Research, v. 21, n.5, p.1111-1115, 1993.

LAMKEY, K.R.; EDWARDS, J.W. The quantitative genetics of heterosis. In: INTERNATIONAL SYMPOSIUM OF THE GENETICS AND EXPLOITATION OF HETEROSIS IN CROPS. Mexico, 1997. Proceedings. Madison: SSSA,ASA, CSSA, 1997. p.31-48.

LAMKEY, K.R.; LEE, M. Quantitative genetics, molecular markers, and plant improvement. In: AUSTRALIAN PLANT BREEDING CONFERENCE,10., Goald Coast, 1993. Focused plant improvement: towards responsible and sustainable agriculture. Camberra: Australian Organizing Committe, 1993. p. 104-105.

LANZA, L.L.B.; SOUZA JR. C.L.; OTTOBONE, L.M.M.; VIEIRA, M.L.C.; SOUZA, A.P. Genetic distance of inbreed lines and prediction of maize single cross performance using RAPD markers. Theoretical and Applied Genetics, v.94, n.8, p.1023-1030, 1997. 
LEWIS, P.O.; ZAYKIN, D. Genetic data analysis: computer program for the analysis of allellic data. Version 1.0 (d12).http://lewis.eeb.uconn.edu (2 janeiro de 2001).

LLAURADÓ, M.; MORENO-GONZALEZ, J.; ARÍES, P. Classification of northern Spanish populations of maize by methods of numerical taxonomy. II. Isozyme variation. Maydica, v.38, p.249-258, 1993.

LORIDON, K.; COURNOYER, B.; GOUBELY, C.; DEPEIGES, A.; PICARD, G. Length polymorphism and allele structure of trinucleotide microsatellites in natural accessions of Arabidopsis thaliana. Theoretical and Applied Genetics, v.97, p.591-604, 1996.

MARUYAMA, T.; FUERST, P. A. Population bottlenecks and nonequilibrium models in population genetics. II. Number of alleles in a small population that was formed by recent bottleneck. Genetics, v. 111, p.675-689, 1985.

MESSMER, M.M.; MELCHINGER, M.; LEE, M.; WOODMAN, W. L.; LEE, E.A.; LAMKEY, K. R. Genetic diversity among progenitors and elite lines from Iowa Stiff Stalk Synthetic (BSSS) maize population: comparison of allozyme and RFLP data. Theoretical and Applied Genetics, v. 83, p.83-97, 1991.

METTLER, L.E.; GREGG, T.G. Genética de população e evolução. São Paulo: EDUSP,1973. 262p.

MILLER, M. P. Tools for population genetic analyses (TFPGA) 1.3: a windows program for the analysis of allozyme and molecular population genetic data. http:www.public.asu.edu (5 janeiro de 1997) 
MOREIRA, R.M.P. Avaliação dos efeitos da deriva genética em duas gerações de amostragens nas populações de milho BR-105 e BR-106. Piracicaba, 1999. 120p. Tese (Doutorado) - Escola Superior de Agricultura "Luiz de Queiroz", Universidade de São Paulo.

MORGANTE, M.; OLIVERI, A .M. PCR-amplified microsatellites as markers in plant genetics. Plant Journal, v.3, p.175-182, 1993.

MURRAY, B. The estimation of genetic distance and population substructure from microsatellite allele frequency data. http:helix.biology.mcmaster.ca. (10 de maio,1996)

NASPOLINI FILHO, V.; GAMA, E.E.G.; VIANNA, R.T.; MORO, J.R. General and combining ability for yield in a diallel cross among 18 maize populations (Zea mays L.). Revista Brasileira de Genética, v.4, p.571-577, 1981.

NEI, M. Genetic distance between populations. American Naturalist, v.106, p.283292, 1972.

NEI, M. Analysis of gene diversity in subdivided populations. Proceedings of the National Academy of Sciences of the USA. v.70, n.12, p.3321-3323, 1973

NEI, M. Estimation of average heterozygosity and genetic distance from small number of individuals. Genetics, v. 89, p. 583-590, 1978.

NEI, M. Molecular evolutionary genetics. New York: Columbia University Press, 1987. 512p.

NEI, M.; ROYCHOUDHURY, A.K. Sampling variance of heterozygosite and genetic distance. Genetics, v.76, p.379-390, 1974. 
NEI, M.; TAJIMA, F. Genetic drift and estimation of effective population size. Genetics, v. 98, p. $625-640,1981$.

OGLIARI, J.B.; BOSCARIOL, R.; CAMARGO, L.E.A. Optimization of PCR amplification of maize microsatellite loci. Genetics and Molecular Biology, v.23, n.2, p.395-398, 2000.

PASTEUR, N,; PASTEUR, G.; BOHOME, F.; CATALAN, J.; BRITTON-DAVIDIAN, J. Pratical isozyme genetics. New York: Ellis Horwood, 1988. 215p.

PEJIC, I.; AJMONE-MARSAN, P.; MORGANTE, M.; KOZUMPLIK, V.; CASTIGLIONI, P.; TARAMINO, G.; MOTTO, M. Comparative analysis of genetic similarity among maize inbred lines detected by RFLPS, RAPDs, SSRs, and AFLPs. Theoretical and Applied Genetics, v.97, n.8, p.1248-1255, 1998.

PINTO, R. M. C. Comparações de marcadores moleculares e cruzamentos dialélicos na alocação de linhagens de milho em grupos heteróticos. Piracicaba, 2000. 147p. Tese (Doutorado) - Escola Superior de Agricultura "Luiz de Queiroz", Universidade de São Paulo.

POWELL, W.; MACHRAY, G.C.; PROVAN, J. Polymorphism revealed by simple sequence repeats. Trends in Plant Science, v.1, n.7, p.215-221, 1996.

REBOURG, C.; DUBREUIL, P.; CHARCOSSET, A. Genetic diversity among maize populations: bulk RFLP analysis of 65 accessions. Maydica, v.44, p.237-249, 1999.

REZENDE, G.D.S.P. Heterose, depressão por endogamia e variabilidade genética associadas à seleção e oscilação genética nas populações de milho BR-105 e BR106. Piracicaba, 1997. 112p. Tese (Doutorado) - Escola Superior de Agricultura," Luiz de Queiroz", Universidade de São Paulo. 
REZENDE, G.D.S.P.; SOUZA Jr., C.L. A reciprocal recurrent selection procedure outlined to integrate hybrid breeding programs in maize. Journal of Genetics and Breeding, v.54, p.57-66, 2000.

ROHLF, F. J. Numerical taxonomy and multivariate analysis system: version 1.70. New York: Exeter, 1992.

SAGHAI-MAROOF, M.A.; SOLIMAN, K.; JORGENSEN, R.A; ALLARD, R.W. Ribosomal DNA spacer-length polymorphism in barley. Mendelian inheritance, chromosomal location, and population dynamics. Proceedings of the National Academy of Sciences of the USA, v.81, p.8014-8018, 1984.

SAGHAI-MAROOF, M.A.; BIYASHEV, R.M.; YANG, G.P.; ZHANG, Q.; ALLARD, R. Extraordinarly polymorphic microsatellite DNA in barley: species diversity, chromosomal locations and population dynamics. Proceedings of the National Academy of Sciences of the USA, v.91, p.5466-5470, 1994.

SANOU, J., GOUESNARD, B., CHARRIER, A. Isozyme variability in west African maize cultivars (Zea mays L.). Maydica, v.42, p.1-11, 1997.

SEBBENN, A.M. Estrutura genética de subpopulações de Genipa americana L. (Rubiaceae) a partir de isoenzimas. Piracicaba, 1997. 107p. Dissertação (Mestrado) - Escola Superior de Agricultura "Luiz de Queiroz", Universidade de São Paulo.

SENIOR, M.L.; HEUN, M. Mapping maize microsatellites and polymerase chain reaction confirmation of the targeted repeats using a CT primer. Genome, v.36, p.884-889, 1993. 
SENIOR, M.L.; MURPHY, J.P.; GOODMAN, M.M.; STUBER, C.W. Utility of SSRs for determining genetic similarities and relationships in maize using an agarose gel system. Crop Science, v.38, p.1088-1098, 1998.

SENIOR, M.L.; CHIN, E.C.L.; LEE, M.; SMITH, J.S.C.; STUBER, C.W. Simple sequence repeat markers developed from maize sequences found in the GeneBank Data base: map construction. Crop Science, v.36, p.1676-1683, 1996.

SIA, E.A.; JINKS-ROBERTSON, S.; PETES, T.D. Genetic control of microsatellite stability. Mutation Research, v.383, p.61-70, 1997.

SLATKIN, M. A measure of population subdivision based on microsatellite allele frequencies. Genetics, v.139, p.457-462, 1995.

SMITH, D.N.; DEVEY, M. Ocurrence and inheritance of microsatellites in Pinus radiata. Genome, v.37, p.977-983, 1994.

SMITH, J.S.C.; CHIN, E.C.L.; SHU, H.; SMITH, O.S.; WALL, S.J.; SENIOR, M.L.; MITCHELL, S.E.; KRESOVICH, S.; ZIEGLE, J. An evaluation of the utility of SSR loci as molecular markers in maize (Zea mays L.): comparisons with data from RFLPS and pedigree. Theoretical and Applied Genetics, v.95, p.163-173, 1997.

SMITH, O . S. Evaluation of recurrent selection in BSSS, BSCBI and BS13 maize populations. Crop Science, v.23, p.35-40, 1983.

SOUZA Jr., C.L. Variâncias genéticas interpopulacionais e suas relações com a obtenção e seleção de híbridos. Piracicaba, 1988. 268p. Tese (Livre-Docência) Escola Superior de Agricultura "Luiz de Queiroz", Universidade de São Paulo.

SOUZA Jr., C.L. Manutenção de coleções de bancos de germoplasmas. Piracicaba: ESALQ: Departamento de Genética, 1995. 41p. 
SOUZA Jr., C.L. Seleção recorrente e desenvolvimento de híbridos. In: REUNION LATINA AMERICANA DE INVESTIGADORES EN MAIZ, 4.; REUNION DE LA ZONA ANDINA DE INVESTIGADORES EN MAIZ, 17., Santa Fé de Bogotá, 1997. Memórias; resúmenes. Santa Fé de Bogotá: Corpoica-Cimmyt, 1997. p.18-19.

SOUZA Jr., C.L.; SANTOS, M.X.; MAGNAVACA, R. Estimativas de parâmetros genéticos na interpopulação de milho BR-105 x BR-106 e suas implicações no melhoramento. Pesquisa Agropecuária Brasileira, v.28, p.473-479, 1993.

STUBER, C.W.; MOLL, R.H. Frequency changes of isozyme alleles in a selection experiment for grain yield in maize (Zea mays L.). Crop Science, v.12, p.337-340, 1972.

SWOFFORD, D.L.; SELANDER, R.B. Biosys-1: a FORTRAN program for the comprehensive analysis for electrophoresis data in population genetics and systematics. Journal of Heredity, v.38, p.1358-1370, 1991.

TARAMINO, G.; TINGEY, S. Simple sequence repeats for germplasm analysis and mapping in maize. Genome, v.39, p.277-287, 1996.

THOMSON, G.; ESPOSTTO, M.S. The genetics of complex diseases. Tibs. v.24, n.12, p.17-20, 1999.

TORGGLER, M.G.F.; CONTEL, E.P.B.; TORGGLER, S.P. Isoenzimas. variabilidade genética em plantas. Ribeirão Preto: Sociedade Brasileira de Genética, 1995. 175p. 
VIARD, F.; BREMOND, P.; LABBO, R.; JUSTY, F.; DELAY, B.; JARNE, P. Microsatellites and the genetics of highly selfing populations in the freshwater snail Bulinus truncates. Genetics, v.142, p.1237-1247, 1996.

WALSH, P.S.; FILDES, N.J.; REYNOLDS, R. Sequence analyses and characterization of stutter products at the tetranucleotide repeat locus vWA. Nucleic Acids Research, v.24, n.24, p.2807-2812, 1996.

WANG, G.; MAHALINGAM, R.; KNAP, H.T. (C_A) and (G_A) anchored simple sequence repeats (ASSRs) generated polymorphism in soybean, Glycine max (L.) Merr. Theoretical and Applied Genetics, v.96, p.1086-1096, 1998.

WANG, Z.; WEBER, J.L.; ZHONG, G.; TANKSLEY, S.D. Survey of plant short tandem DNA repeats. Theoretical and Applied Genetics, v.88, p.1-6, 1994.

WAPLES, R.S. A generalized approach for estimating effective population size from temporal changes in allele frequency. Genetics, v.121, p.379-391, 1989.

WEIR, B.S. Genetic data analysis. Sunderland: Sinauer Associates, 1996.445 p.

WEIR, B.S.; COCKERHAM, C.C. Estimating F-statistic for the analysis of population structure. Evolution, v.38, p.1358-1370, 1984.

WIEHE,T. The effect of selective sweeps on the variance of the allele distribution of a linked multiallele locus: hitchhiking of microssatellites. Theoretical Population Biology, v. 53, p.272-283, 1998. 
WRIGHT, S. The genetical structure of populations. Annals of Eugenetics, v.15, p.313-354, 1951.

WRIGHT, S. The interpretation of population structure by F-statistic with special regard to systems of mating. Evolution, v.19, p.395-420. 1965. 